\title{
Halogenated Sesquiterpenoids from the Red Alga Laurencia tristicha Collected in Taiwan
}

Jia-Yu Chen,${ }^{\dagger}$ Chiung-Yao Huang, ${ }^{\dagger}$ Yun-Sheng Lin, ${ }^{\ddagger}$ Tsong-Long Hwang, ${ }^{\S}$ Wei-Lung Wang, ${ }^{\perp}$ Shu-Fen Chiou, ${ }^{\dagger}$ and Jyh-Horng Sheu ${ }^{*}, \dagger, \|, \nabla, \circ$

\section{${ }^{\dagger}$ Department of Marine Biotechnology and Resources, National Sun Yat-sen University, Kaohsiung 804, Taiwan}

${ }^{\ddagger}$ Department of Biological Science \& Technology, Mei Ho University, Pingtung 912, Taiwan

${ }^{\S}$ Graduate Institute of Natural Products, College of Medicine, Chang Gung University; Research Center for Industry of Human Ecology and Graduate Institute of Health Industry Technology, Chang Gung University of Science and Technology; Department of Anesthesiology, Chang Gung Memorial Hospital, Taoyuan 333,

Taiwan

${ }^{\perp}$ Department of Biology, National Changhua University of Education, Changhua 500, Taiwan

${ }^{\|}$Institute of Natural Products, Kaohsiung Medical University, Kaohsiung 807, Taiwan

${ }^{\nabla}$ Department of Medical Research, China Medical University Hospital, China Medical University, Taichung 404, Taiwan

${ }^{\circ}$ Frontier Center for Ocean Science and Technology, National Sun Yat-sen University,

Kaohsiung 804, Taiwan

*Author to whom correspondence should be addressed; E-Mail: sheu@mail.nsysu.edu.tw; Tel.: +886-7-525-2000 (ext. 5030); Fax: +886-7-525-5020 


\section{List of Contents}

S1. ESIMS spectrum of 1

S2. HREIMS spectrum of $\mathbf{1}$

S3. ${ }^{1} \mathrm{H}$ NMR spectrum of 1 in $\mathrm{CDCl}_{3}$

S4. ${ }^{13} \mathrm{C}$ NMR spectrum of 1 in $\mathrm{CDCl}_{3}$

S5. DEPT spectra of $\mathbf{1}$ in $\mathrm{CDCl}_{3}$

S6. HSQC spectrum of $\mathbf{1}$ in $\mathrm{CDCl}_{3}$

S7. COSY spectrum of $\mathbf{1}$ in $\mathrm{CDCl}_{3}$

S8. $\mathrm{HMBC}$ spectrum of $\mathbf{1}$ in $\mathrm{CDCl}_{3}$

S9. NOESY spectrum of $\mathbf{1}$ in $\mathrm{CDCl}_{3}$

S10. ESIMS spectrum of 2

S11. HREIMS spectrum of 2

S12. ${ }^{1} \mathrm{H}$ NMR spectrum of 2 in $\mathrm{CDCl}_{3}$

S13. ${ }^{13} \mathrm{C}$ NMR spectrum of 2 in $\mathrm{CDCl}_{3}$

S14. DEPT spectra of 2 in $\mathrm{CDCl}_{3}$

S15. HSQC spectrum of 2 in $\mathrm{CDCl}_{3}$

S16. COSY spectrum of 2 in $\mathrm{CDCl}_{3}$

S17. $\mathrm{HMBC}$ spectrum of 2 in $\mathrm{CDCl}_{3}$

S18. NOESY spectrum of $\mathbf{2}$ in $\mathrm{CDCl}_{3}$

S19. ESIMS spectrum of $\mathbf{3}$

S20. HREIMS spectrum of $\mathbf{3}$

S21. ${ }^{1} \mathrm{H}$ NMR spectrum of $\mathbf{3}$ in $\mathrm{CDCl}_{3}$

S22. ${ }^{13} \mathrm{C}$ NMR spectrum of 3 in $\mathrm{CDCl}_{3}$

S23. DEPT spectra of $\mathbf{3}$ in $\mathrm{CDCl}_{3}$

S24. HSQC spectrum of 3 in $\mathrm{CDCl}_{3}$

S25. COSY spectrum of $\mathbf{3}$ in $\mathrm{CDCl}_{3}$

S26. $\mathrm{HMBC}$ spectrum of $\mathbf{3}$ in $\mathrm{CDCl}_{3}$

S27. NOESY spectrum of $\mathbf{3}$ in $\mathrm{CDCl}_{3}$

S28. ESIMS spectrum of 4

S29. HREIMS spectrum of 4

S30. ${ }^{1} \mathrm{H}$ NMR spectrum of 4 in $\mathrm{CDCl}_{3}$

S31. ${ }^{13} \mathrm{C}$ NMR spectrum of 4 in $\mathrm{CDCl}_{3}$

S32. DEPT spectra of 4 in $\mathrm{CDCl}_{3}$

S33. HSQC spectrum of 4 in $\mathrm{CDCl}_{3}$

S34. COSY spectrum of 4 in $\mathrm{CDCl}_{3}$

S35. HMBC spectrum of 4 in $\mathrm{CDCl}_{3}$

S36. NOESY spectrum of 4 in $\mathrm{CDCl}_{3}$

S37. ESIMS spectrum of 5

S38. HREIMS spectrum of 5

S39. ${ }^{1} \mathrm{H}$ NMR spectrum of 5 in $\mathrm{CDCl}_{3}$

S40. ${ }^{13} \mathrm{C}$ NMR spectrum of 5 in $\mathrm{CDCl}_{3}$

S41. DEPT spectra of 5 in $\mathrm{CDCl}_{3}$

S42. HSQC spectrum of 5 in $\mathrm{CDCl}_{3}$

S43. COSY spectrum of 5 in $\mathrm{CDCl}_{3}$
P3

$\mathrm{P} 4$

P5

P6

P7

$\mathrm{P} 8$

P9

P10

P11

P12

$\mathrm{P} 13$

P14

P15

P16

P17

P18

P19

P20

$\mathrm{P} 21$

$\mathrm{P} 22$

$\mathrm{P} 23$

P24

$\mathrm{P} 25$

P26

P27

P28

P29

P30

P31

P32

P33

P34

P35

P36

P37

P38

P39

P40

P41

P42

P43

P44

P45
S44. $\mathrm{HMBC}$ spectrum of 5 in $\mathrm{CDCl}_{3} \quad \mathrm{P} 46$

S45. NOESY spectrum of 5 in $\mathrm{CDCl}_{3} \quad \mathrm{P} 47$

S46. ESIMS spectrum of $6 \quad$ P48

S47. HREIMS spectrum of $6 \quad$ P49

S48. ${ }^{1} \mathrm{H}$ NMR spectrum of 6 in $\mathrm{CDCl}_{3} \quad \mathrm{P} 50$

S49. ${ }^{13} \mathrm{C}$ NMR spectrum of 6 in $\mathrm{CDCl}_{3} \quad \mathrm{P} 51$

S50. DEPT spectra of 6 in $\mathrm{CDCl}_{3} \quad \mathrm{P} 52$

S51. HSQC spectrum of 6 in $\mathrm{CDCl}_{3} \quad$ P53

S52. COSY spectrum of 6 in $\mathrm{CDCl}_{3} \quad \mathrm{P} 54$

S53. $\mathrm{HMBC}$ spectrum of 6 in $\mathrm{CDCl}_{3} \quad$ P55

S54. NOESY spectrum of 6 in $\mathrm{CDCl}_{3} \quad$ P56

S55. ESIMS spectrum of $7 \quad$ P57

S56. HREIMS spectrum of $7 \quad$ P58

S57. ${ }^{1} \mathrm{H}$ NMR spectrum of 7 in $\mathrm{CDCl}_{3} \quad$ P59

S58. ${ }^{13} \mathrm{C}$ NMR spectrum of 7 in $\mathrm{CDCl}_{3} \quad \mathrm{P} 60$

559. DEPT spectra of 7 in $\mathrm{CDCl}_{3} \quad \mathrm{P} 61$

S60. HSQC spectrum of 7 in $\mathrm{CDCl}_{3} \quad \mathrm{P} 62$

S61. COSY spectrum of 7 in $\mathrm{CDCl}_{3} \quad \mathrm{P} 63$

S62. $\mathrm{HMBC}$ spectrum of 7 in $\mathrm{CDCl}_{3} \quad \mathrm{P} 64$

S63. NOESY spectrum of 7 in $\mathrm{CDCl}_{3} \quad \mathrm{P} 65$

S64. ESIMS spectrum of $8 \quad$ P66

S65. HREIMS spectrum of $8 \quad$ P67

S66. ${ }^{1} \mathrm{H}$ NMR spectrum of 8 in $\mathrm{CDCl}_{3} \quad$ P68

S67. ${ }^{13} \mathrm{C}$ NMR spectrum of 8 in $\mathrm{CDCl}_{3} \quad$ P69

S68. DEPT spectra of 8 in $\mathrm{CDCl}_{3} \quad \mathrm{P} 70$

S69. HSQC spectrum of 8 in $\mathrm{CDCl}_{3} \quad \mathrm{P} 71$

S70. $\mathrm{COSY}$ spectrum of 8 in $\mathrm{CDCl}_{3} \quad \mathrm{P} 72$

S71. $\mathrm{HMBC}$ spectrum of $\mathbf{8}$ in $\mathrm{CDCl}_{3} \quad \mathrm{P} 73$

S72. NOESY spectrum of 8 in $\mathrm{CDCl}_{3} \quad \mathrm{P} 74$

S73. ESIMS spectrum of $9 \quad$ P75

S74. HREIMS spectrum of $9 \quad$ P76

S75. ${ }^{1} \mathrm{H}$ NMR spectrum of 9 in $\mathrm{CDCl}_{3} \quad \mathrm{P} 77$

S76. ${ }^{13} \mathrm{C}$ NMR spectrum of 9 in $\mathrm{CDCl}_{3} \quad \mathrm{P} 78$

S77. DEPT spectra of 9 in $\mathrm{CDCl}_{3} \quad$ P79

S78. HSQC spectrum of 9 in $\mathrm{CDCl}_{3} \quad \mathrm{P} 80$

S79. COSY spectrum of 9 in $\mathrm{CDCl}_{3} \quad \mathrm{P} 81$

S80. $\mathrm{HMBC}$ spectrum of 9 in $\mathrm{CDCl}_{3} \quad \mathrm{P} 82$

S81. NOESY spectrum of 9 in $\mathrm{CDCl}_{3} \quad \mathrm{P} 83$

S82. X-ray crystal structure of 12 P84

X-ray Crystallographic Analysis of 12. $\quad$ P84 


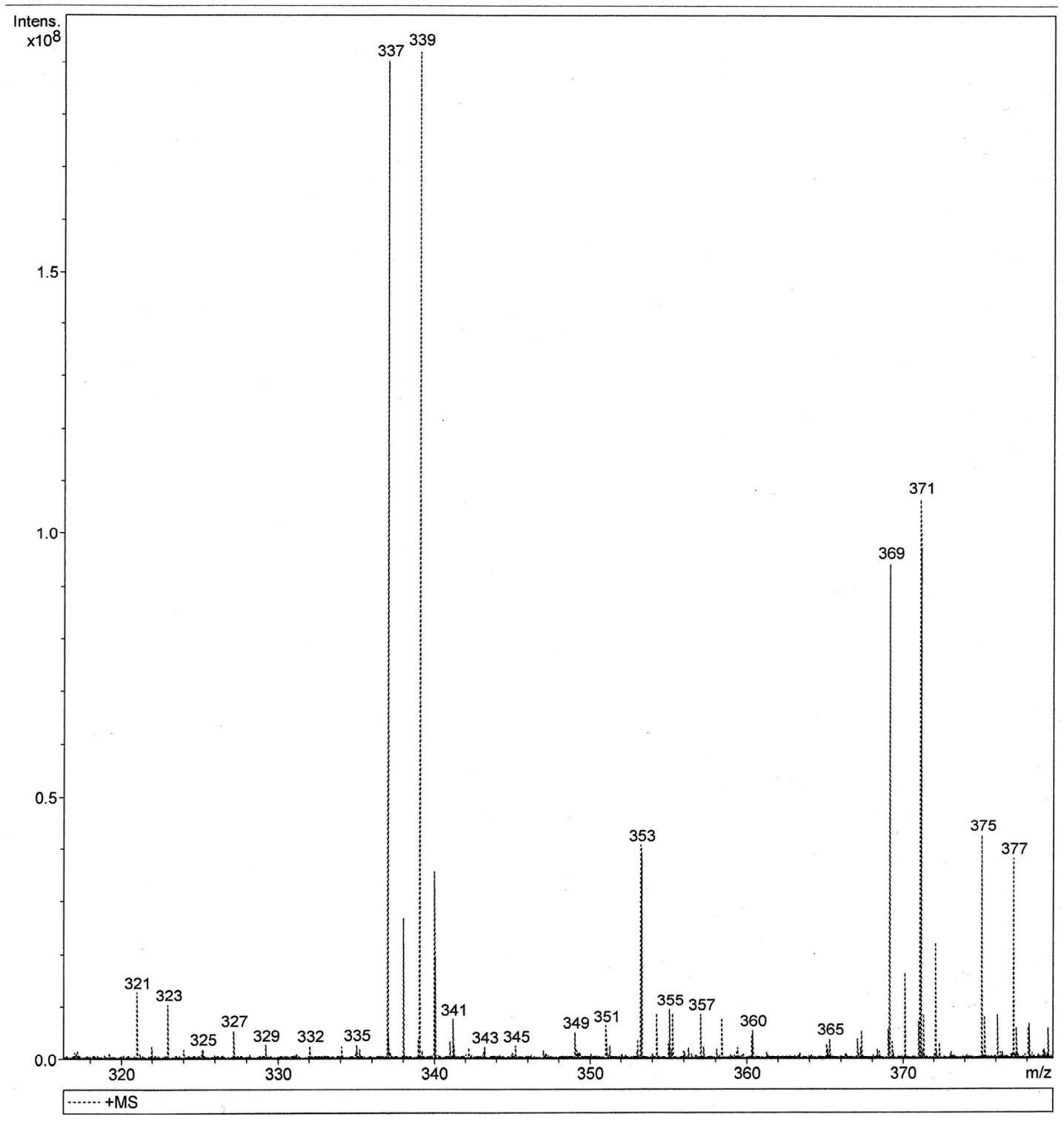

S1. ESIMS spectrum of 1 


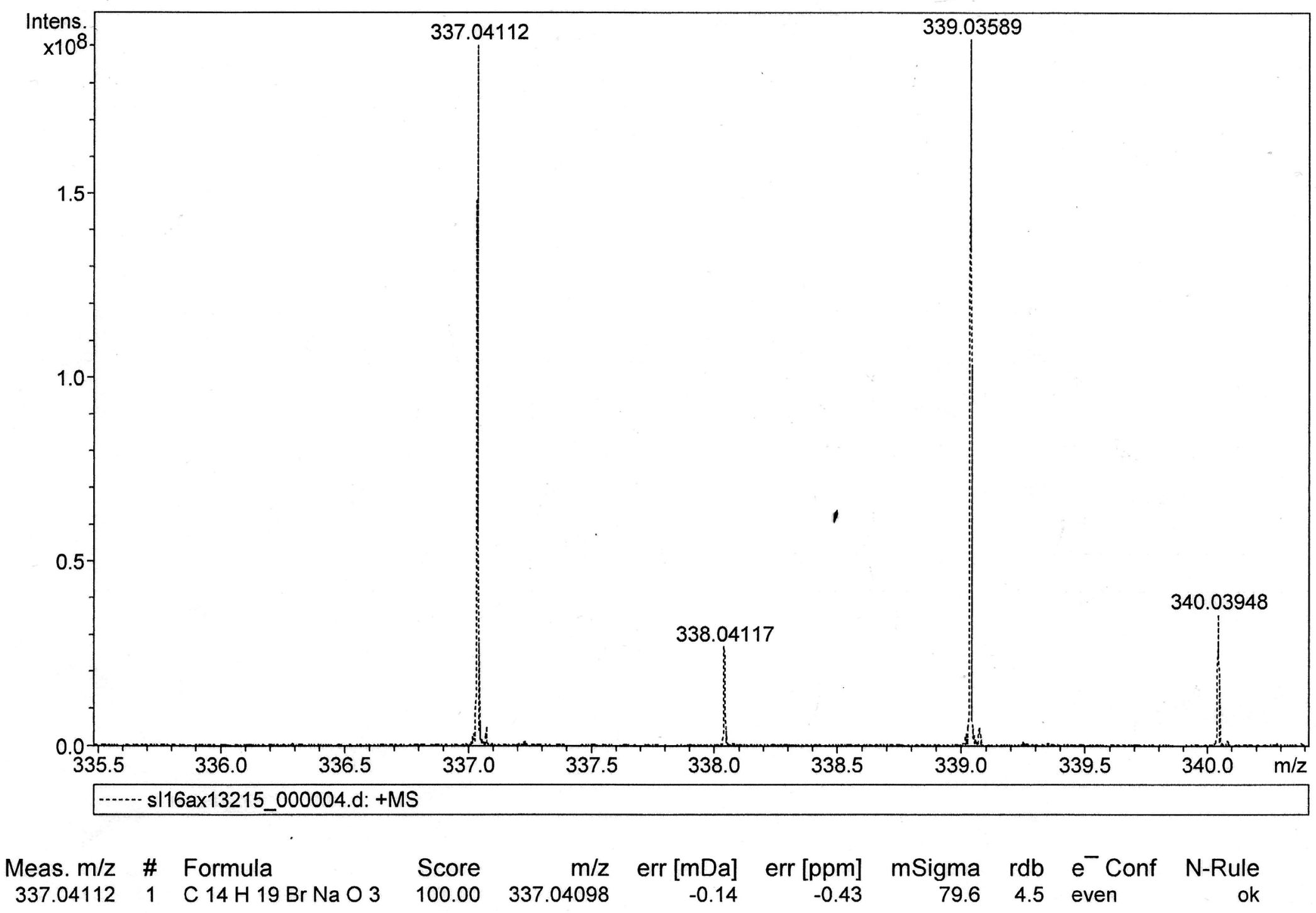

S2. HREIMS spectrum of $\mathbf{1}$ 


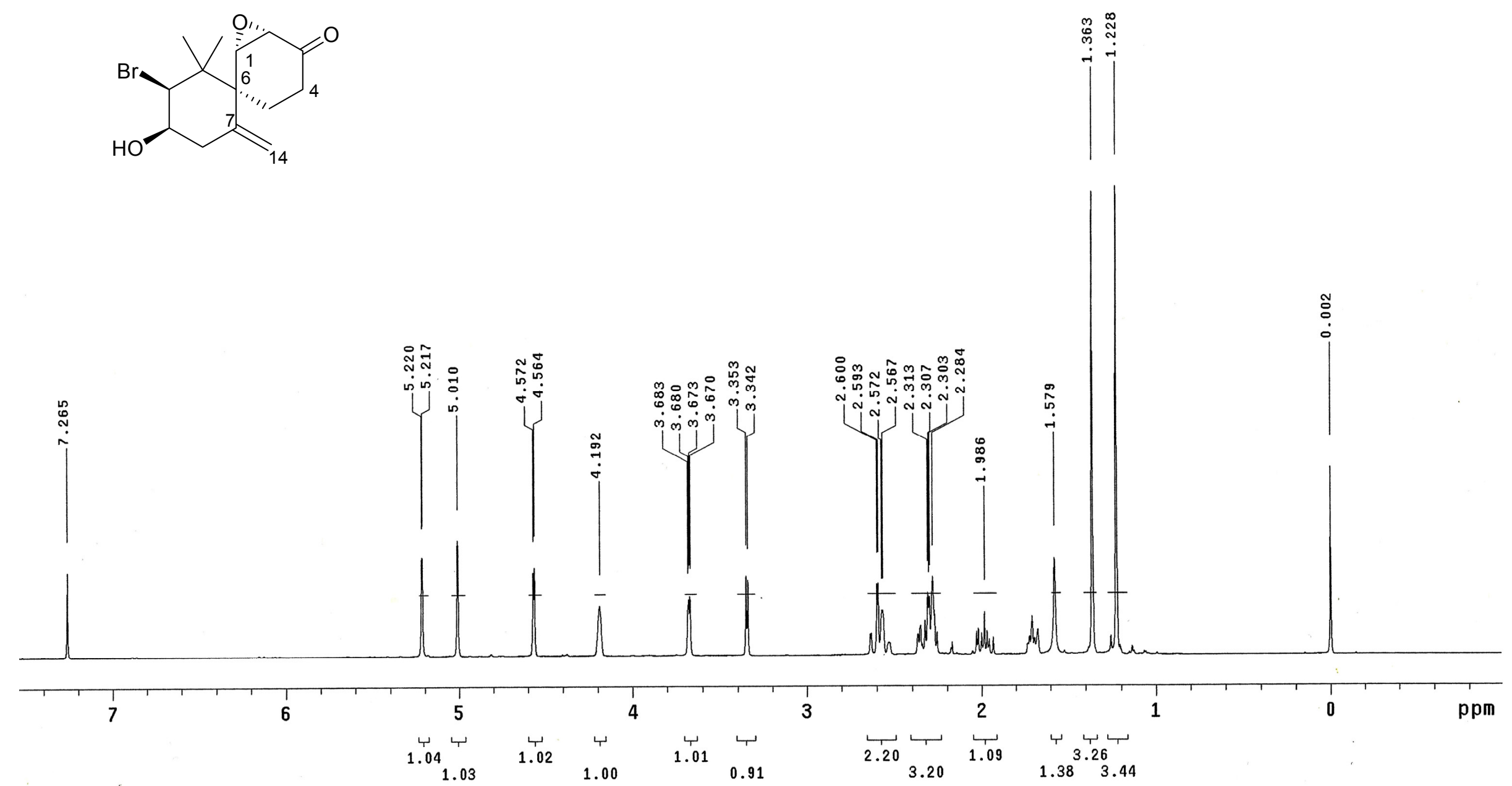

S3. ${ }^{1} \mathrm{H}$ NMR spectrum of $\mathbf{1}$ in $\mathrm{CDCl}_{3}$ 


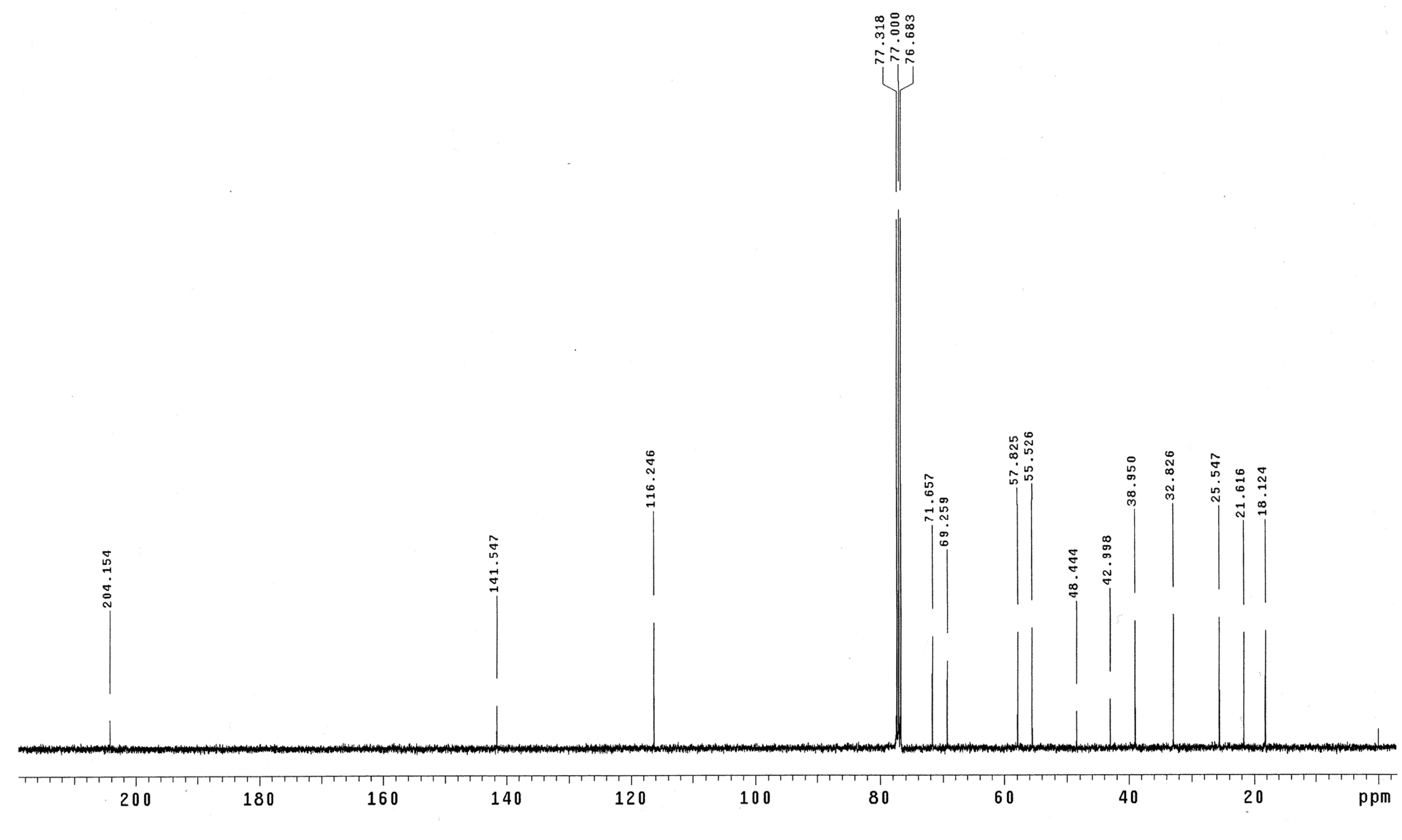

S4. ${ }^{13} \mathrm{C}$ NMR spectrum of $\mathbf{1}$ in $\mathrm{CDCl}_{3}$ 

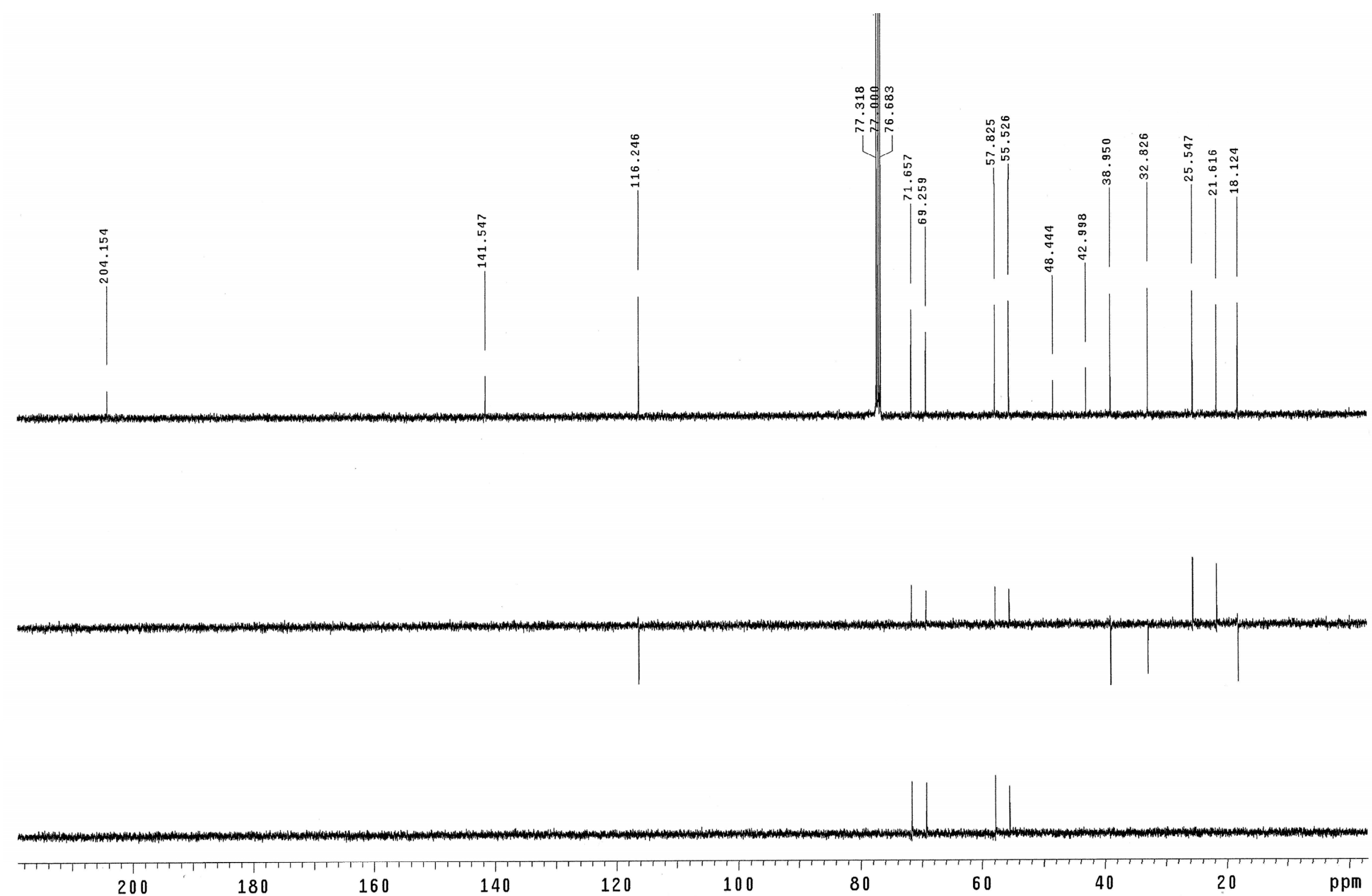

S5. DEPT spectra of $\mathbf{1}$ in $\mathrm{CDCl}_{3}$ 


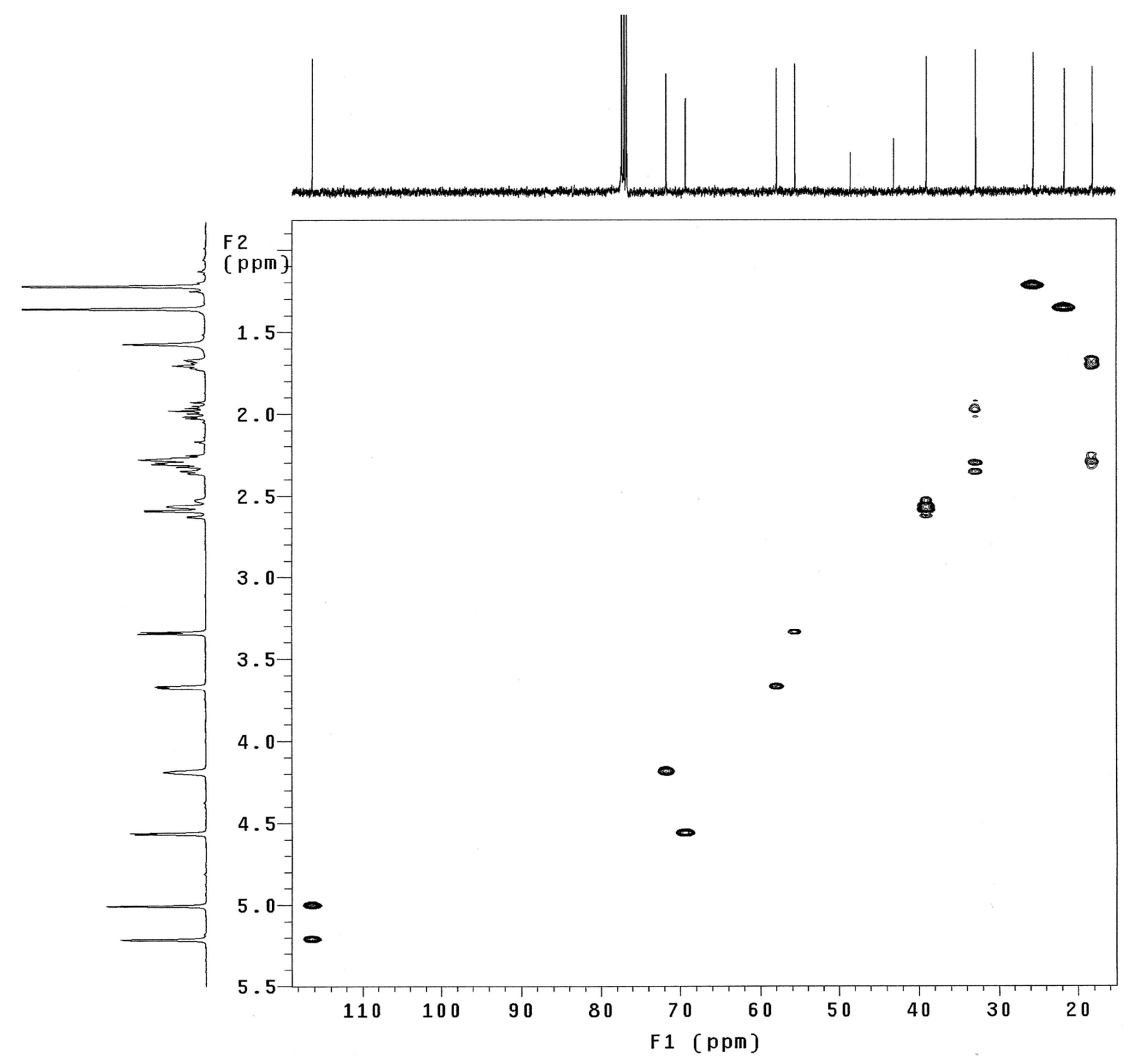

S6. $\mathrm{HSQC}$ spectrum of $\mathbf{1}$ in $\mathrm{CDCl}_{3}$ 


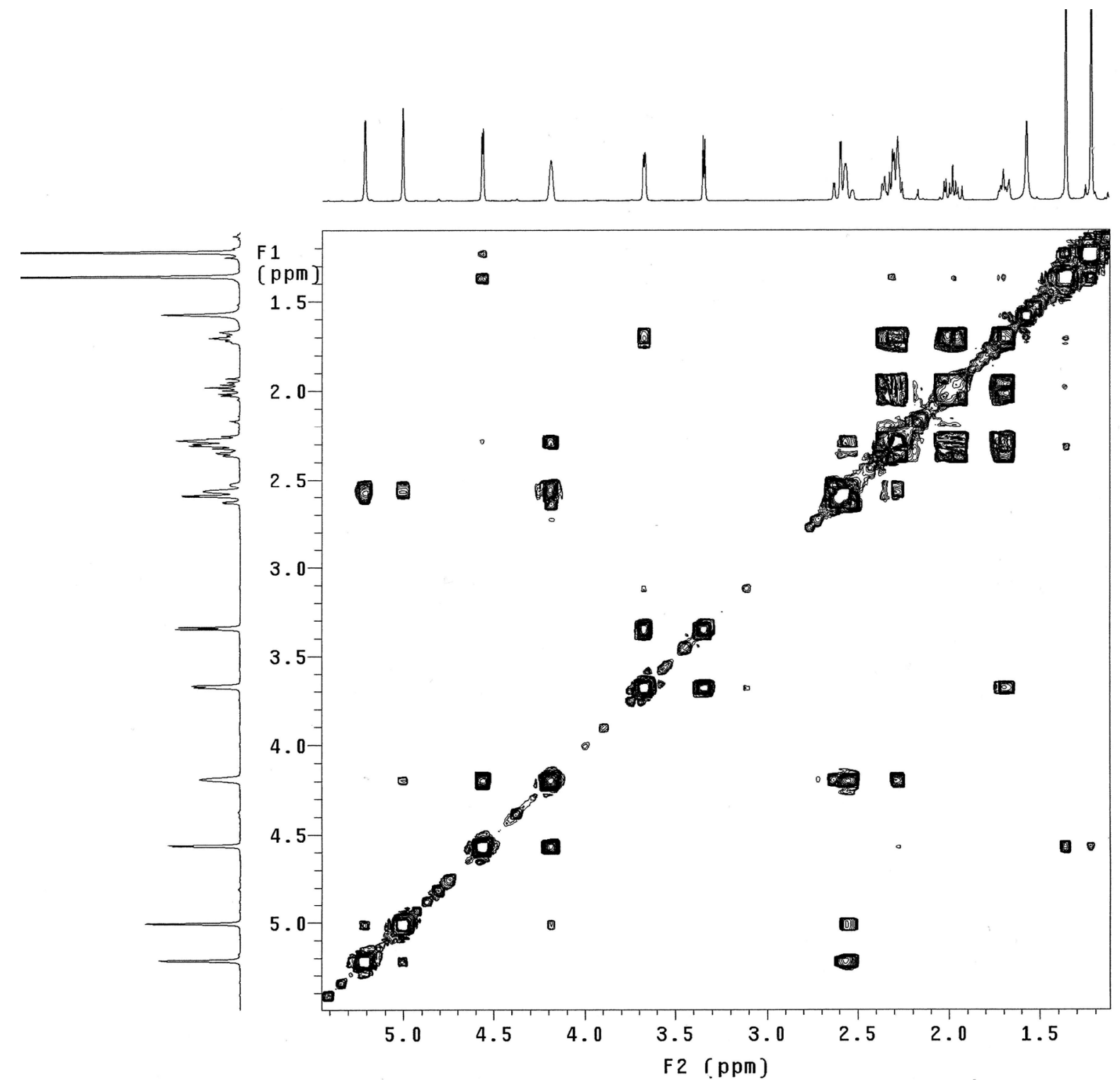

S7. COSY spectrum of 1 in $\mathrm{CDCl}_{3}$ 


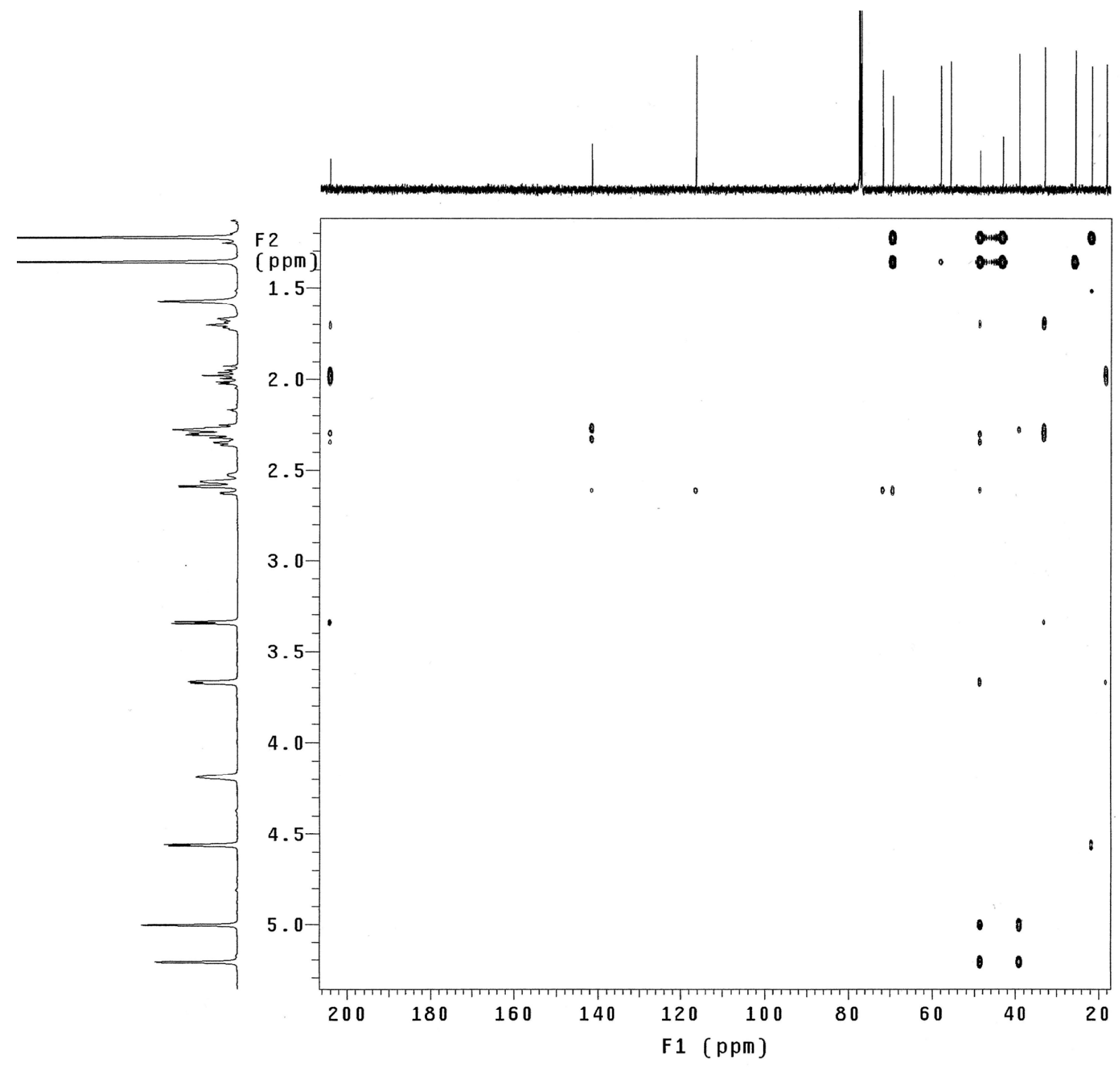

S8. $\mathrm{HMBC}$ spectrum of $\mathbf{1}$ in $\mathrm{CDCl}_{3}$ 


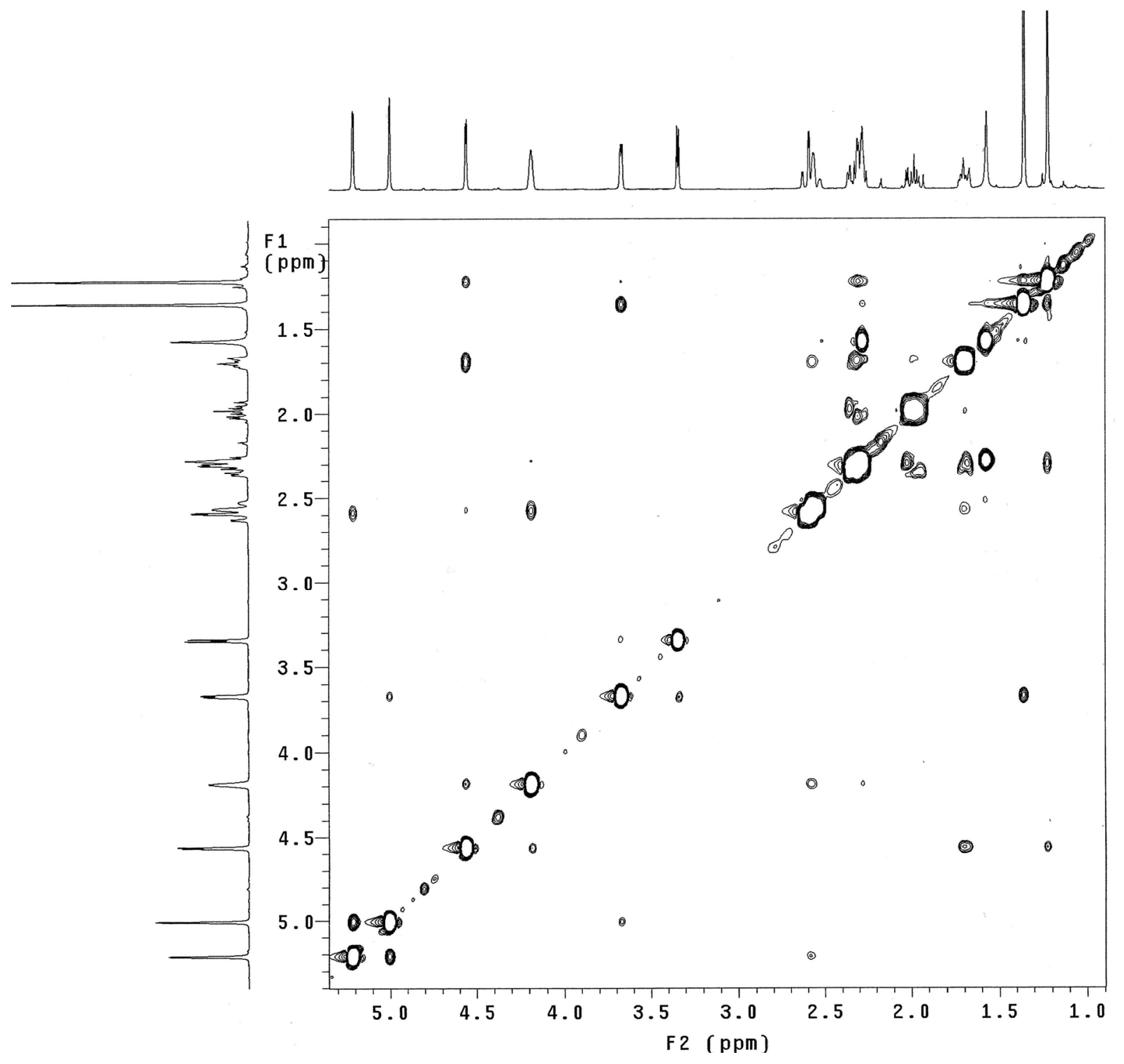

S9. NOESY spectrum of $\mathbf{1}$ in $\mathrm{CDCl}_{3}$ 


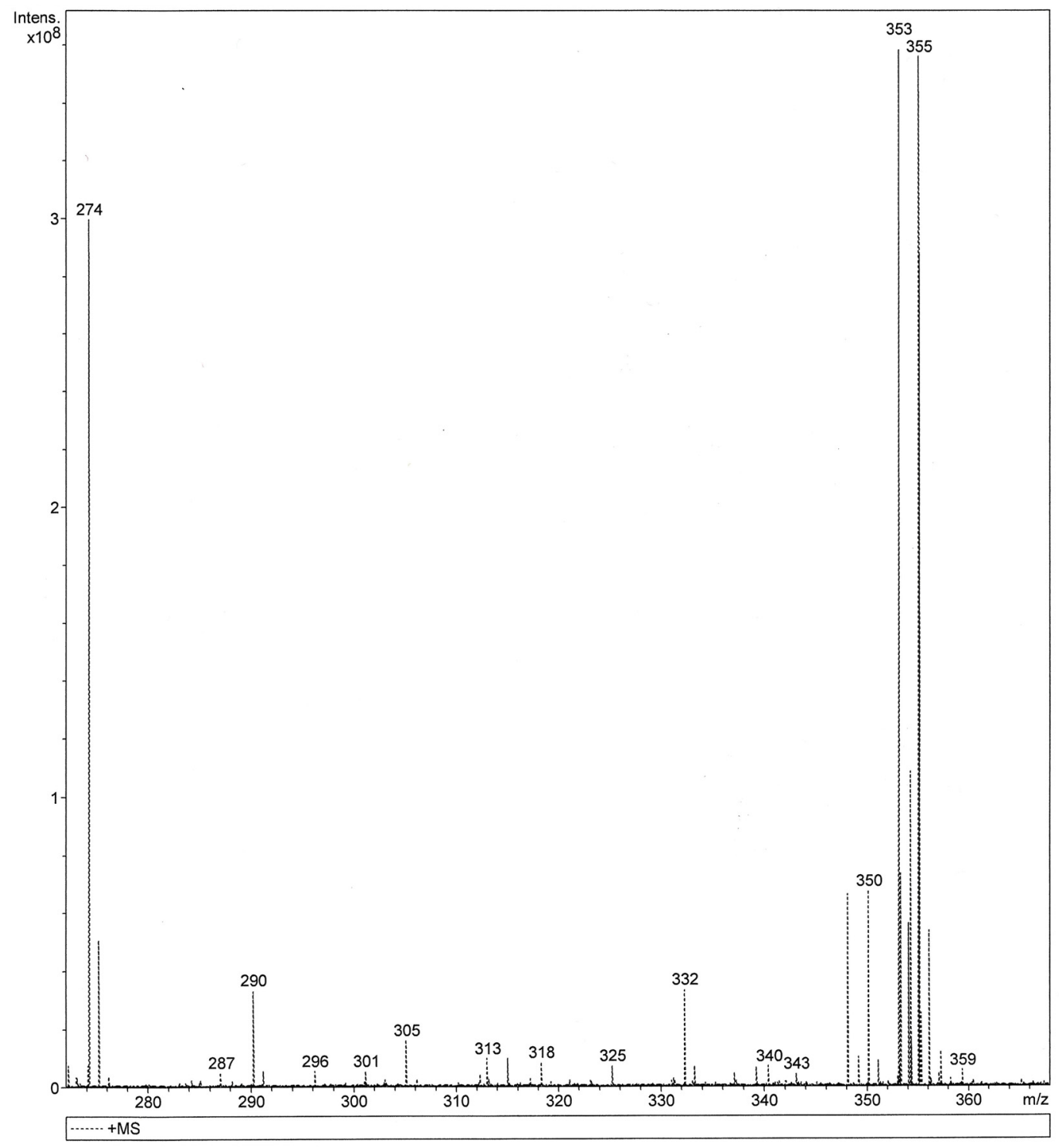

S10. ESIMS spectrum of 2 


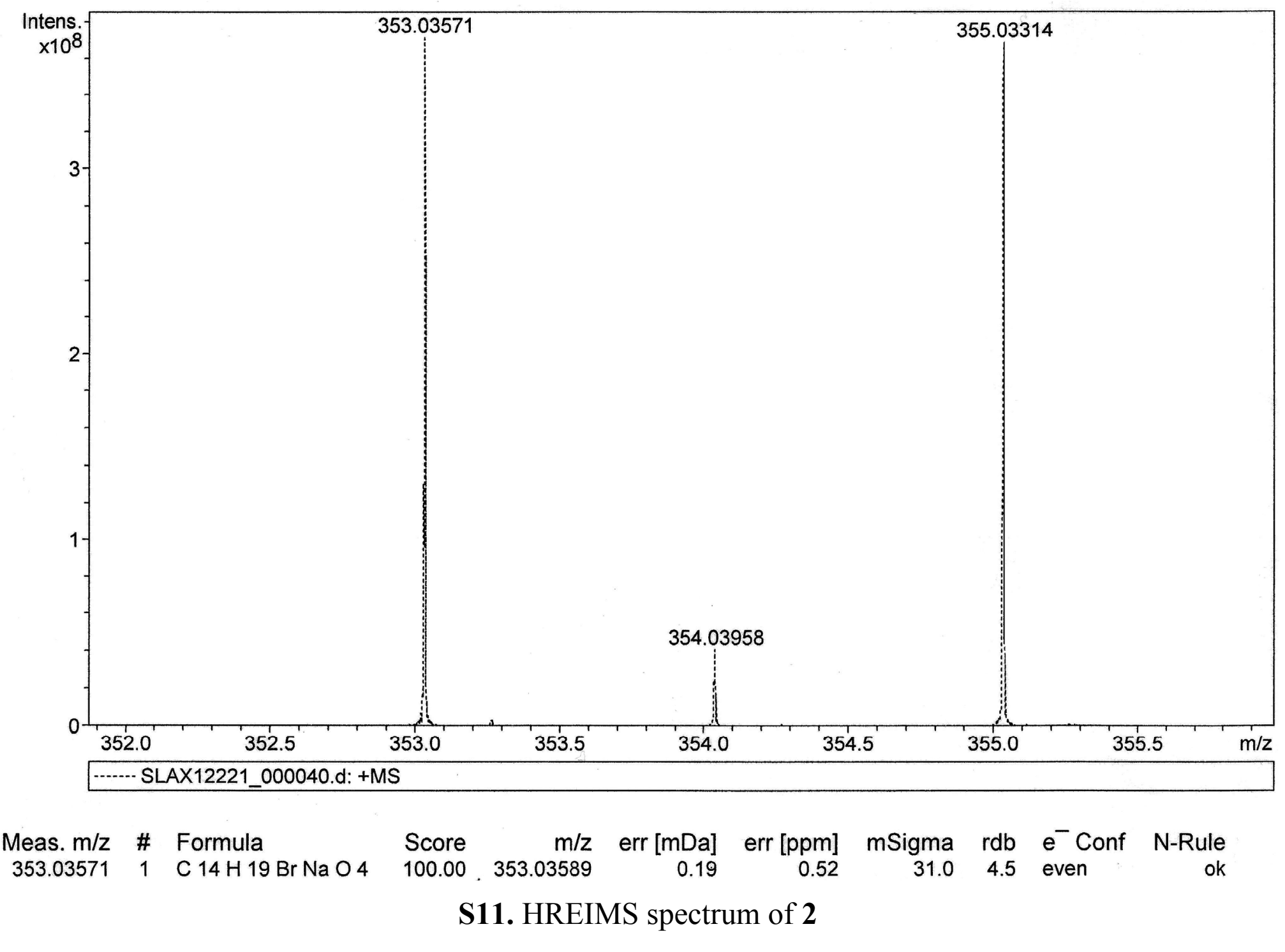




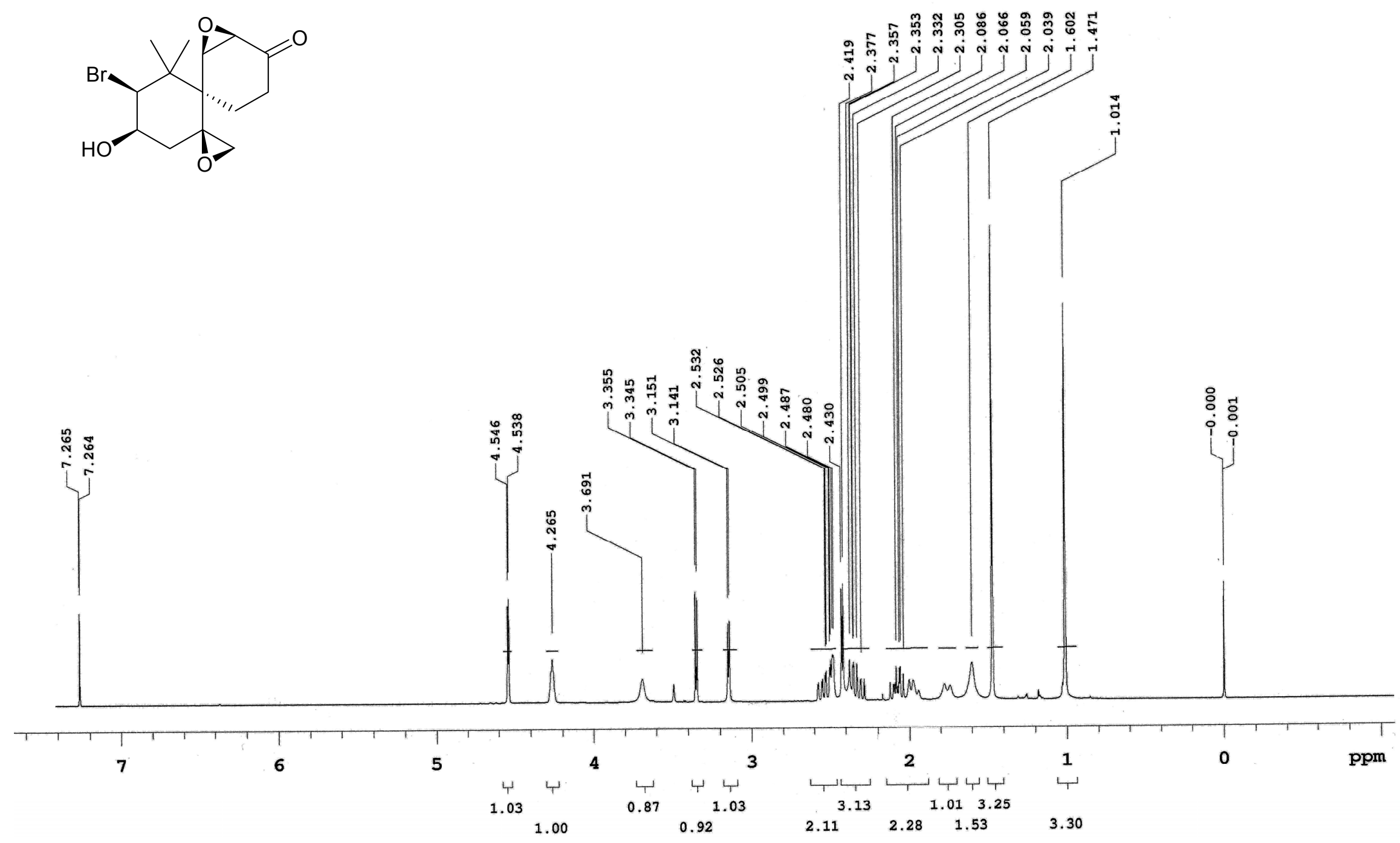

S12. ${ }^{1} \mathrm{H}$ NMR spectrum of 2 in $\mathrm{CDCl}_{3}$ 


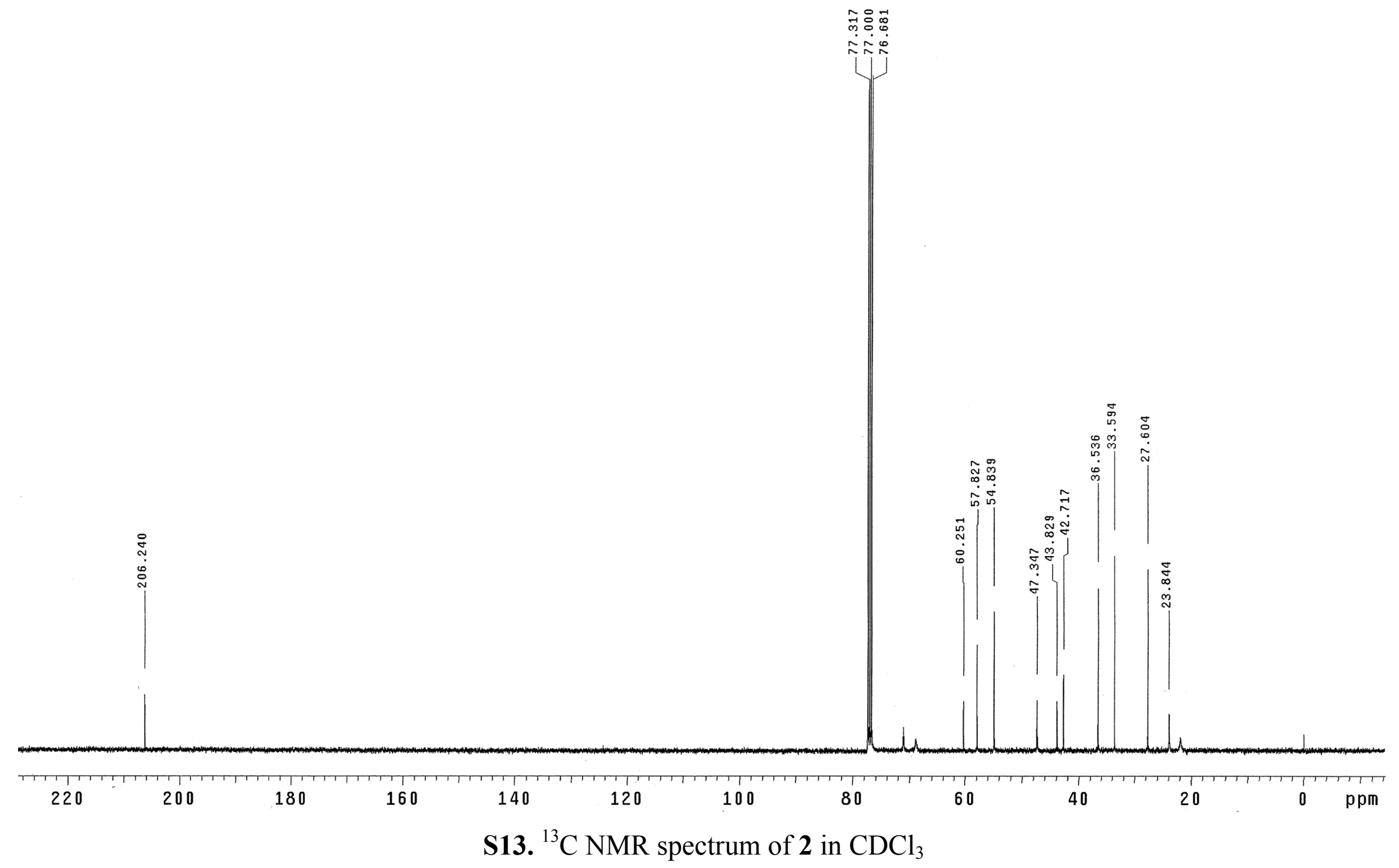



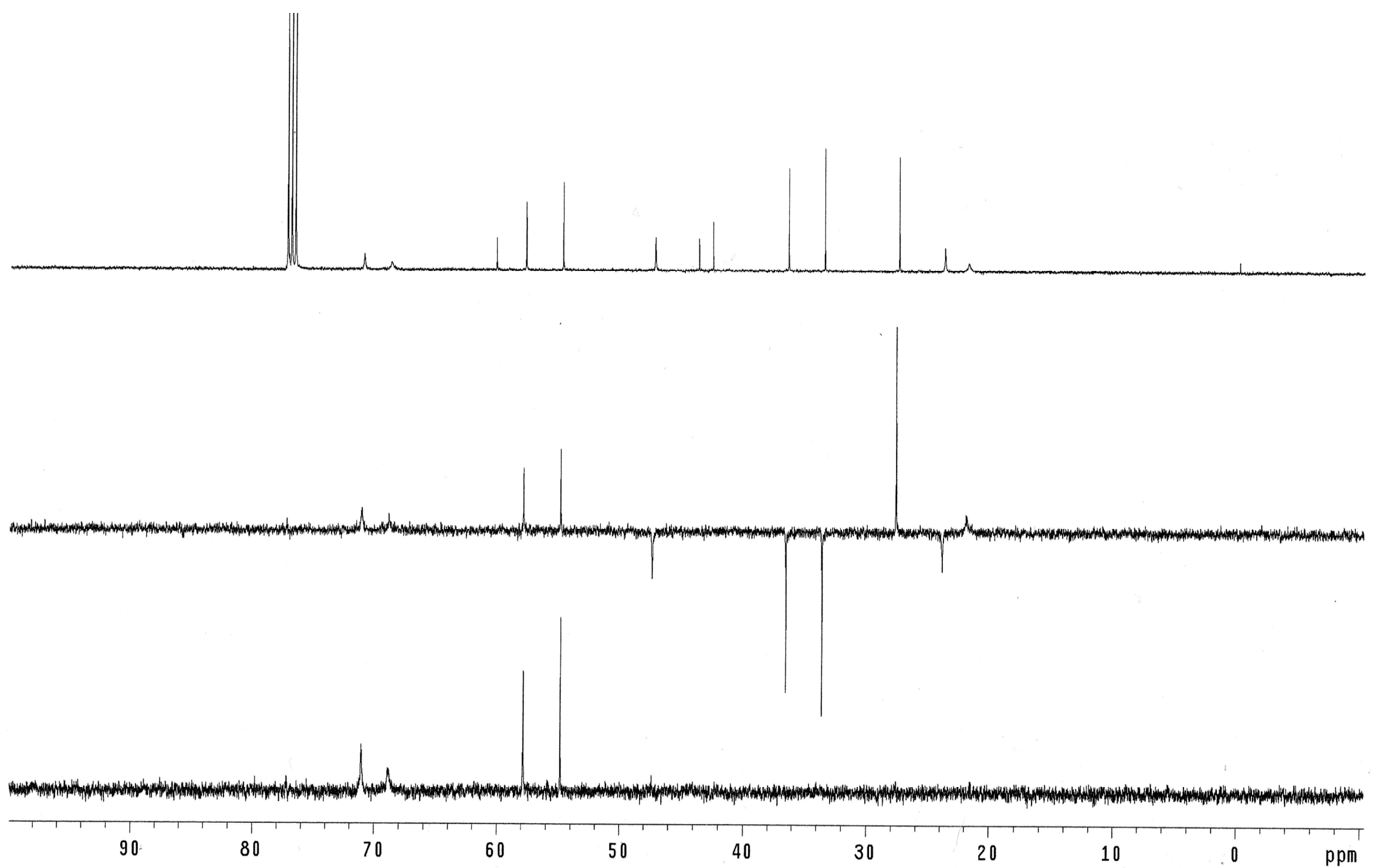

S14. DEPT spectra of $\mathbf{2}$ in $\mathrm{CDCl}_{3}$ 


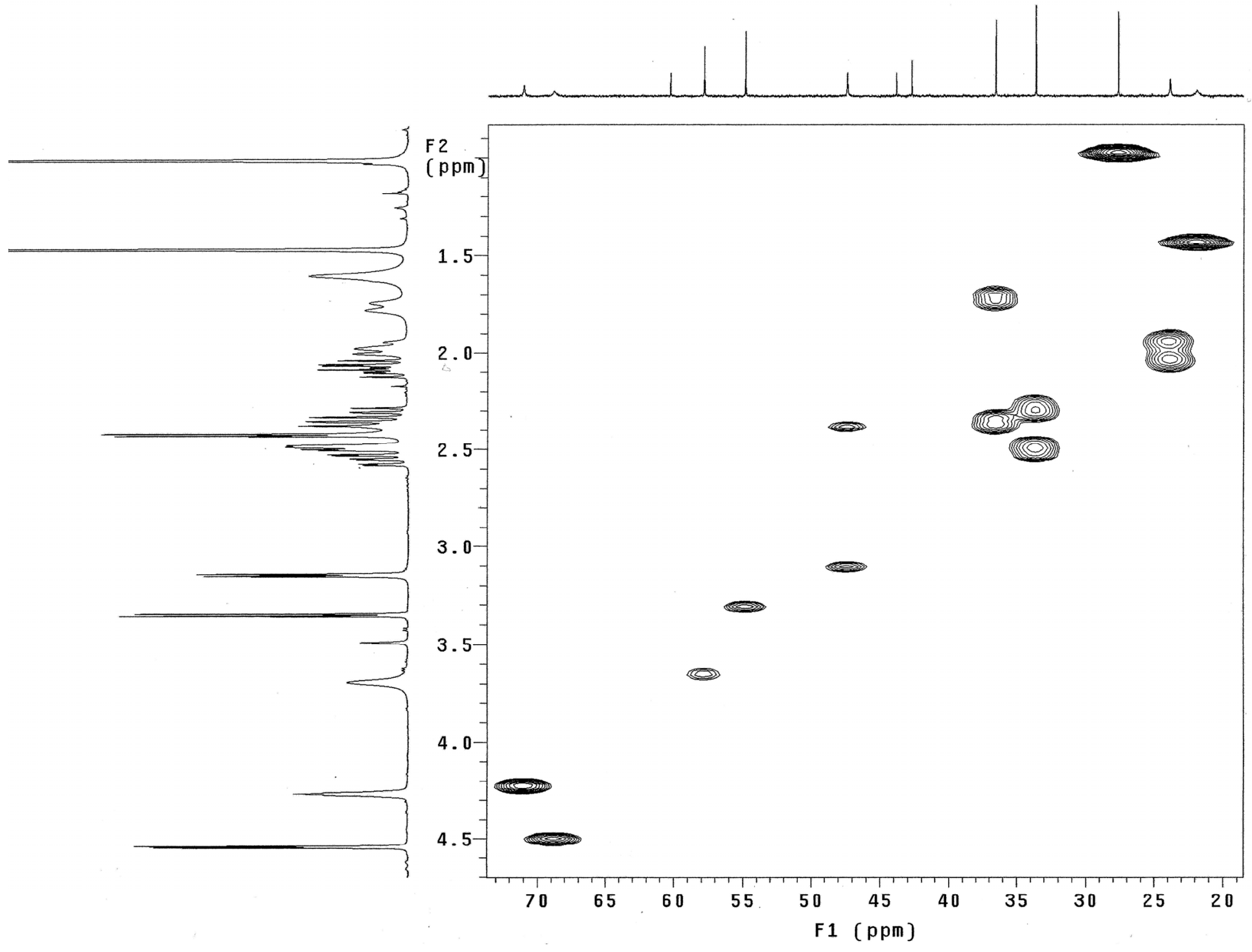

S15. HSQC spectrum of $\mathbf{2}$ in $\mathrm{CDCl}_{3}$ 


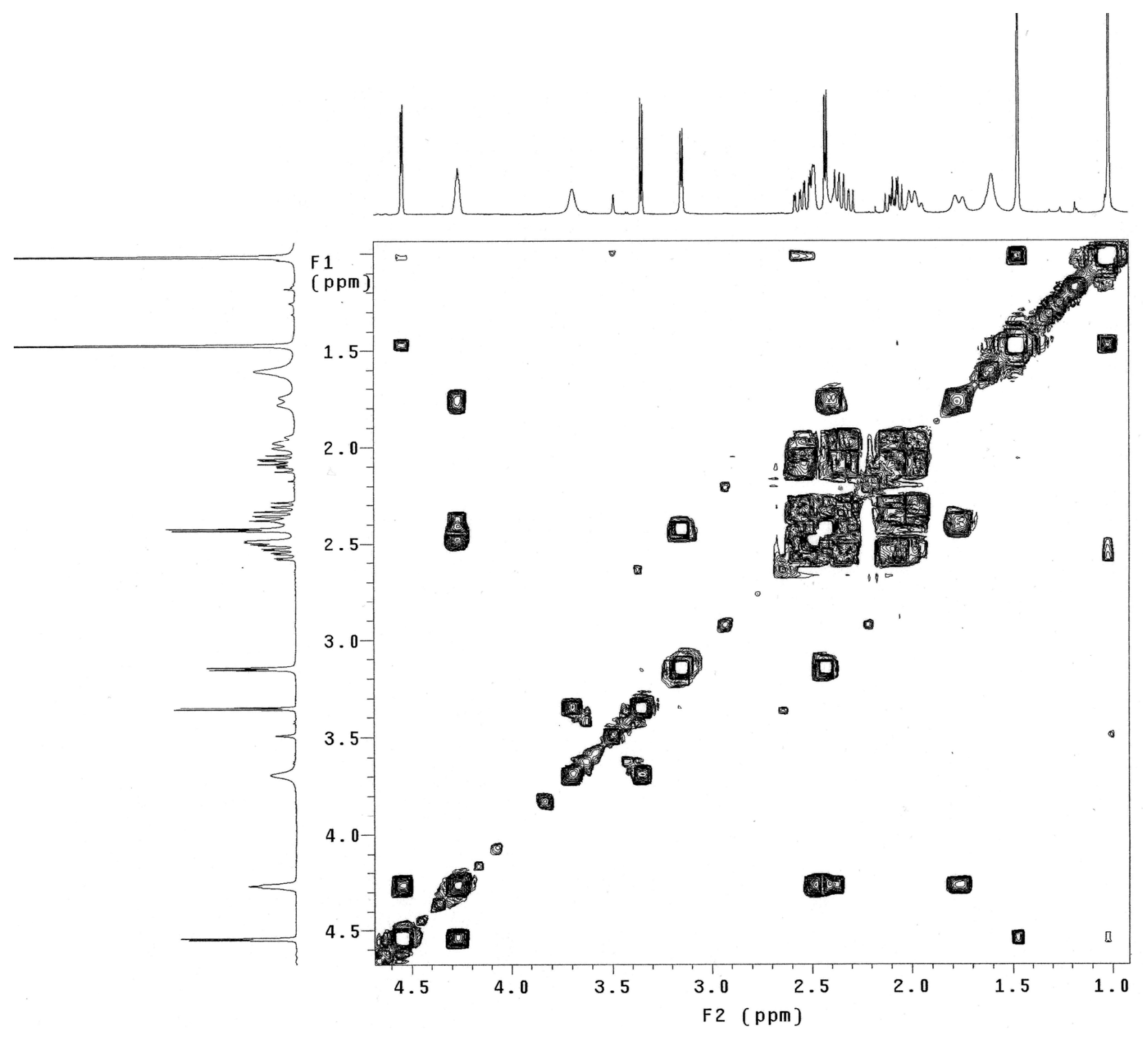

S16. COSY spectrum of $\mathbf{2}$ in $\mathrm{CDCl}_{3}$ 


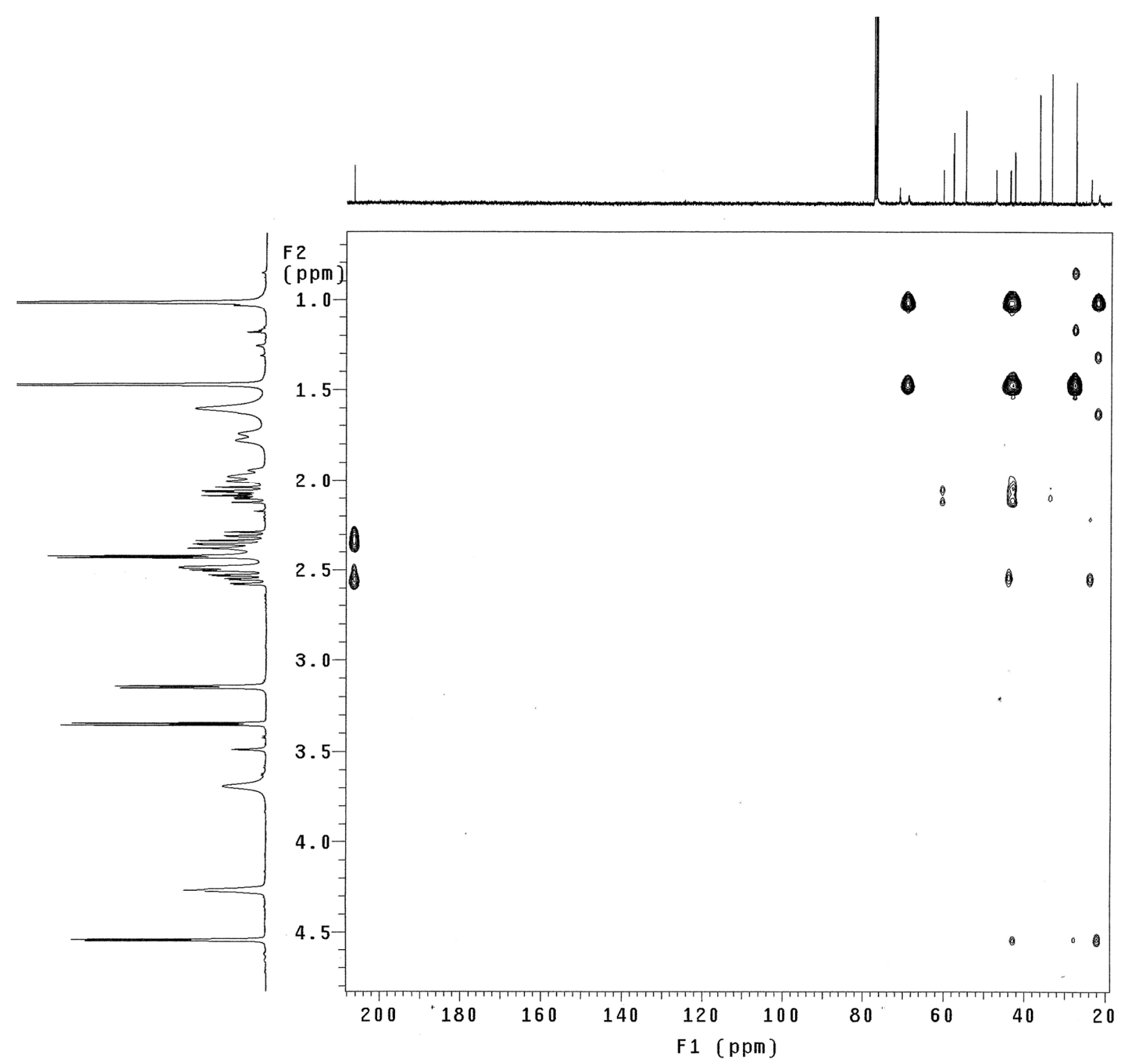

S17. $\mathrm{HMBC}$ spectrum of $\mathbf{2}$ in $\mathrm{CDCl}_{3}$ 


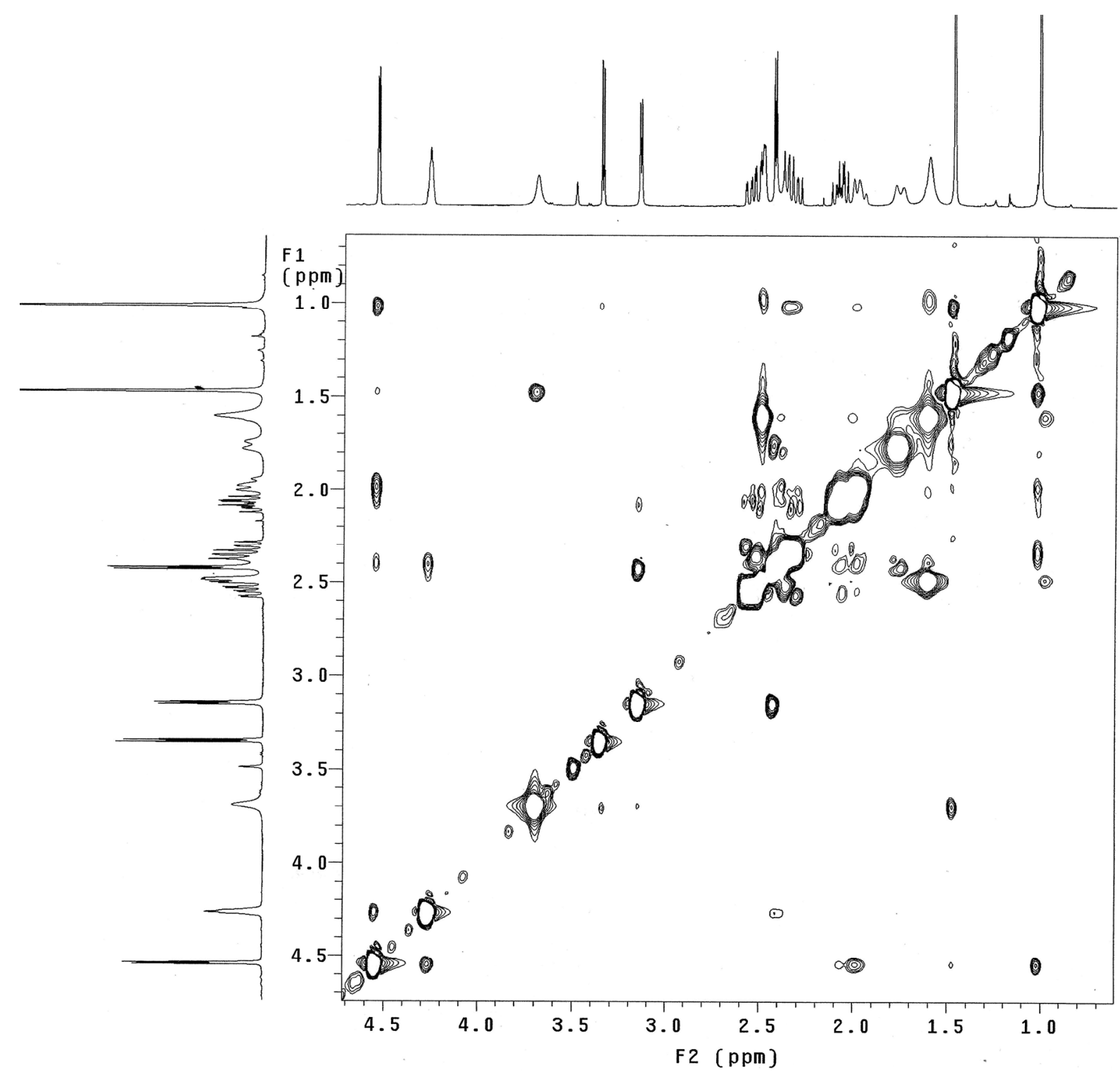

S18. NOESY spectrum of $\mathbf{2}$ in $\mathrm{CDCl}_{3}$ 


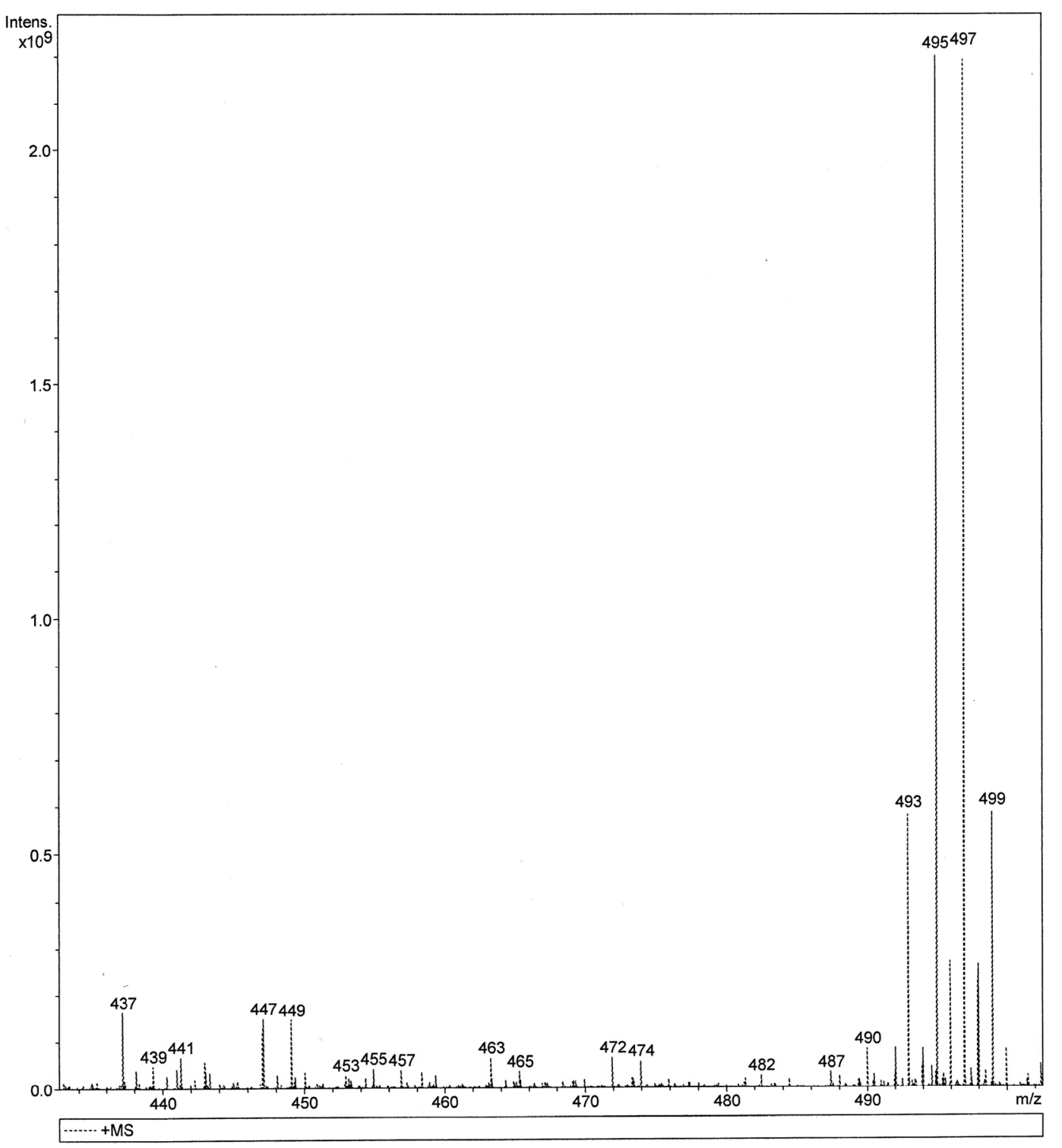

S19. ESIMS spectrum of 3 


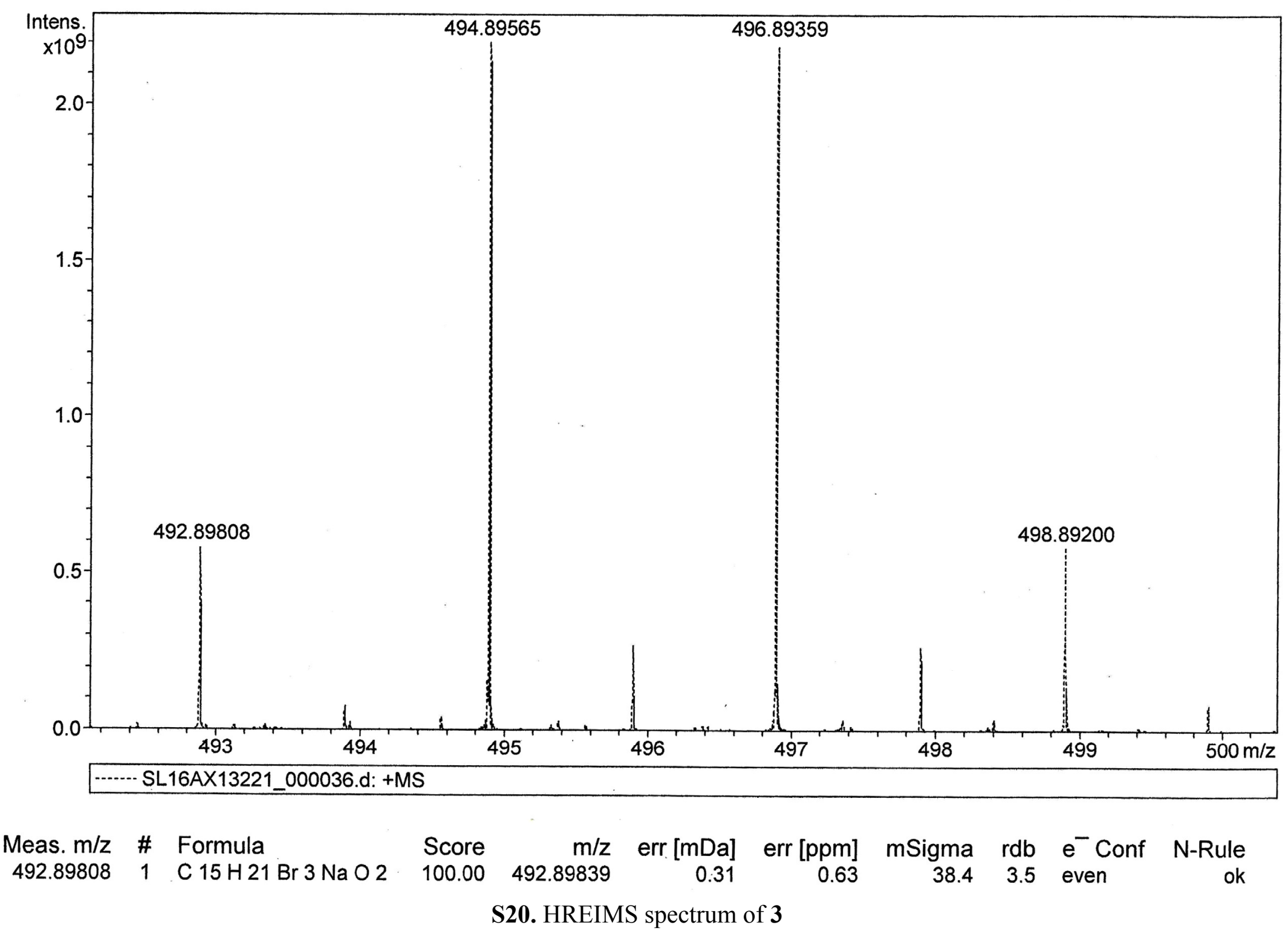




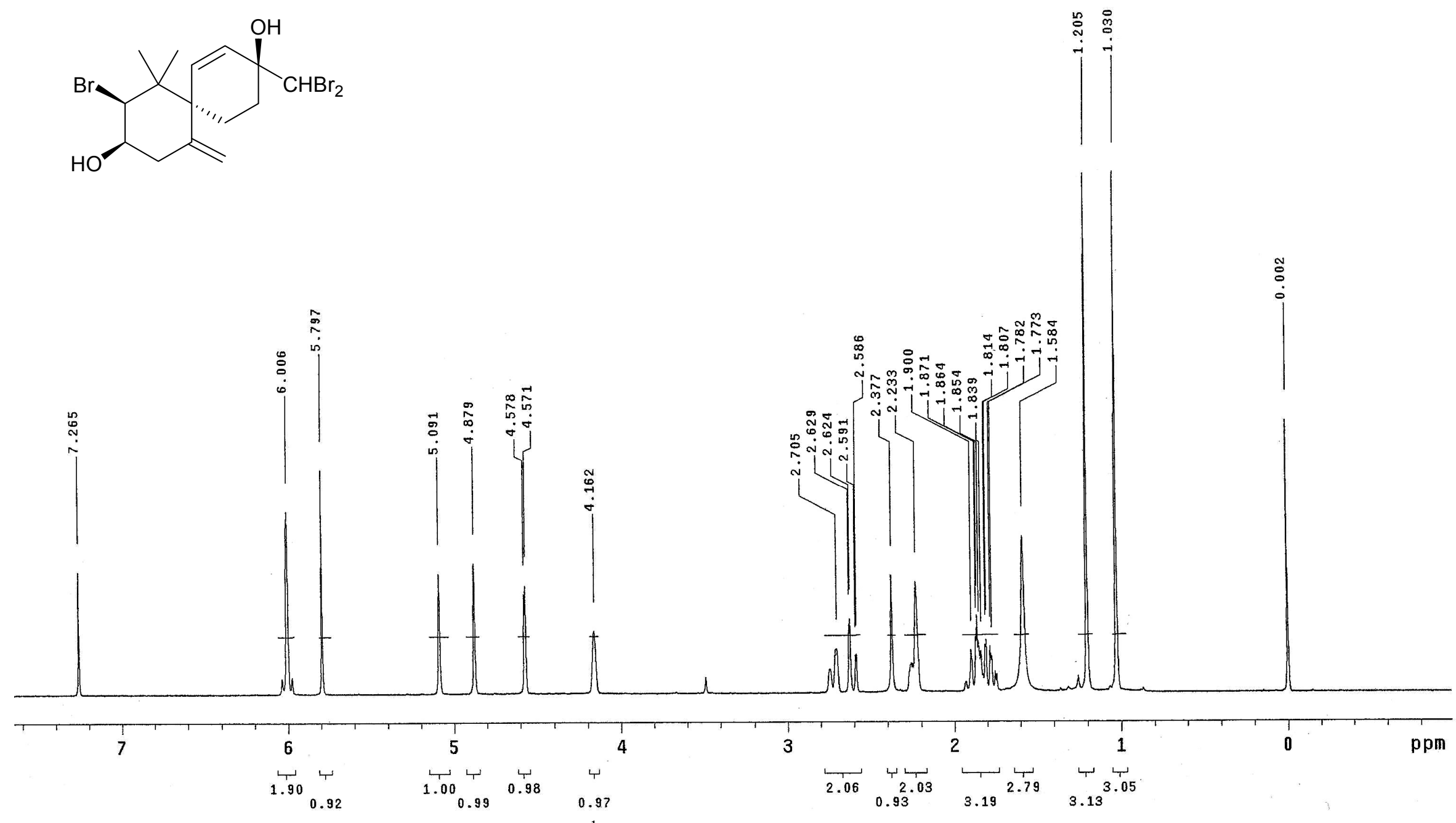

S21. ${ }^{1} \mathrm{H}$ NMR spectrum of $\mathbf{3}$ in $\mathrm{CDCl}_{3}$ 


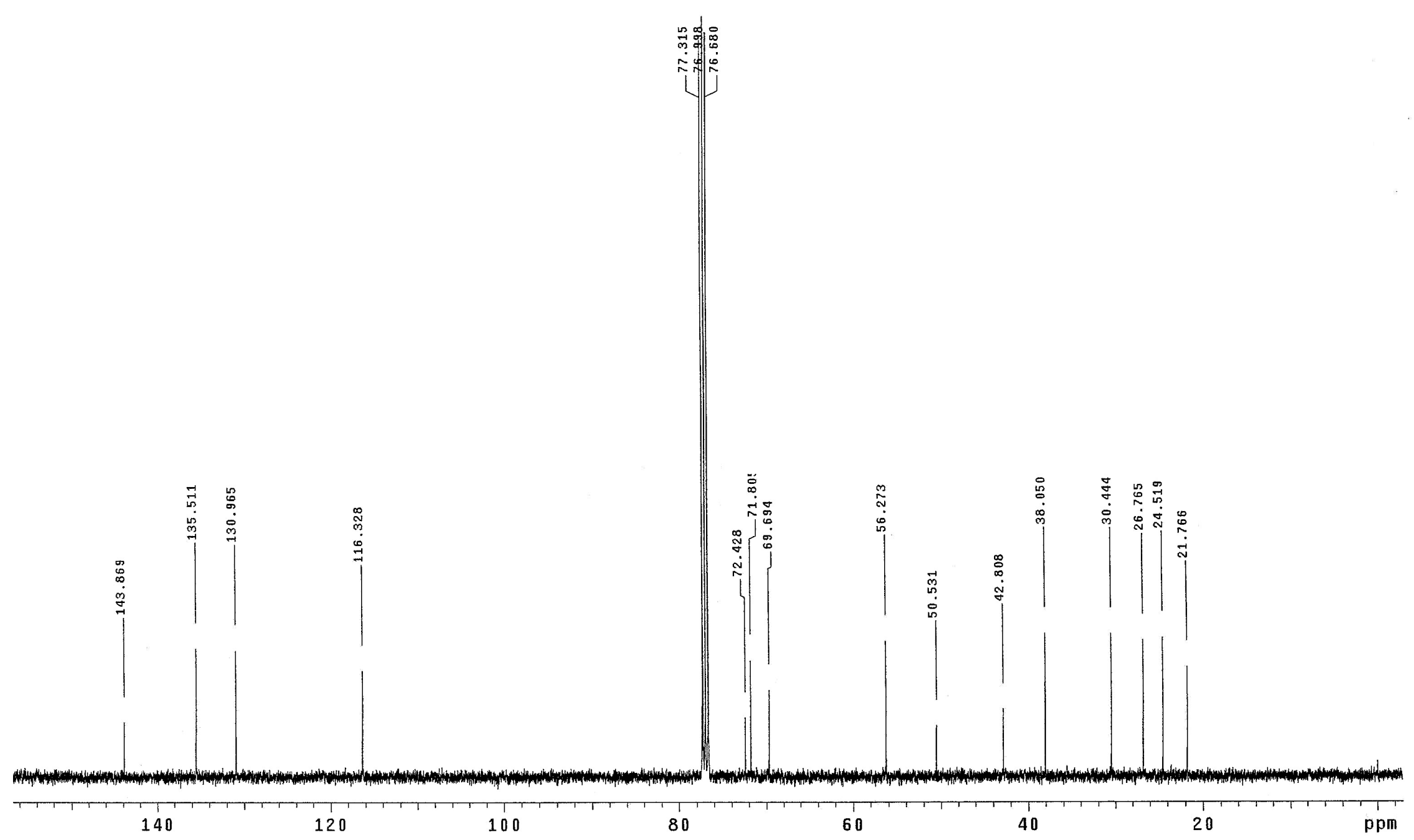

S22. ${ }^{13} \mathrm{C}$ NMR spectrum of $\mathbf{3}$ in $\mathrm{CDCl}_{3}$ 

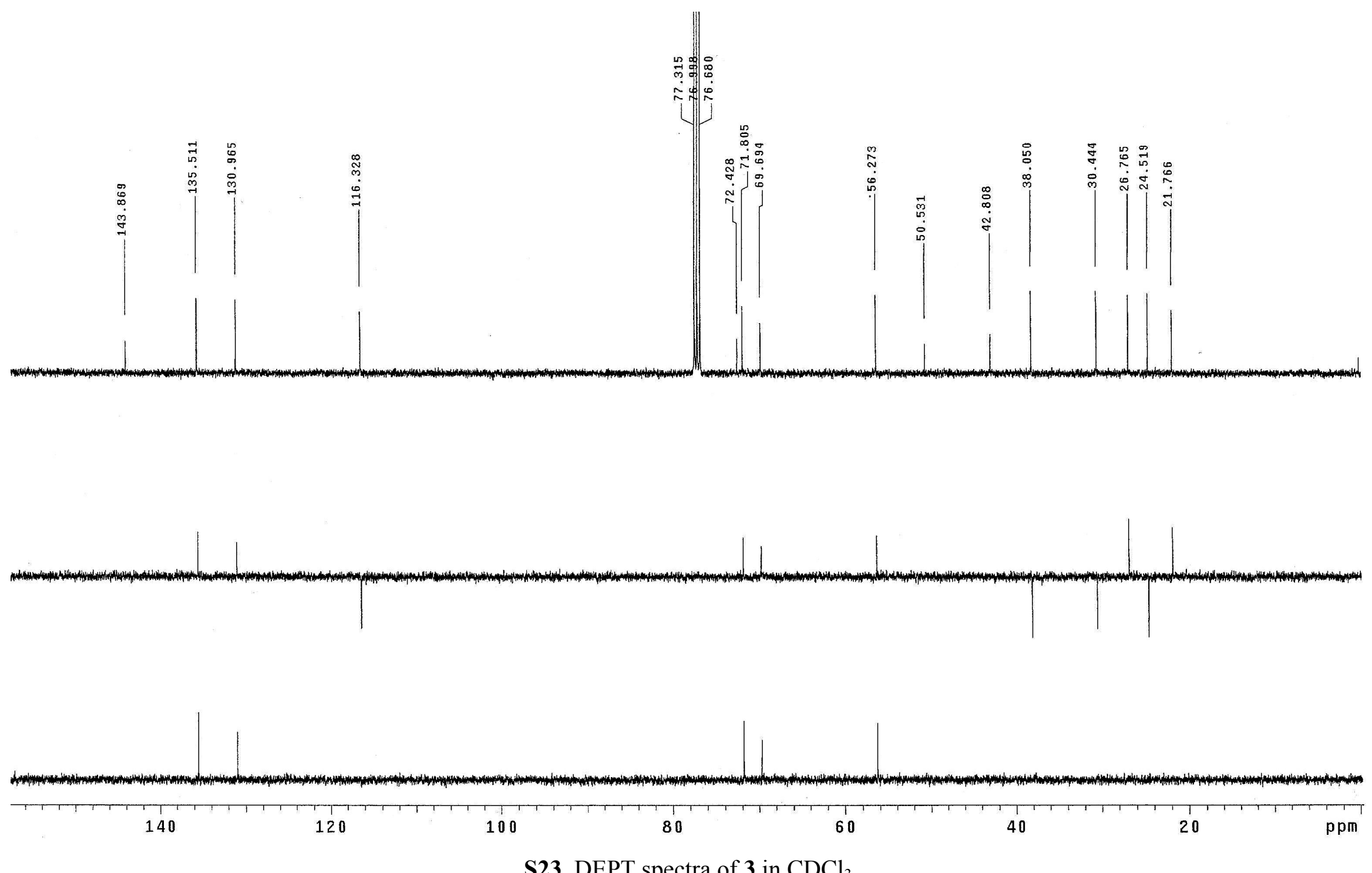

S23. DEPT spectra of $\mathbf{3}$ in $\mathrm{CDCl}_{3}$ 


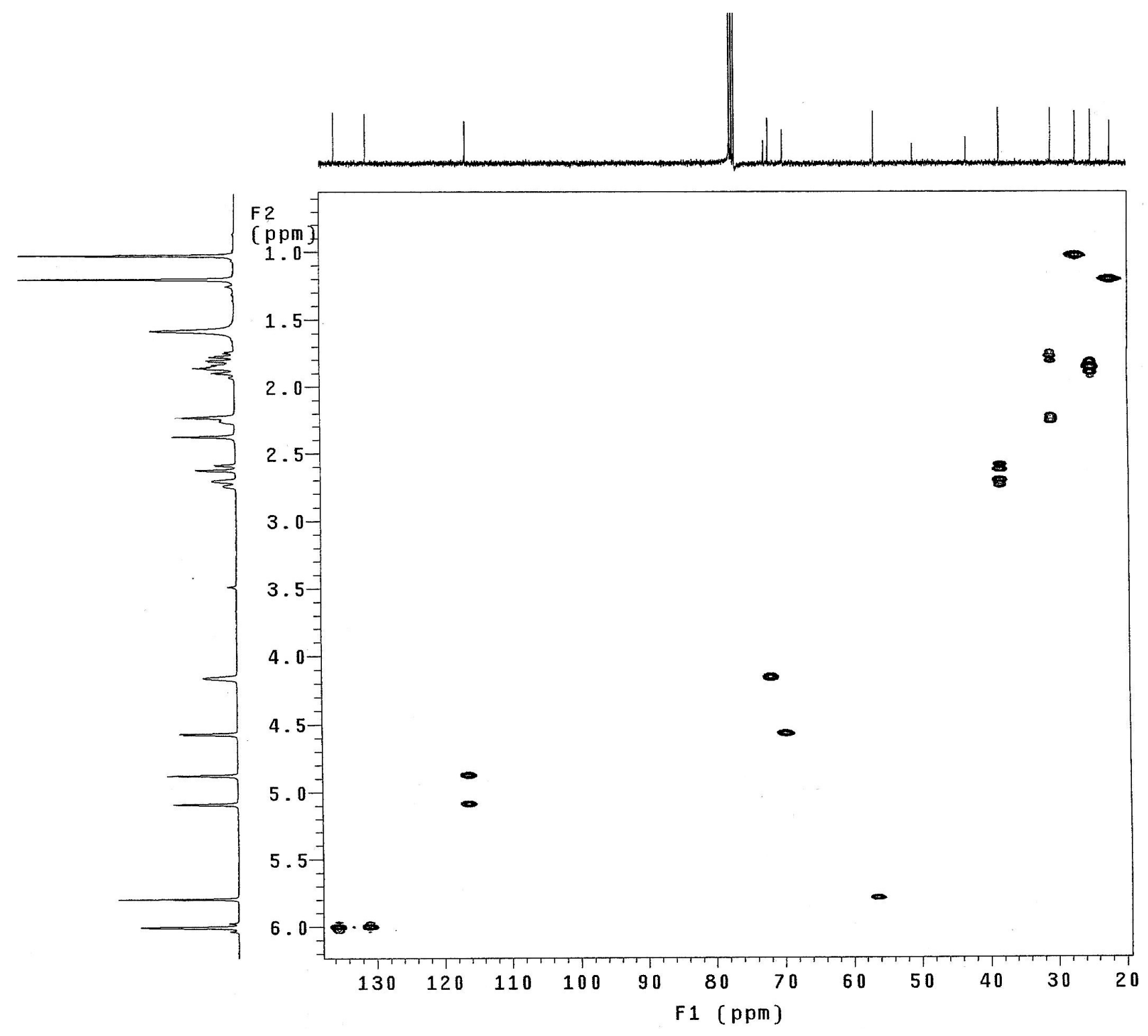

S24. HSQC spectrum of $\mathbf{3}$ in $\mathrm{CDCl}_{3}$ 


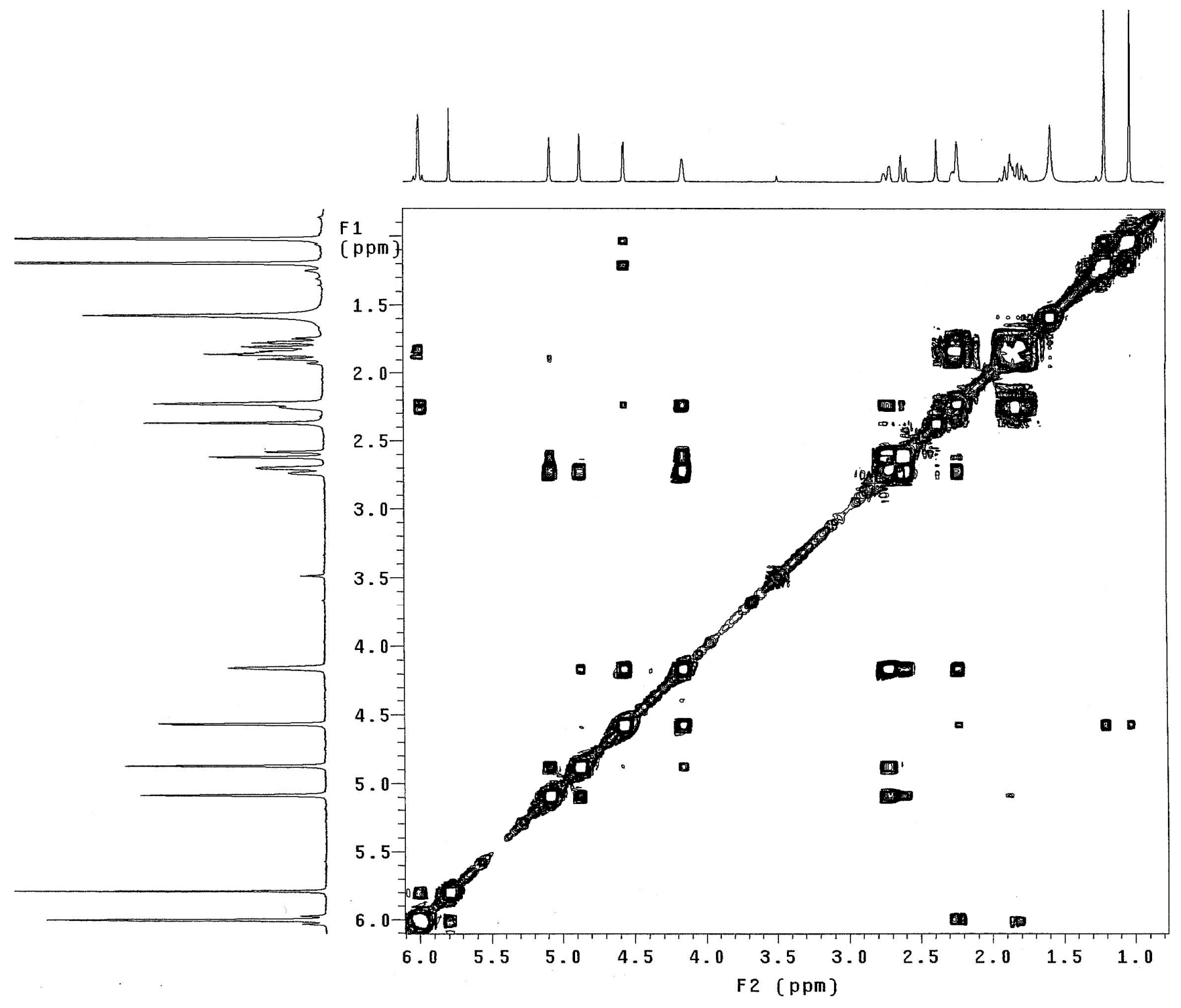

S25. COSY spectrum of $\mathbf{3}$ in $\mathrm{CDCl}_{3}$ 


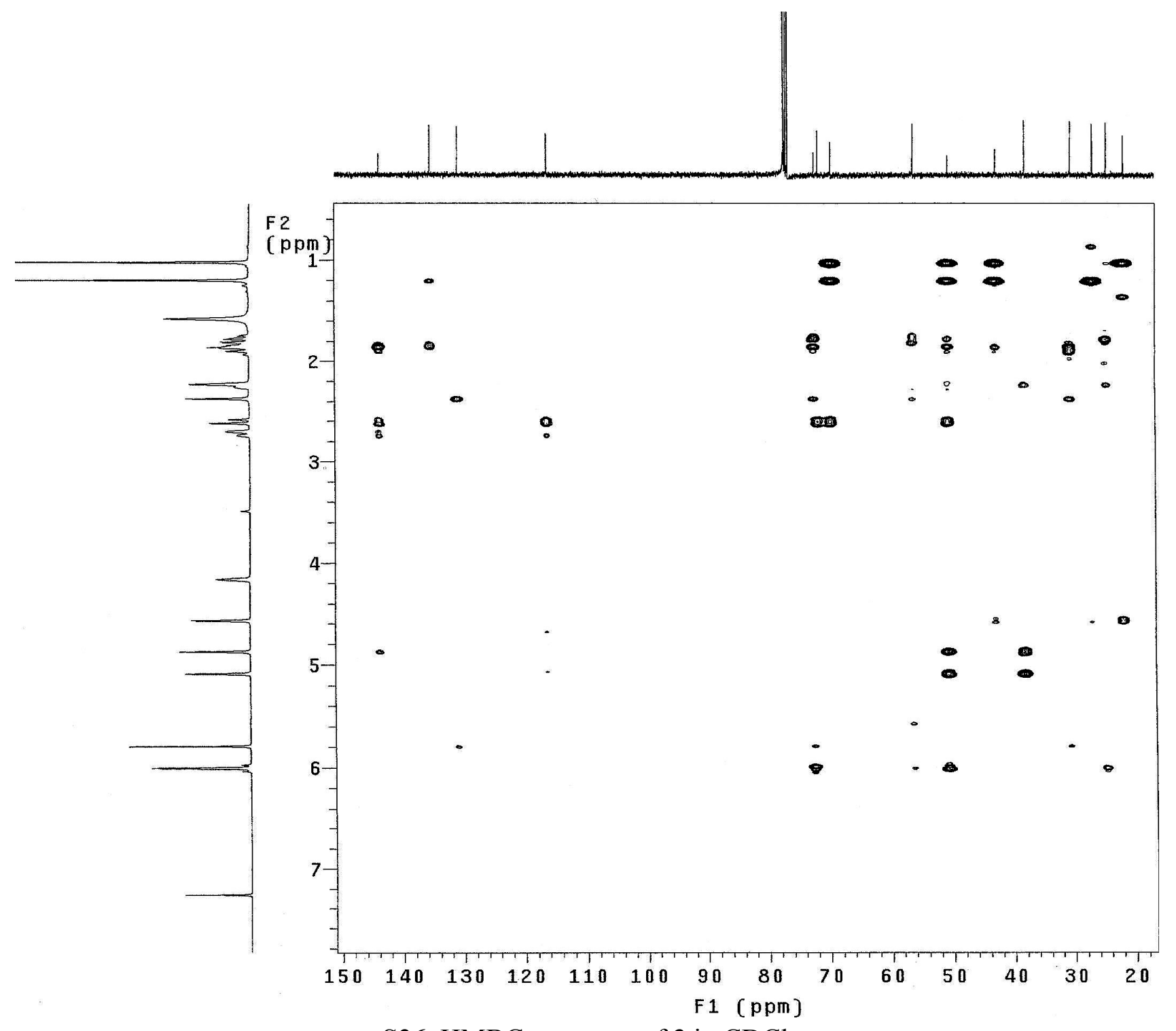

S26. $\mathrm{HMBC}$ spectrum of $\mathbf{3}$ in $\mathrm{CDCl}_{3}$ 


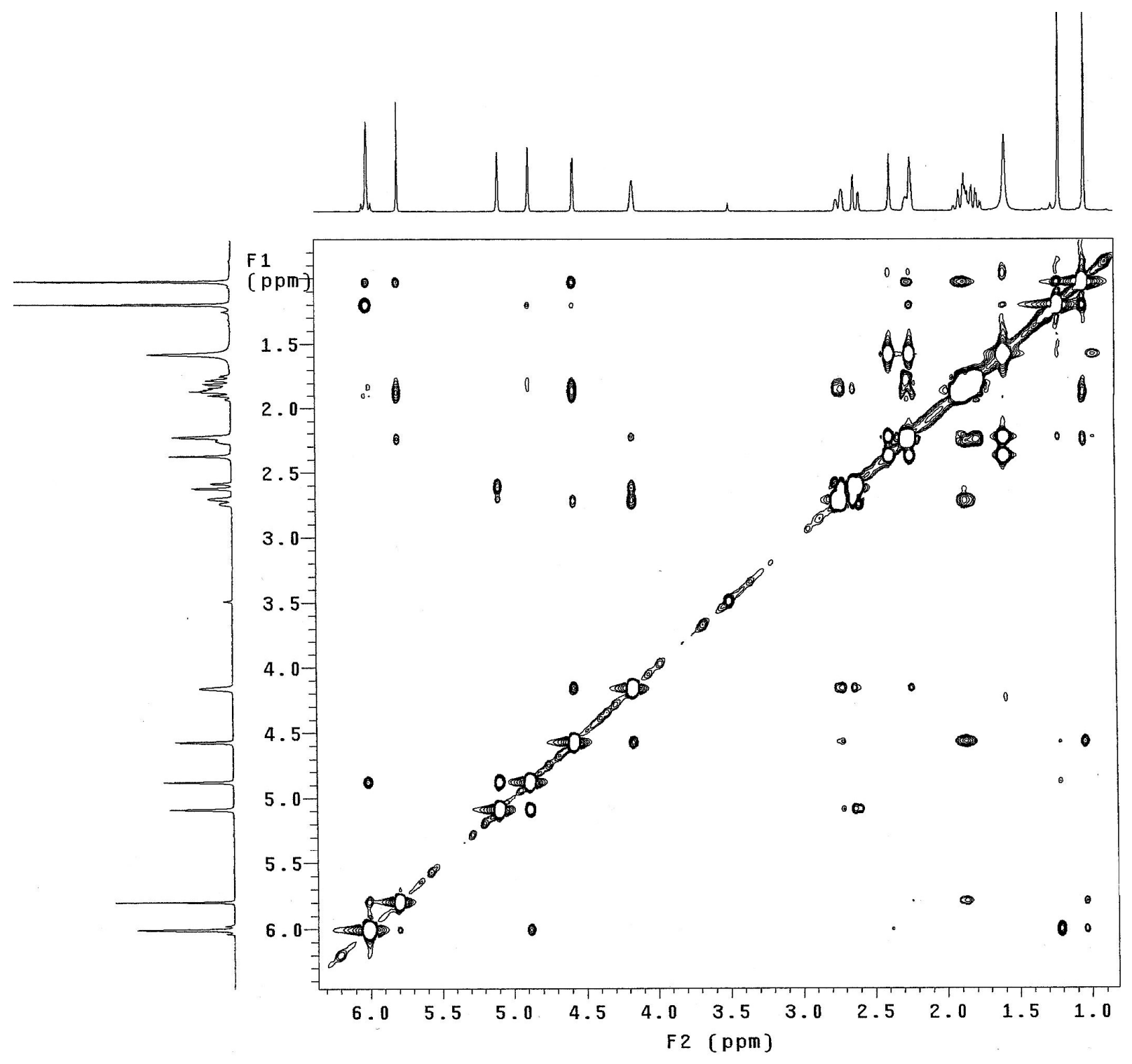

S27. NOESY spectrum of $\mathbf{3}$ in $\mathrm{CDCl}_{3}$ 


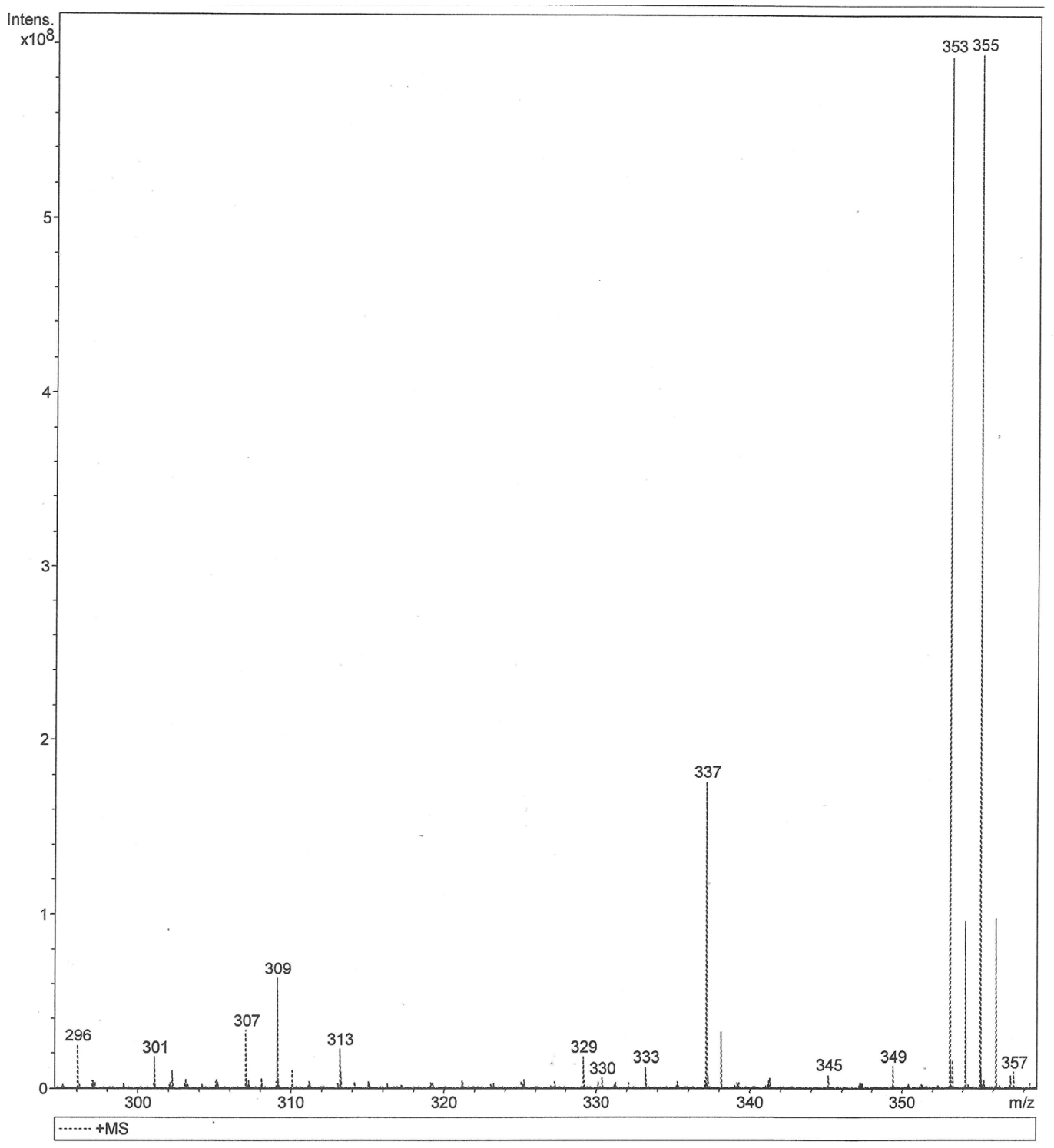

S28. ESIMS spectrum of 4 


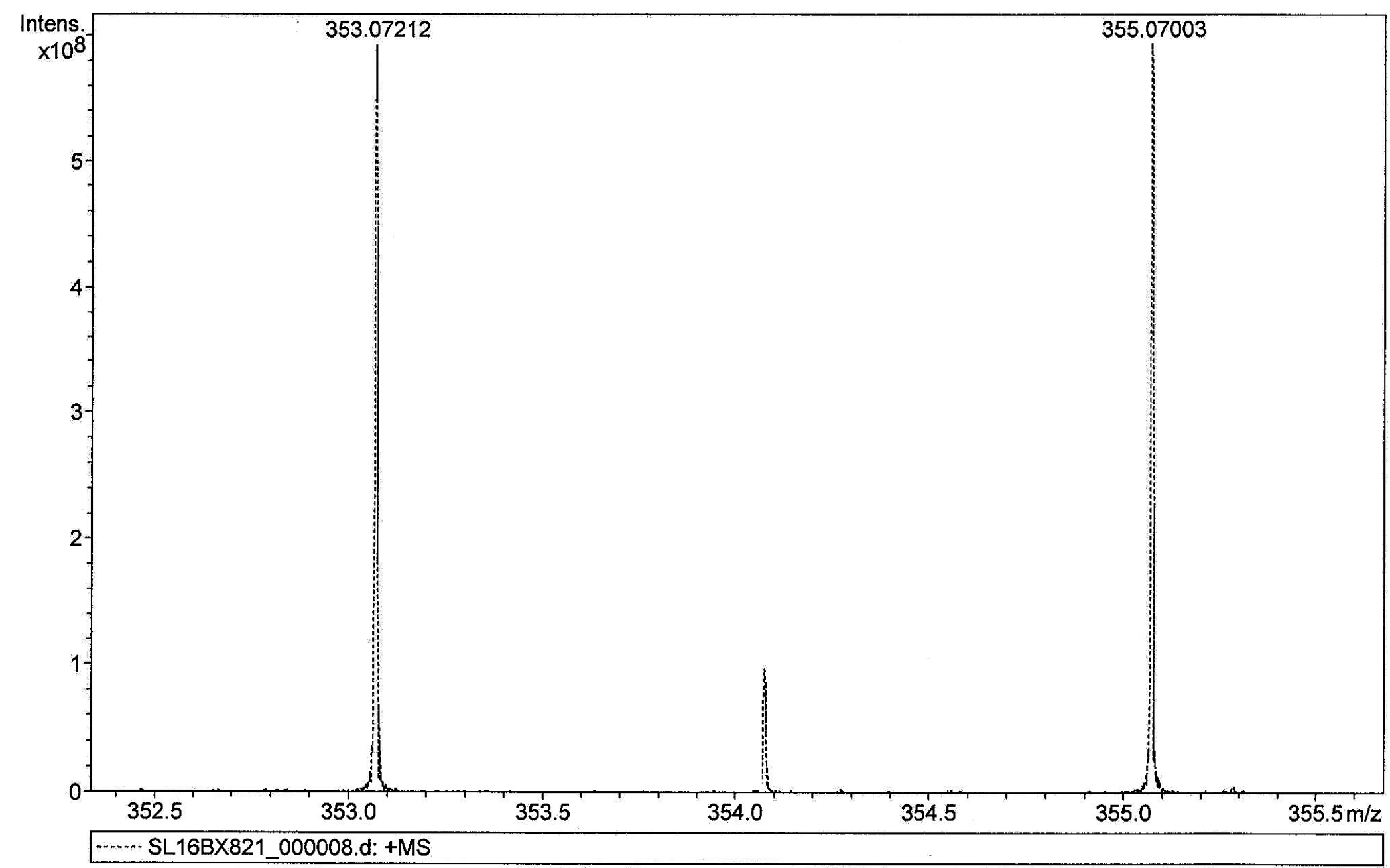

Meas. $\mathrm{m} / \mathrm{z}$ \# Formula 353.07212

Score

$\mathrm{m} / \mathrm{z}$ err $[\mathrm{mD}$

\section{err [ppm] mSigma rdb} $5.6 \quad 3.5$ even

Conf N-Rule

S29. HREIMS spectrum of 4 


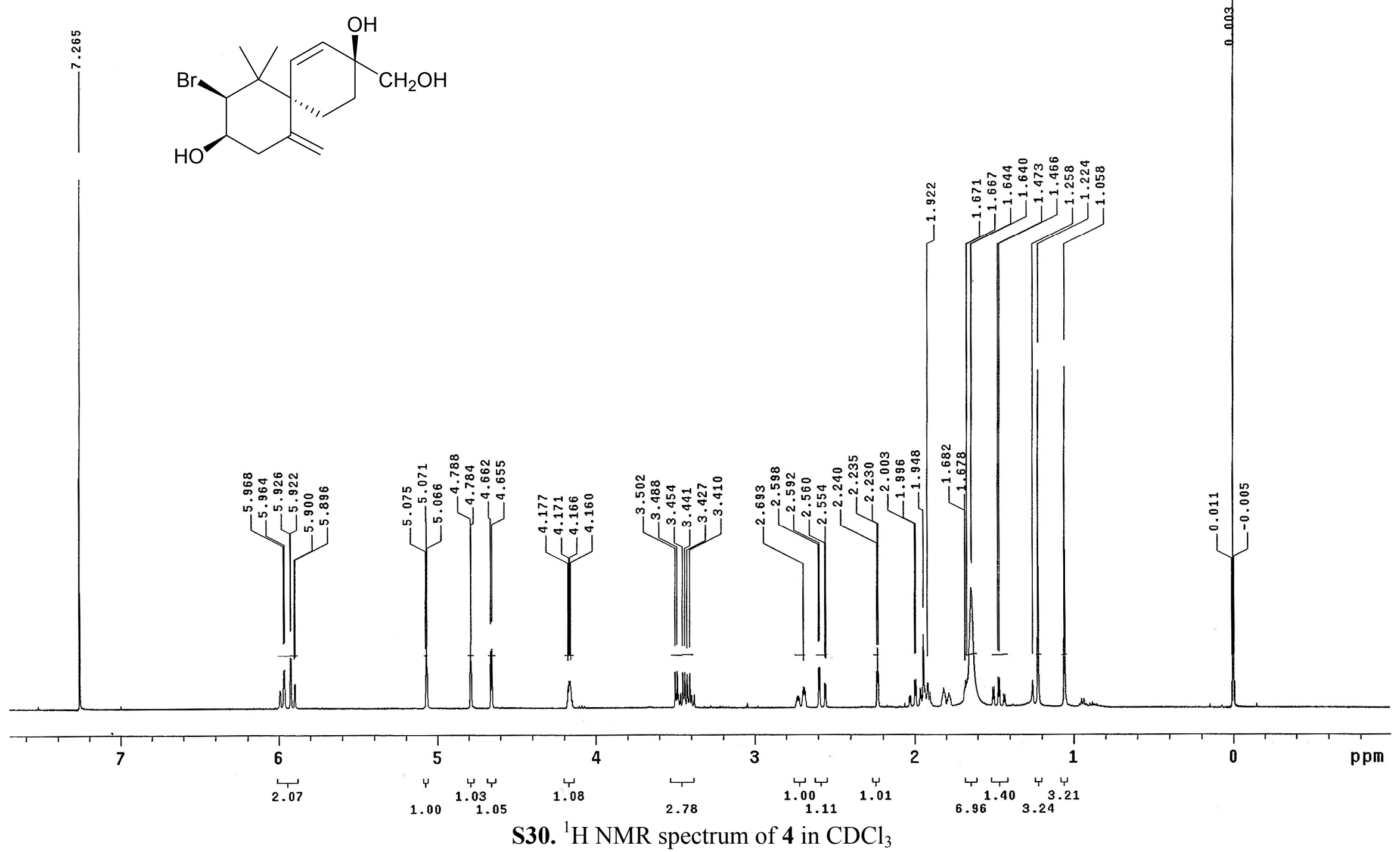




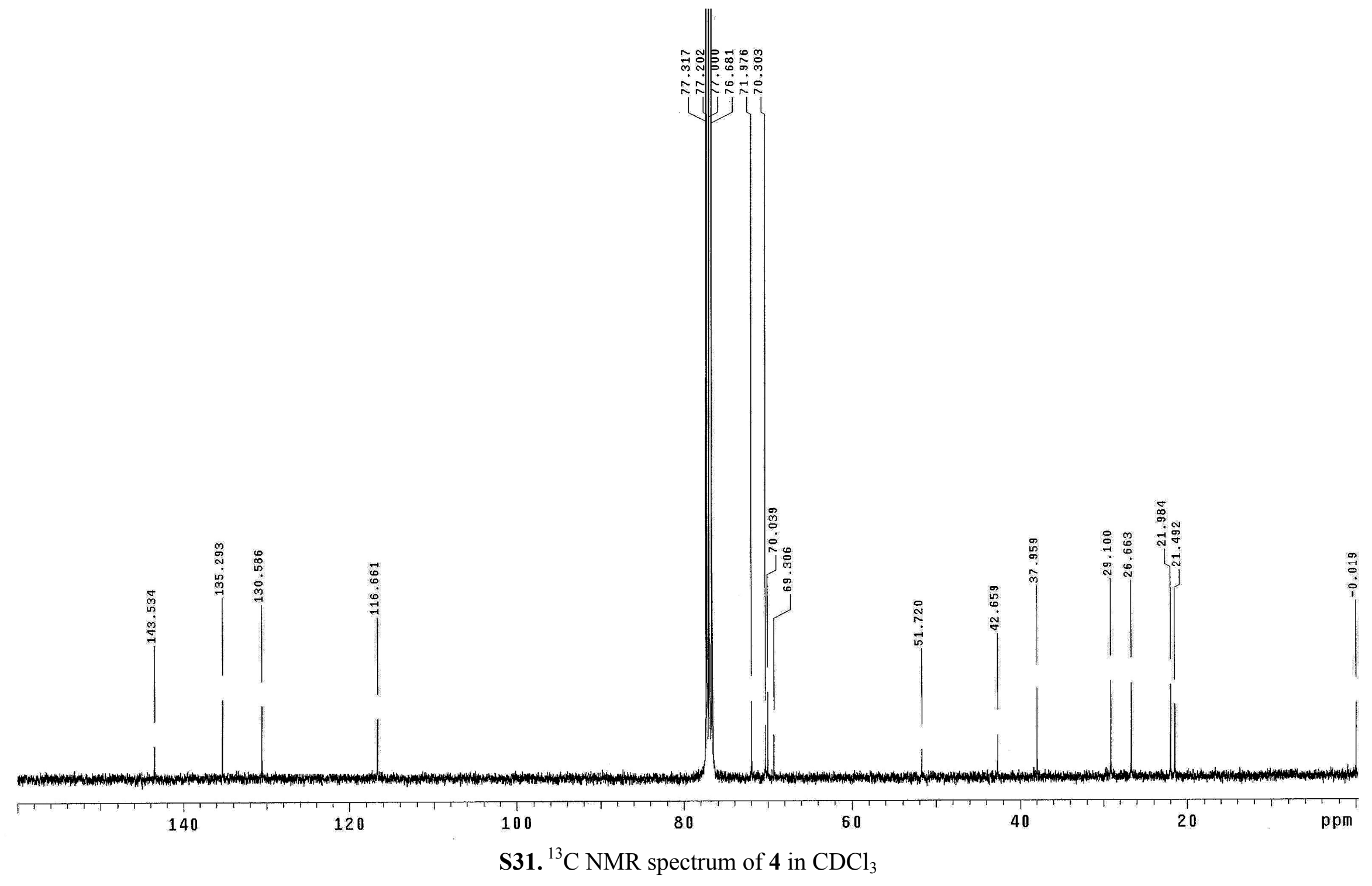



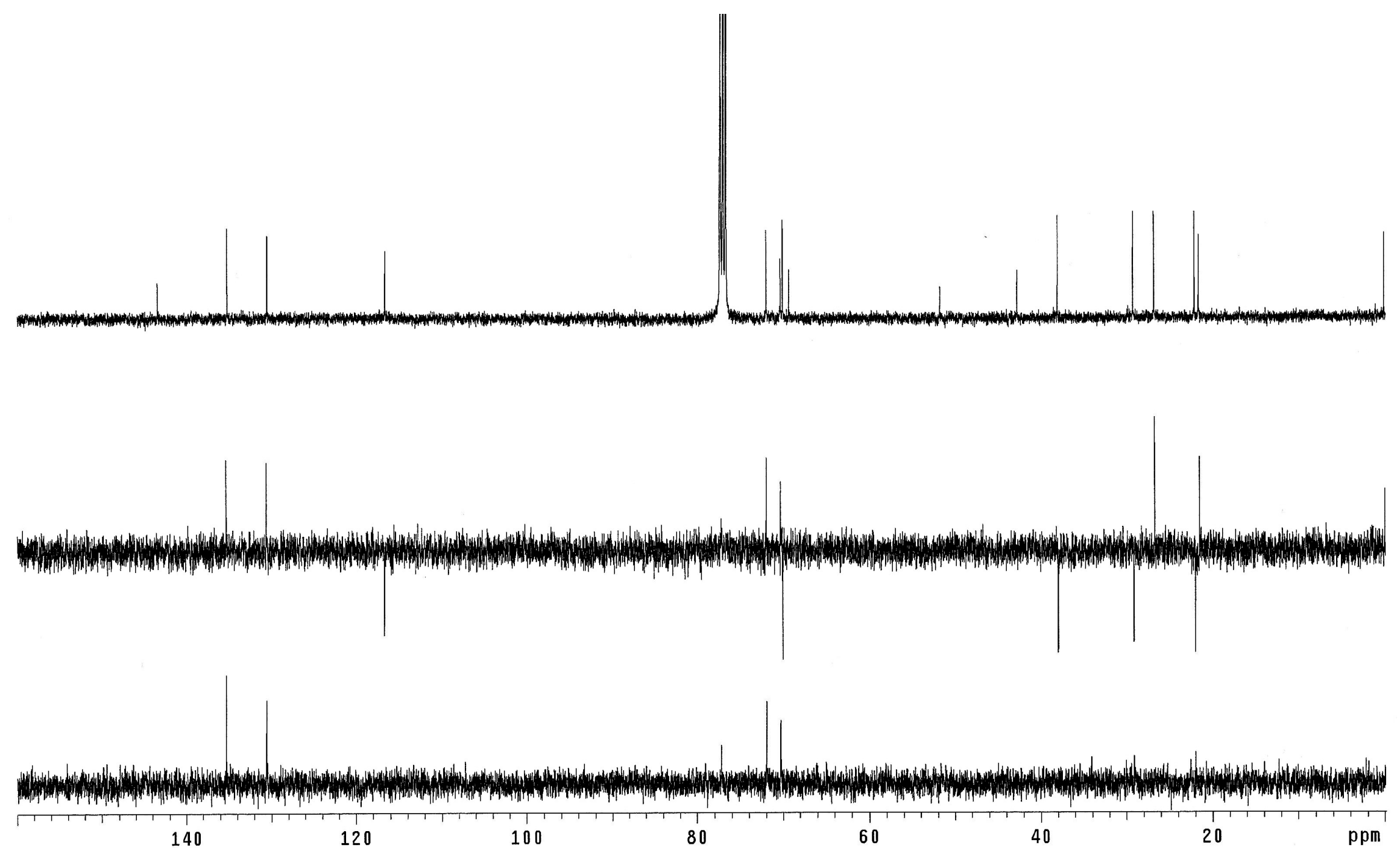

S32. DEPT spectra of 4 in $\mathrm{CDCl}_{3}$ 


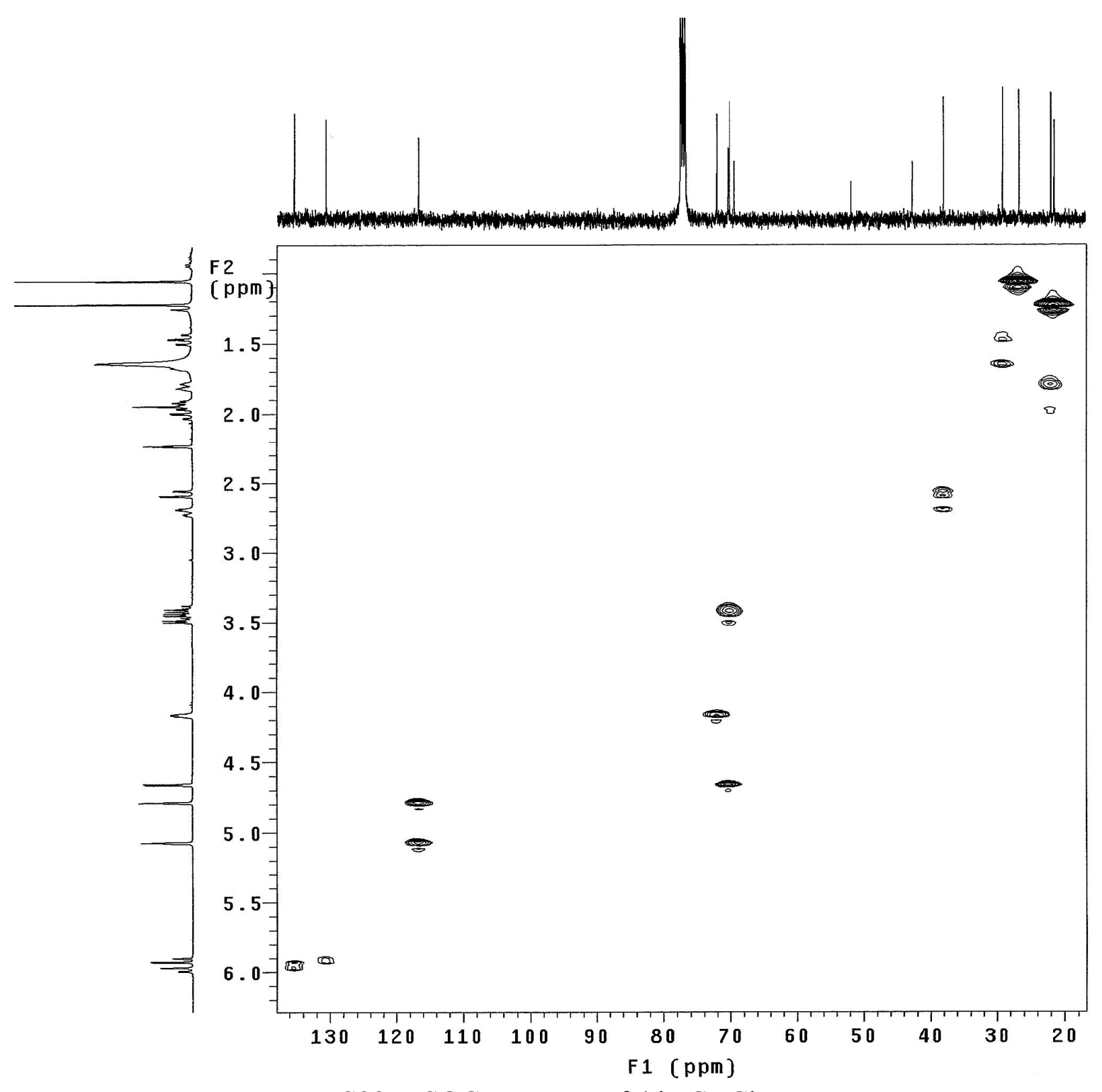

S33. HSQC spectrum of $\mathbf{4}$ in $\mathrm{CDCl}_{3}$ 


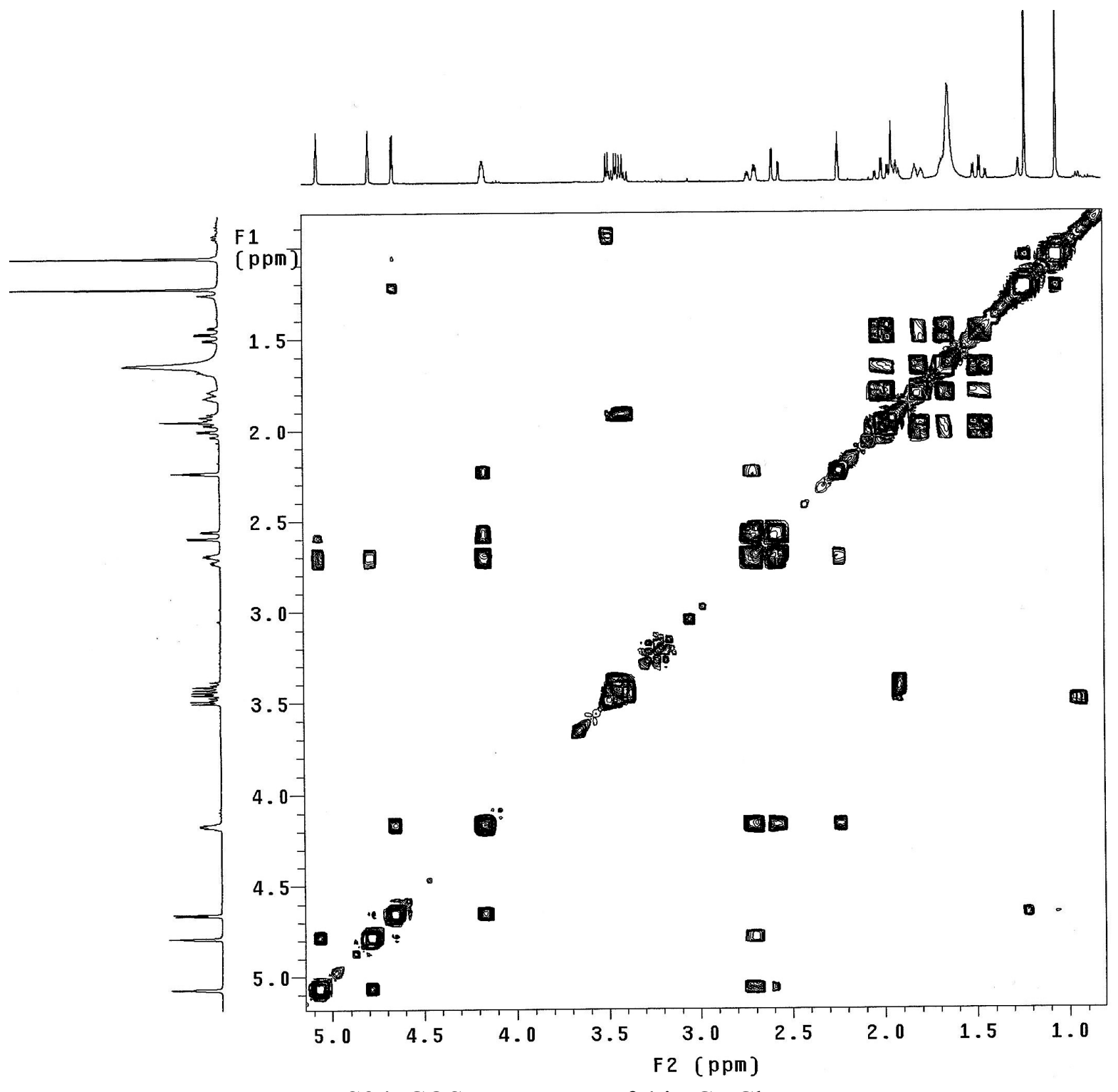

S34. COSY spectrum of 4 in $\mathrm{CDCl}_{3}$ 


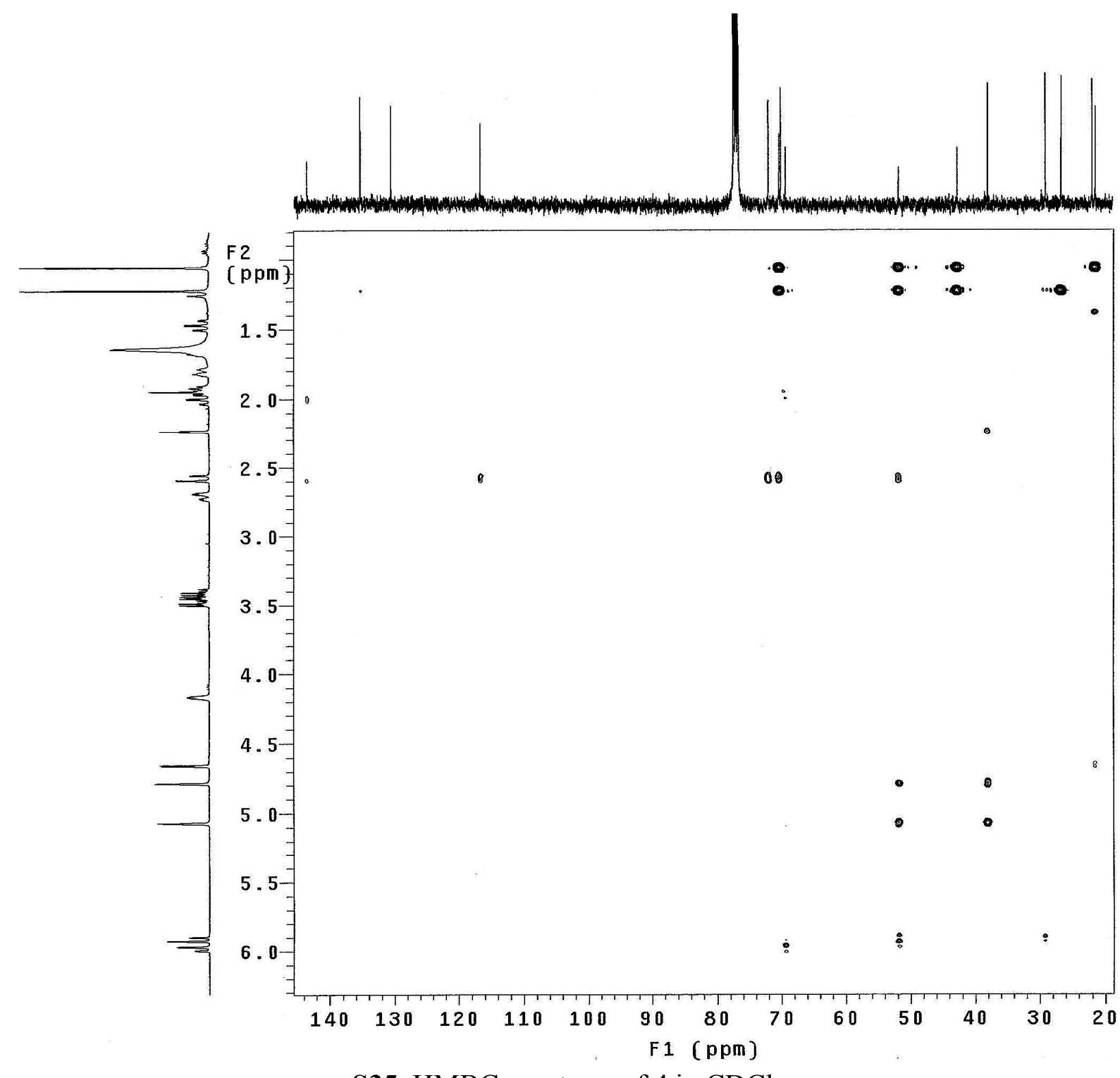

S35. $\mathrm{HMBC}$ spectrum of 4 in $\mathrm{CDCl}_{3}$ 


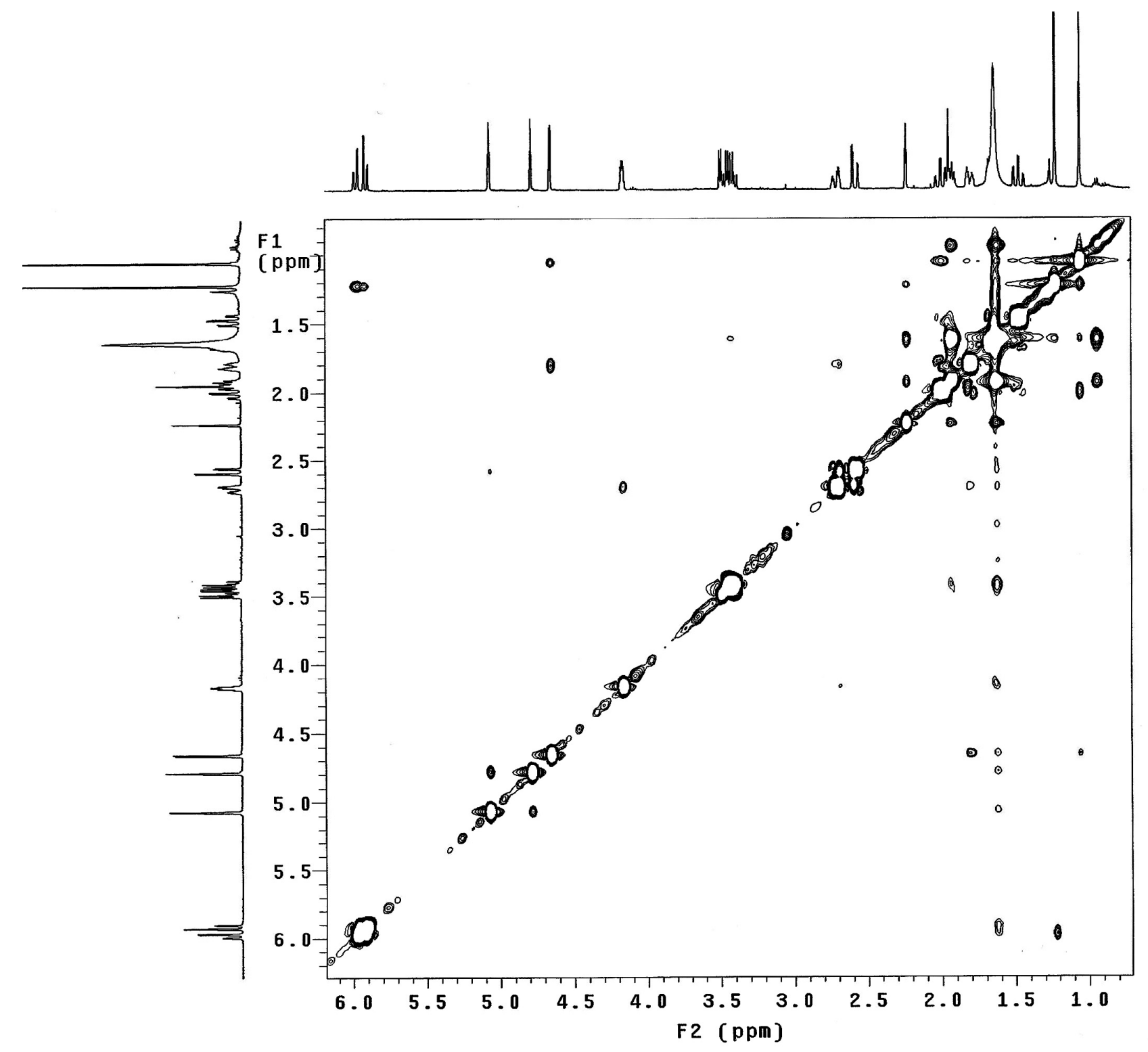

S36. NOESY spectrum of 4 in $\mathrm{CDCl}_{3}$ 


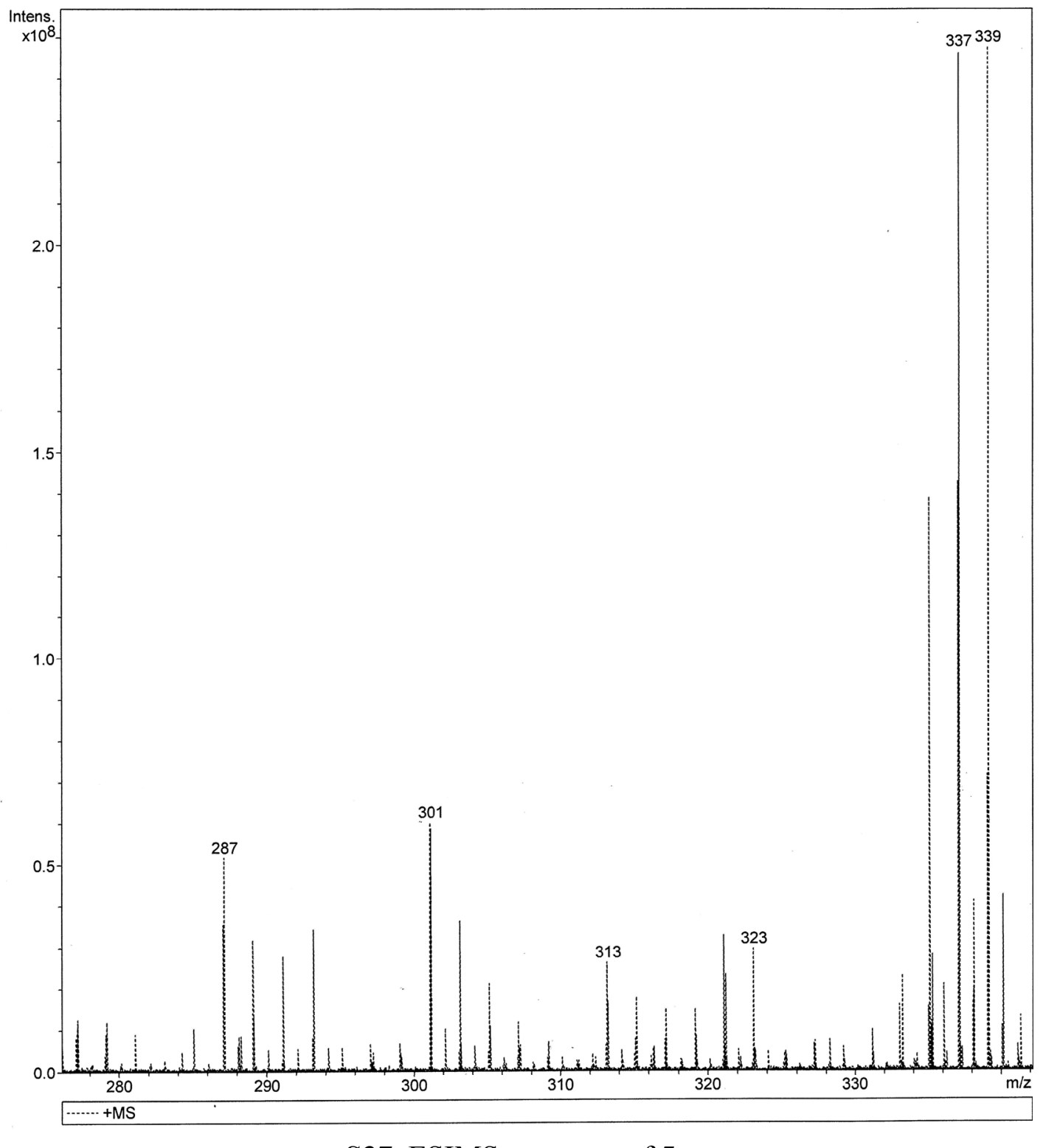

S37. ESIMS spectrum of 5 


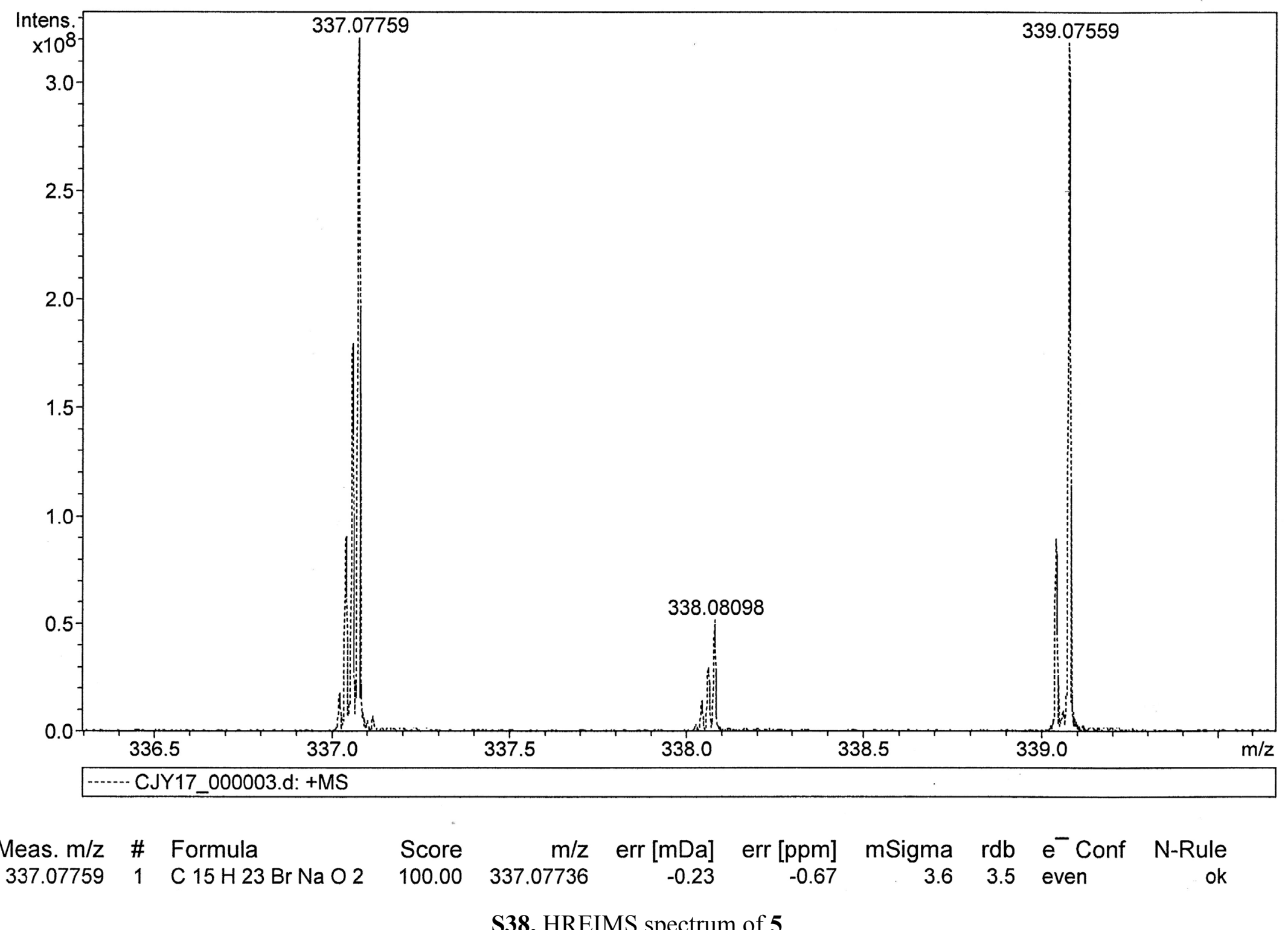

S38. HREIMS spectrum of 5 

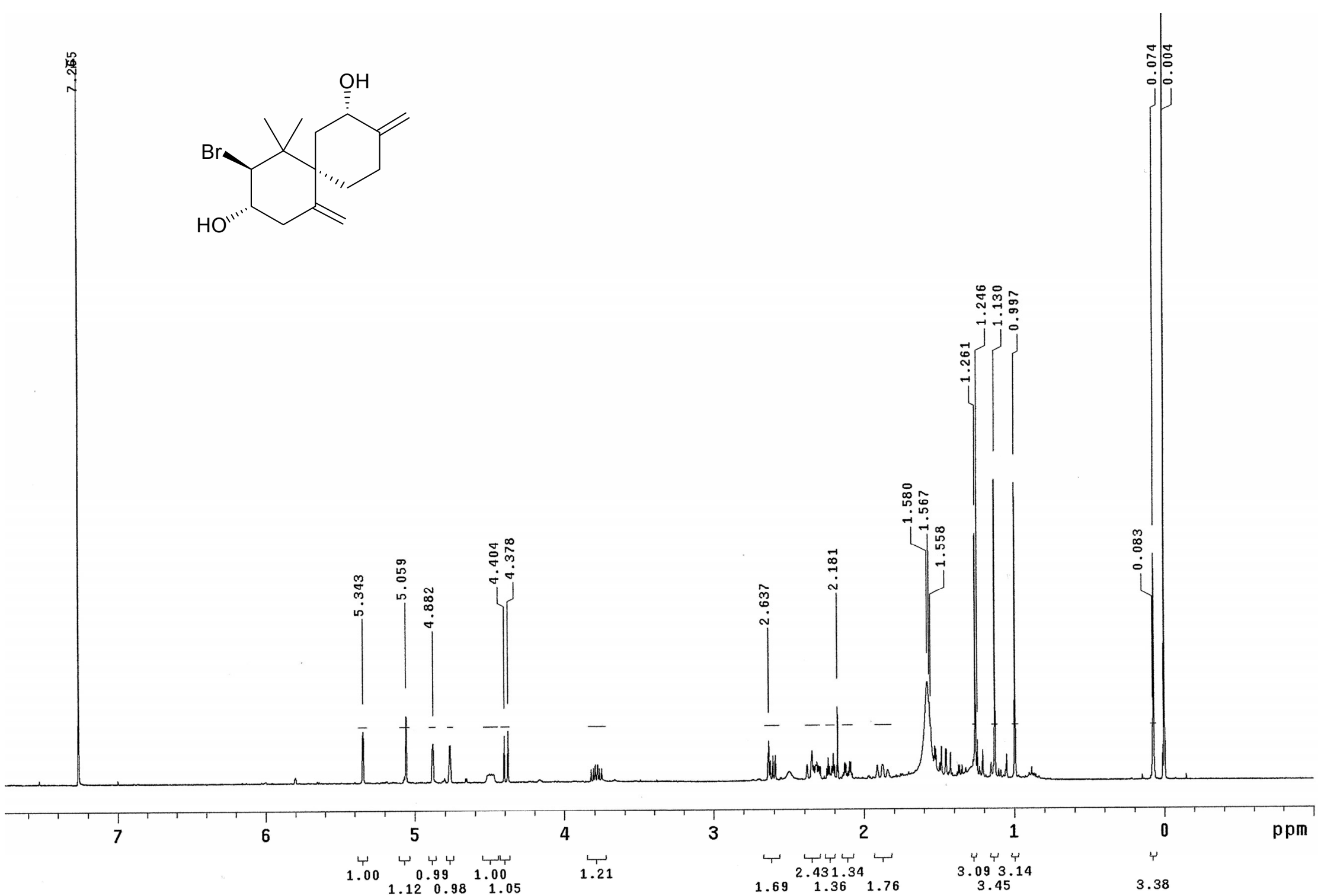

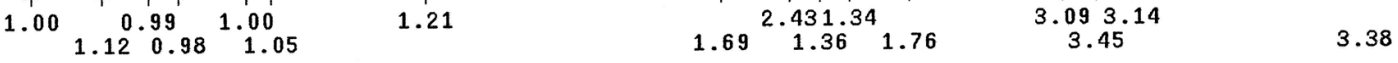

S39. ${ }^{1} \mathrm{H}$ NMR spectrum of 5 in $\mathrm{CDCl}_{3}$ 


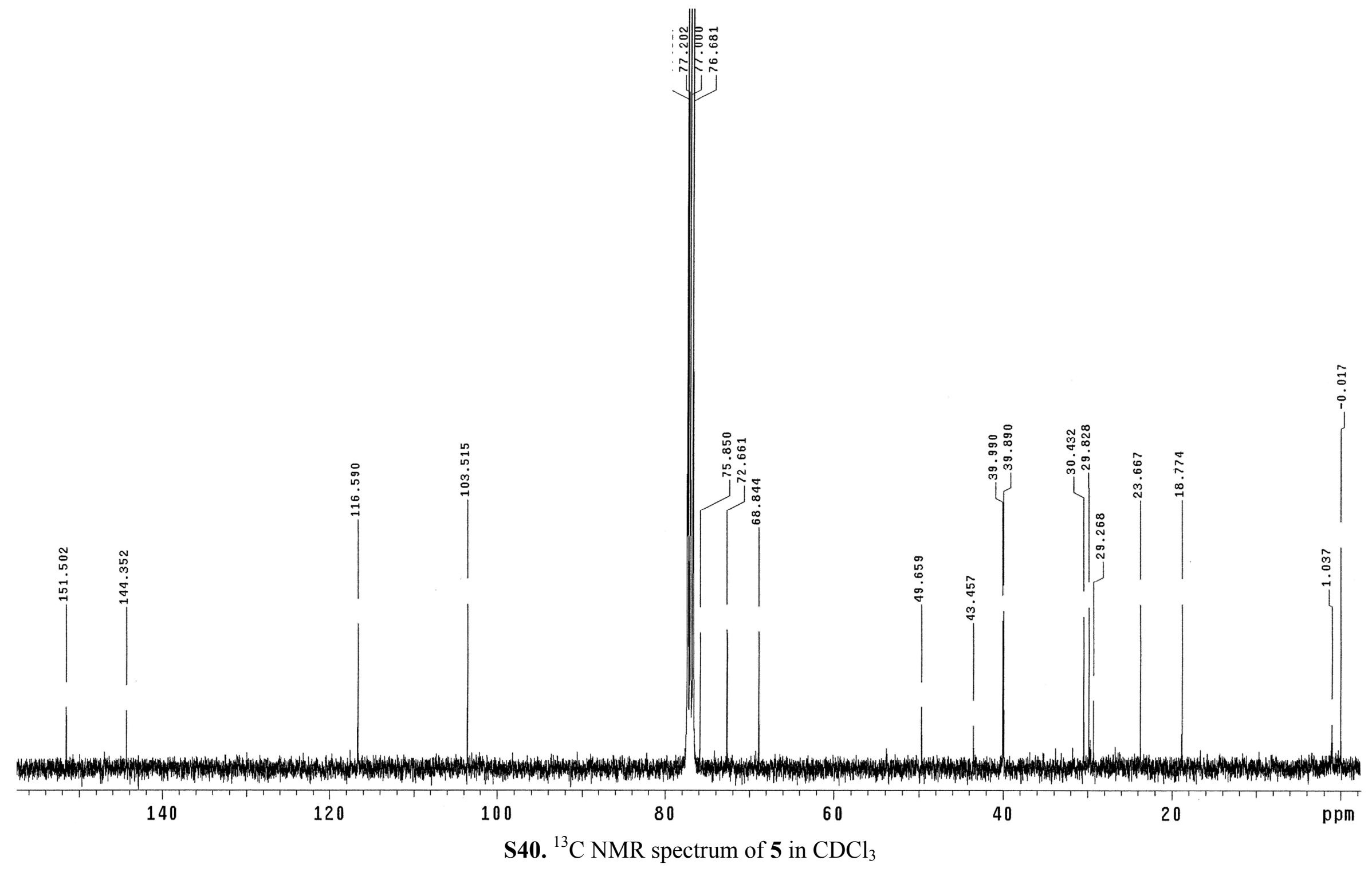



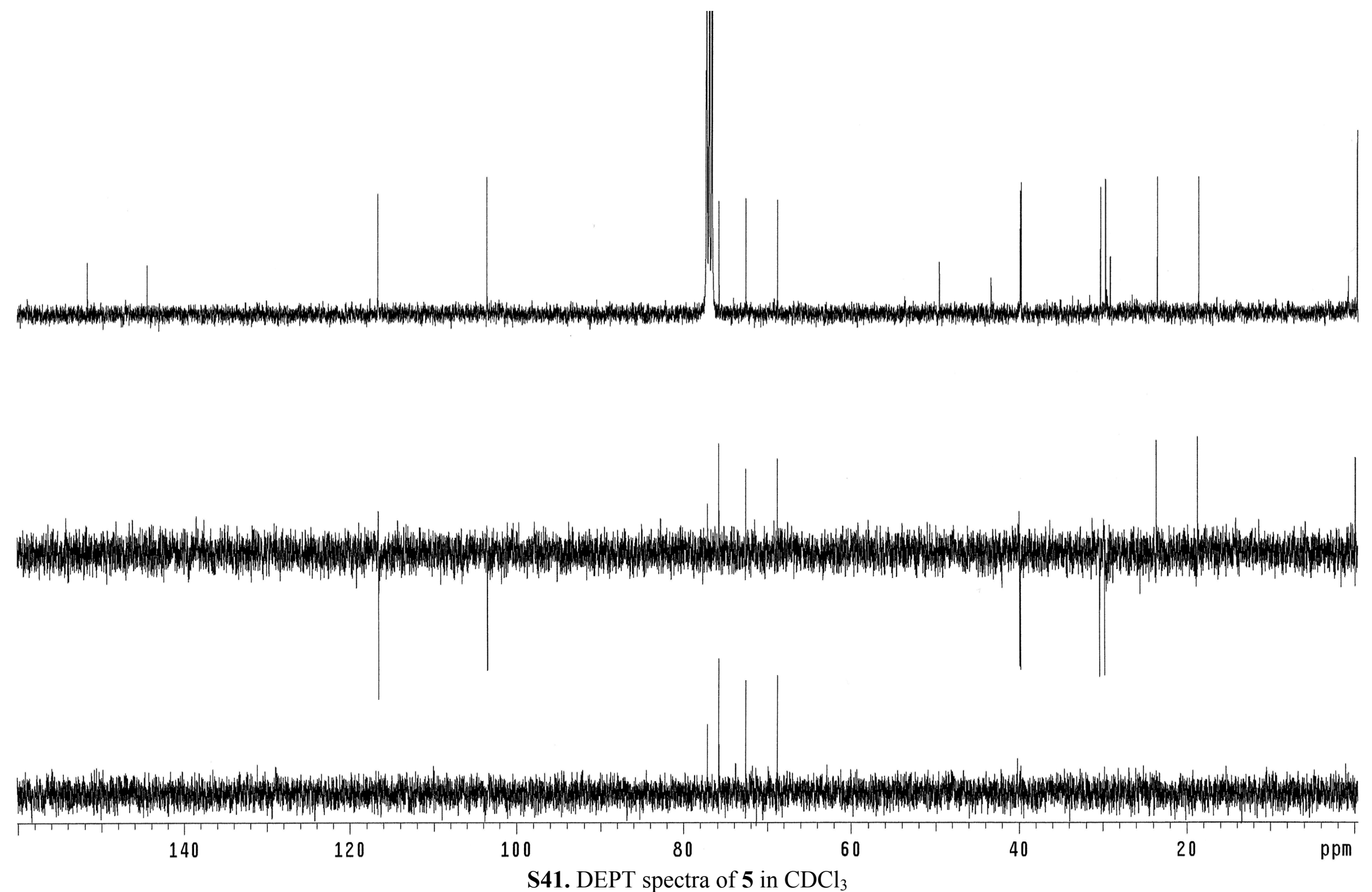


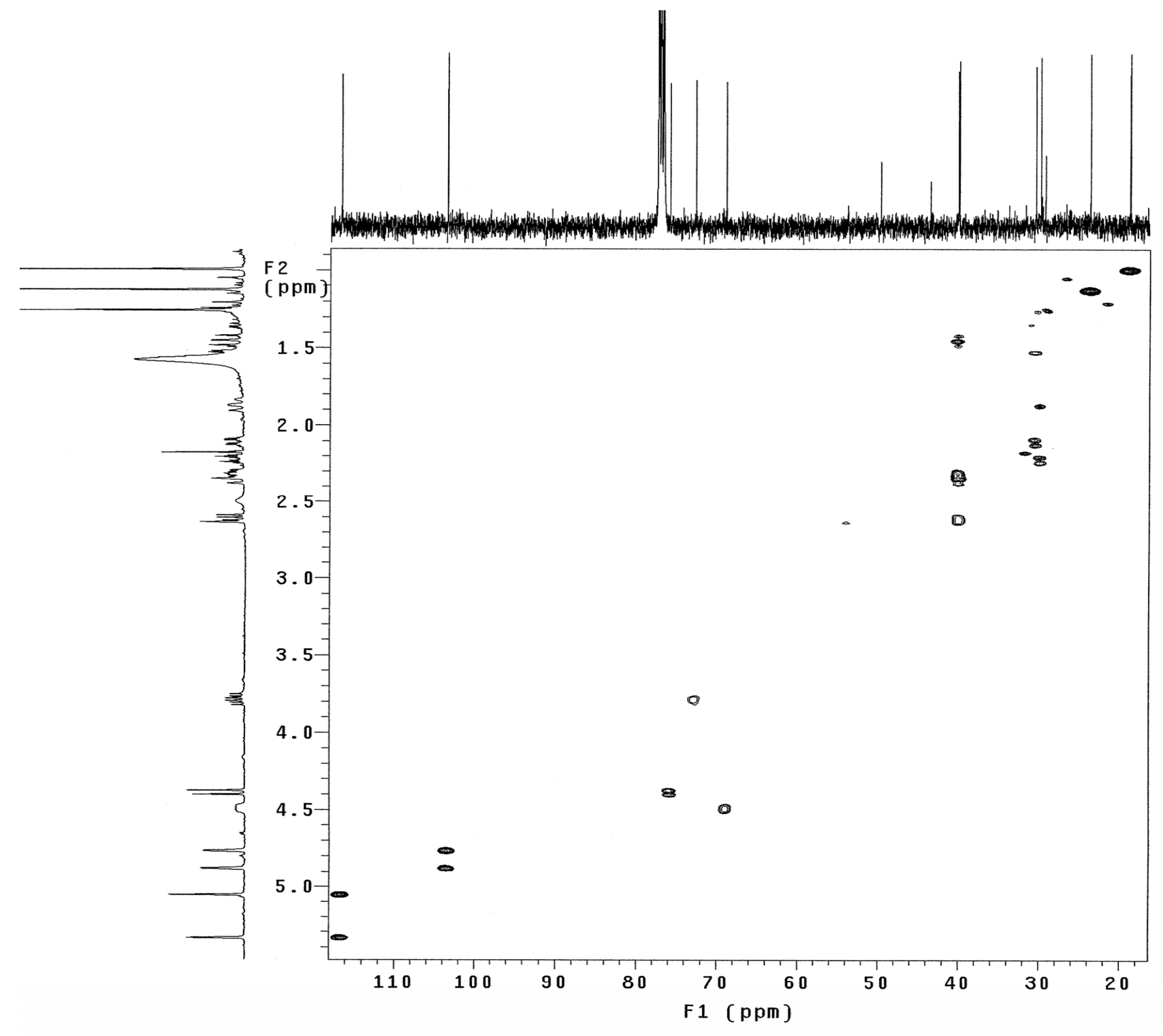

S42. HSQC spectrum of 5 in $\mathrm{CDCl}_{3}$ 


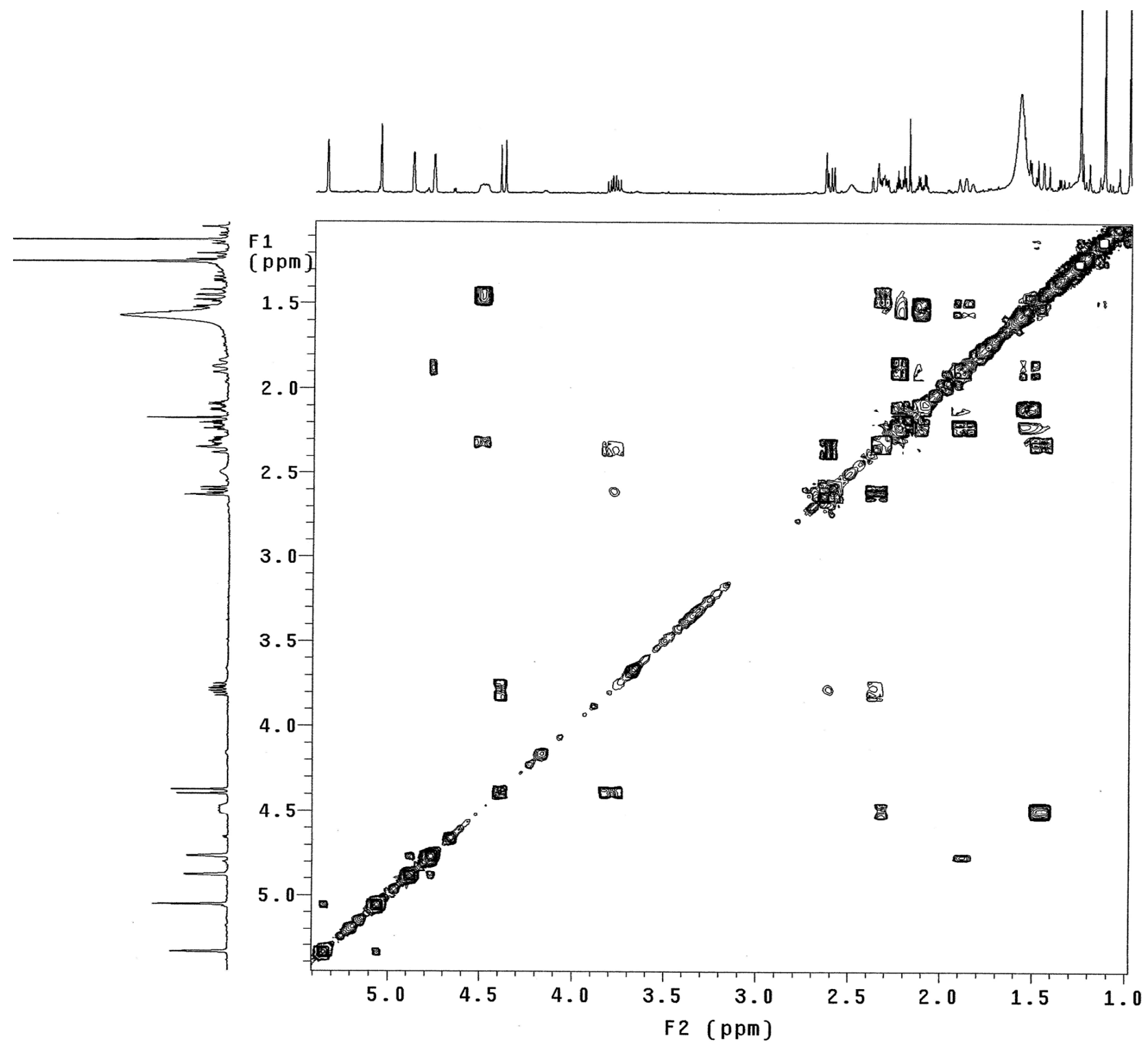

S43. COSY spectrum of 5 in $\mathrm{CDCl}_{3}$ 


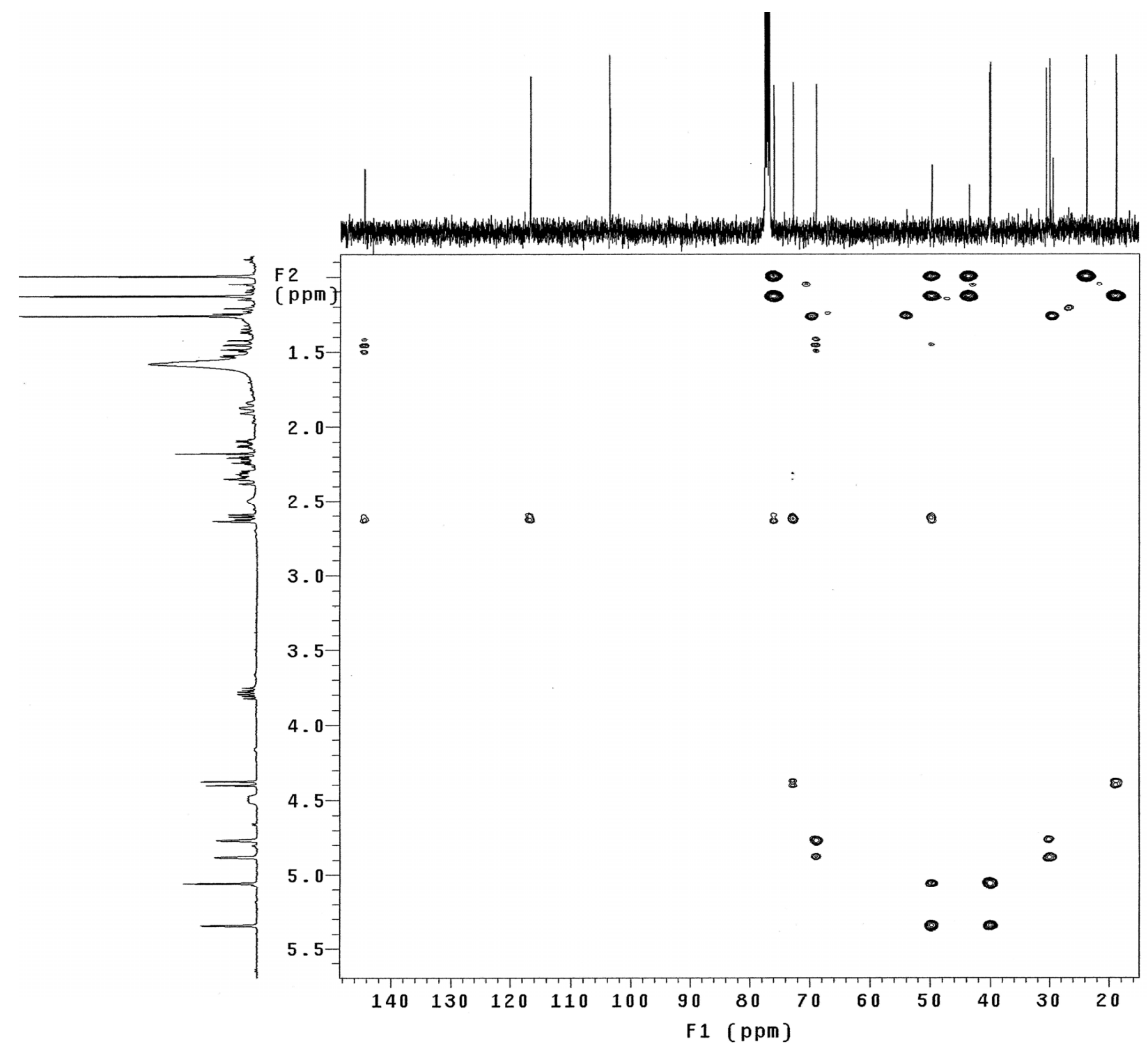

S44. $\mathrm{HMBC}$ spectrum of 5 in $\mathrm{CDCl}_{3}$ 


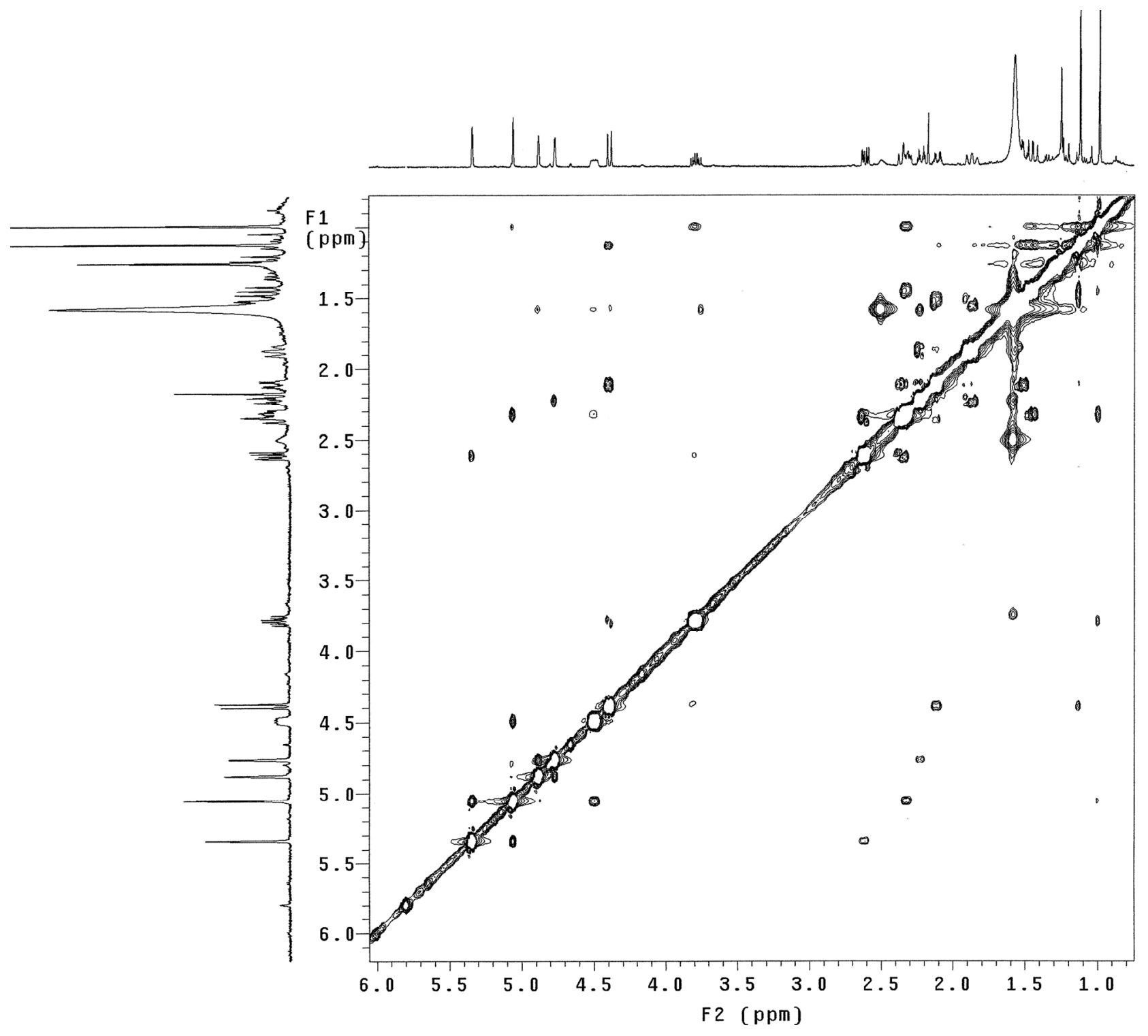

S45. NOESY spectrum of 5 in $\mathrm{CDCl}_{3}$ 


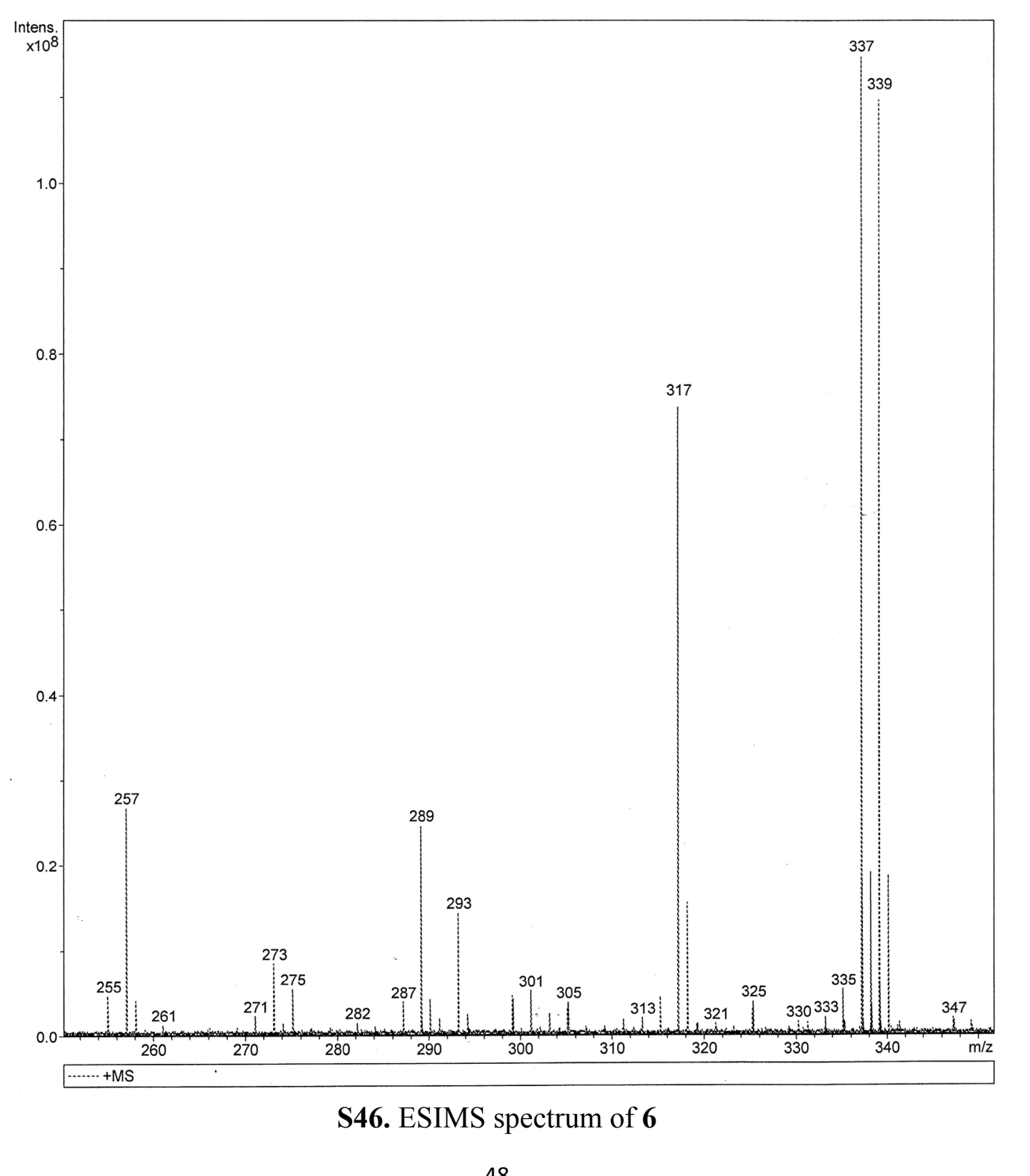




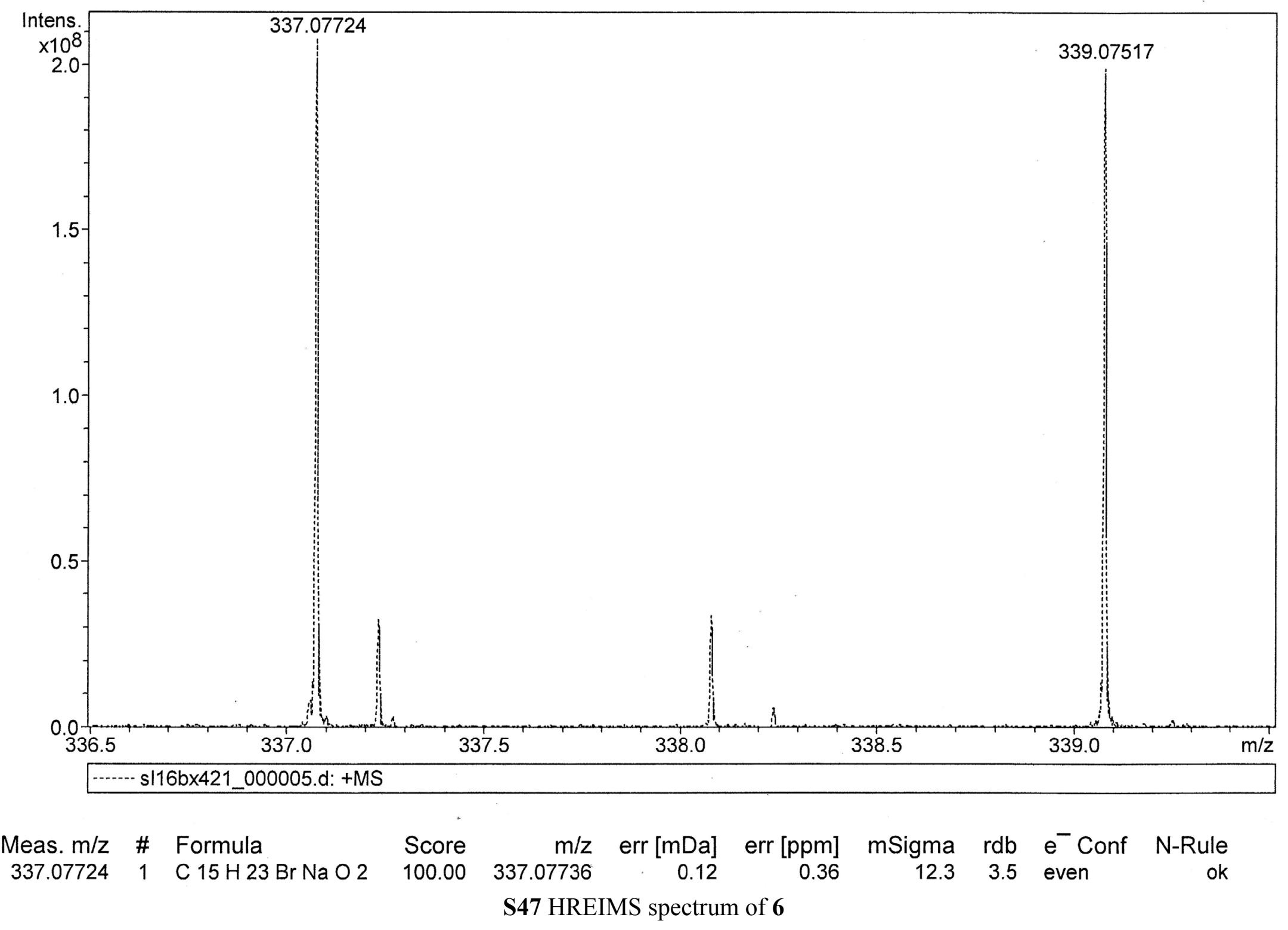



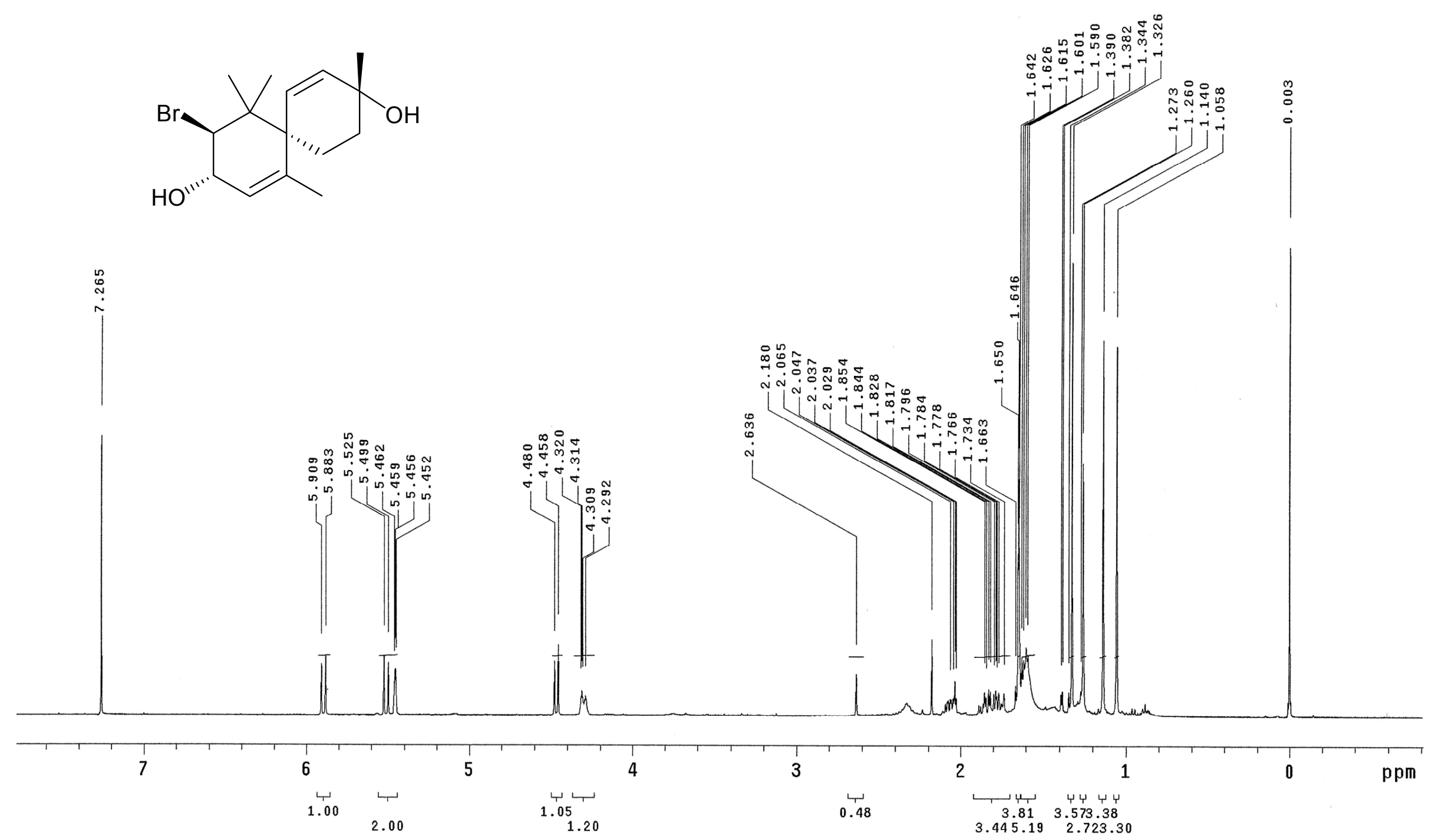

S48. ${ }^{1} \mathrm{H}$ NMR spectrum of 6 in $\mathrm{CDCl}_{3}$ 


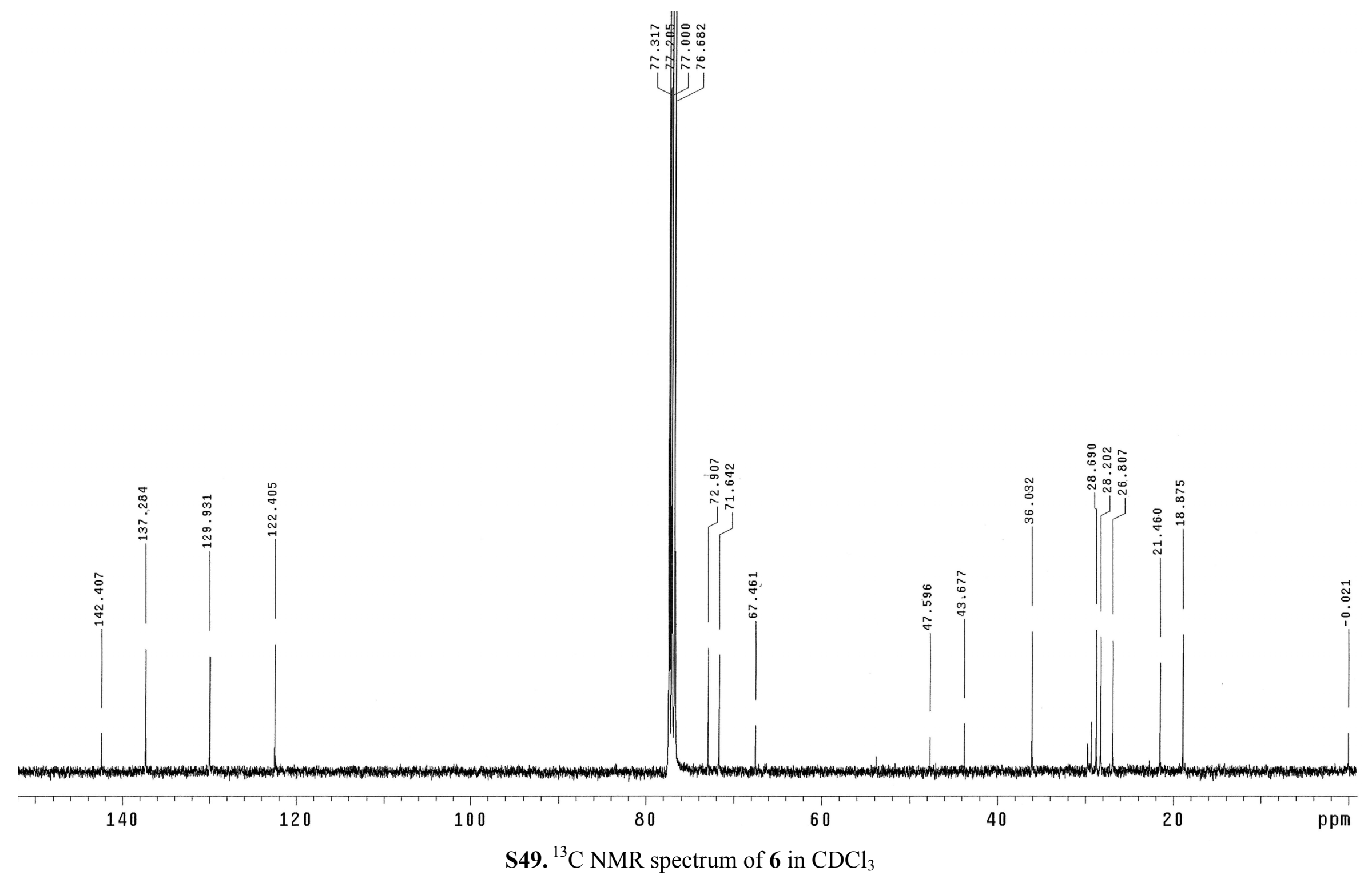



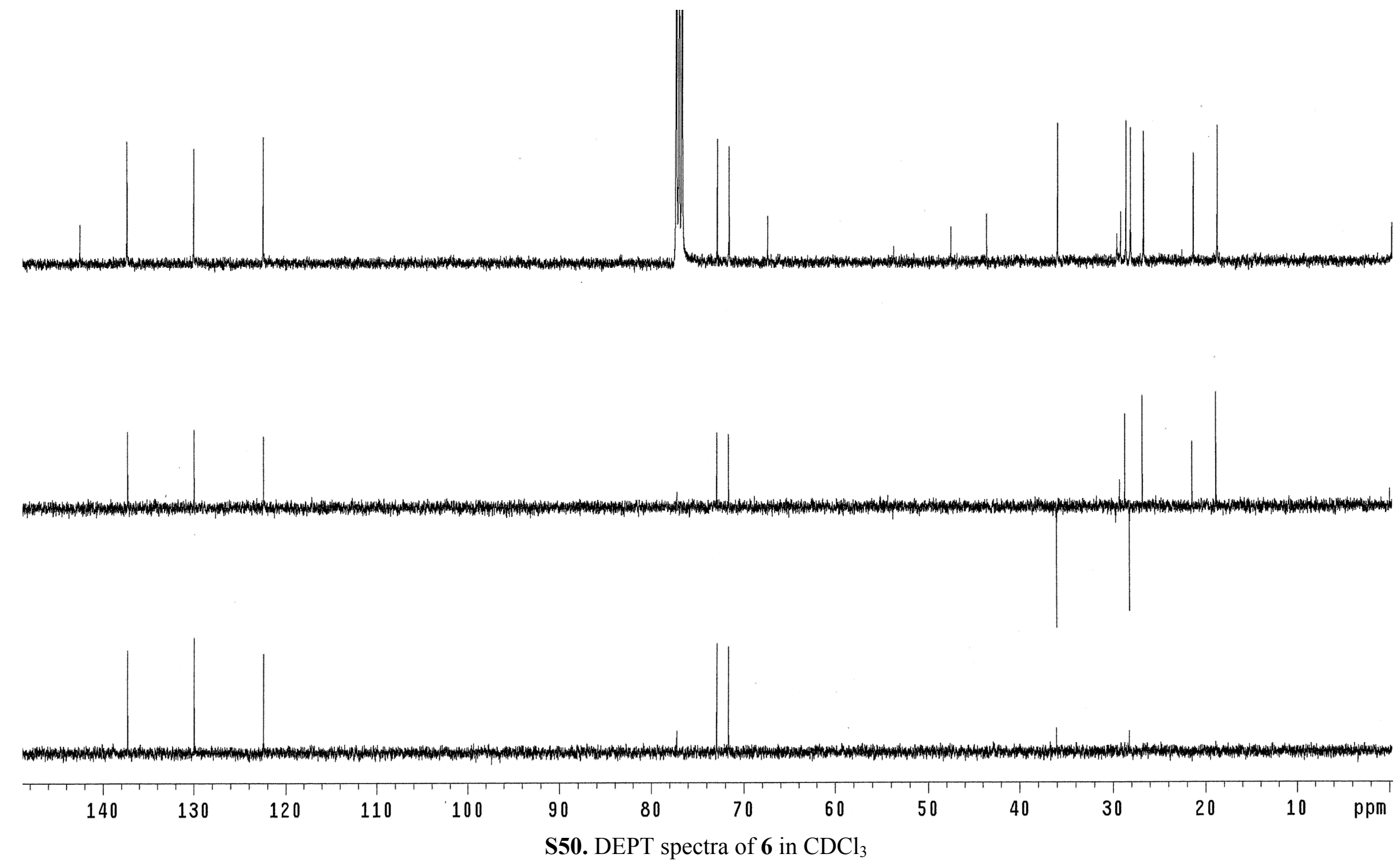


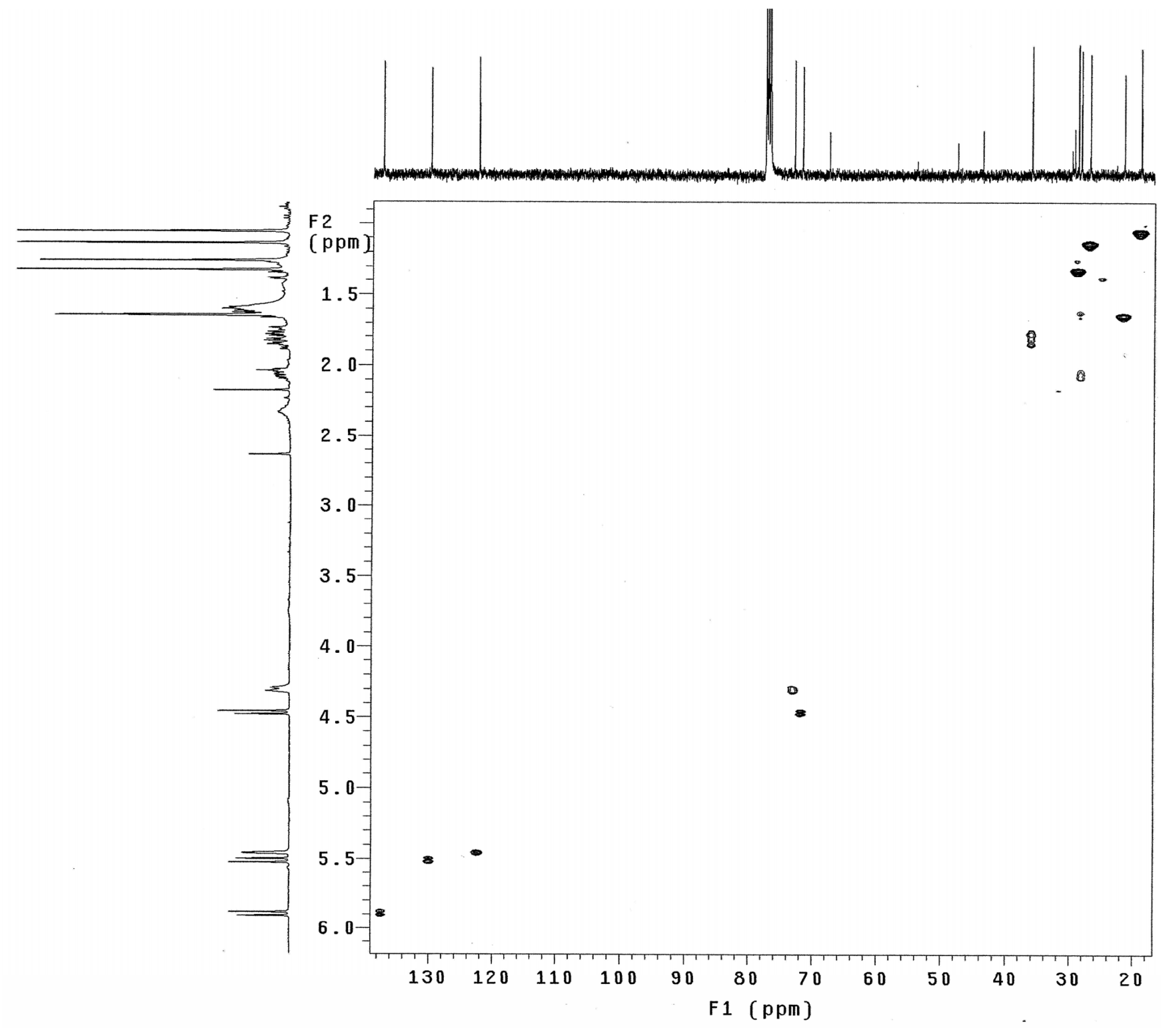

S51. HSQC spectrum of 6 in $\mathrm{CDCl}_{3}$ 


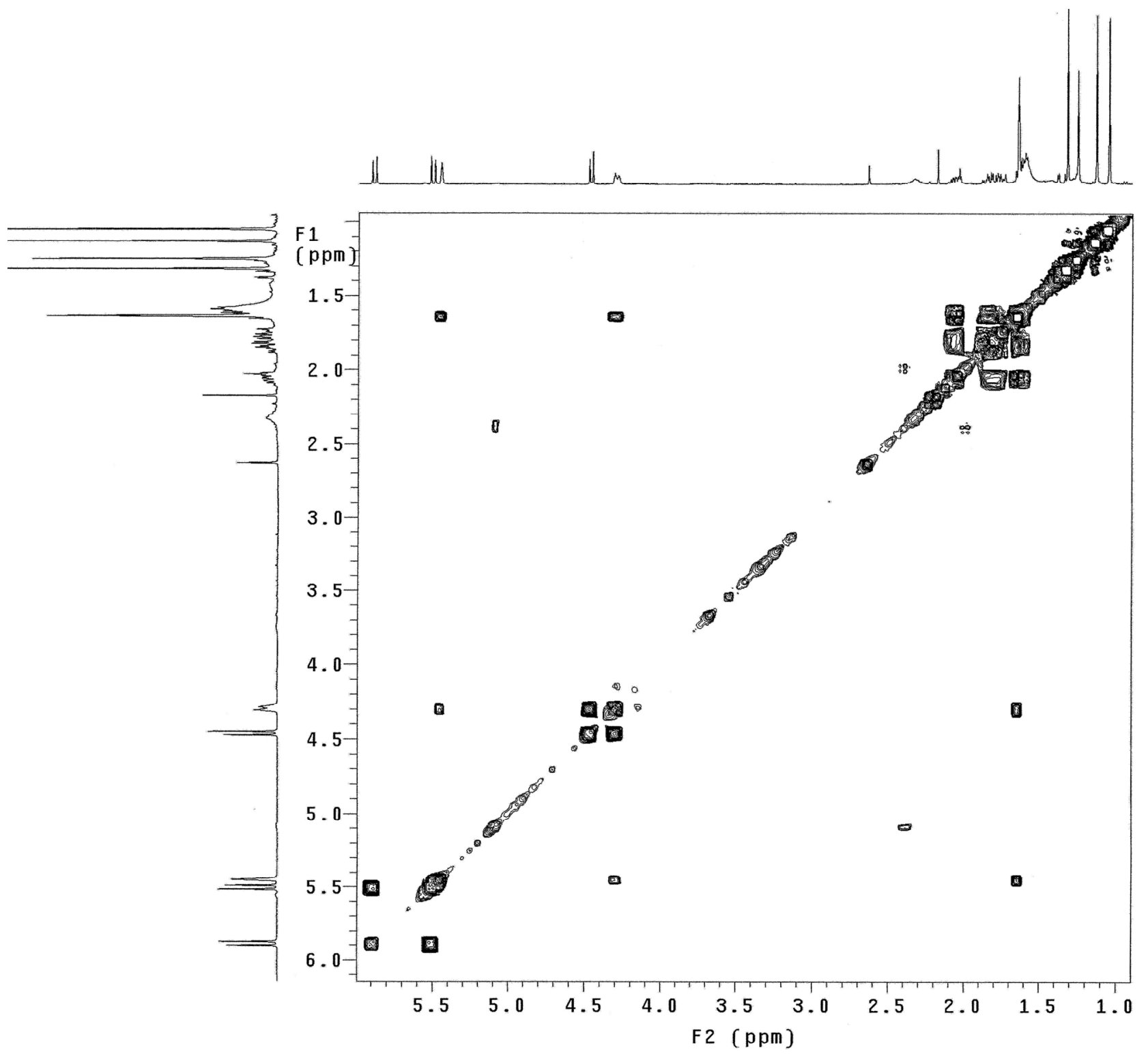

S52. COSY spectrum of 6 in $\mathrm{CDCl}_{3}$ 


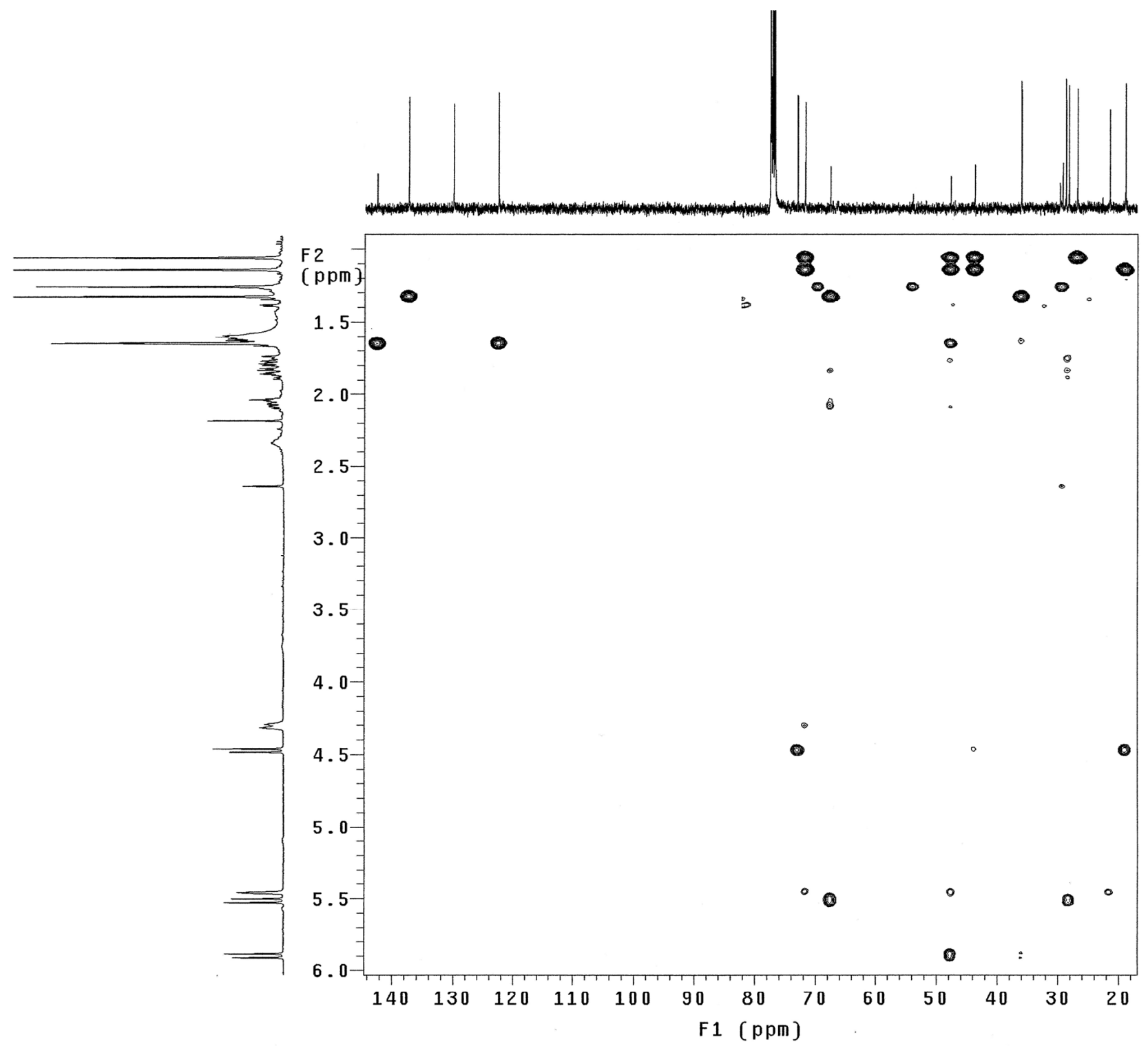

S53. $\mathrm{HMBC}$ spectrum of $\mathbf{6}$ in $\mathrm{CDCl}_{3}$ 


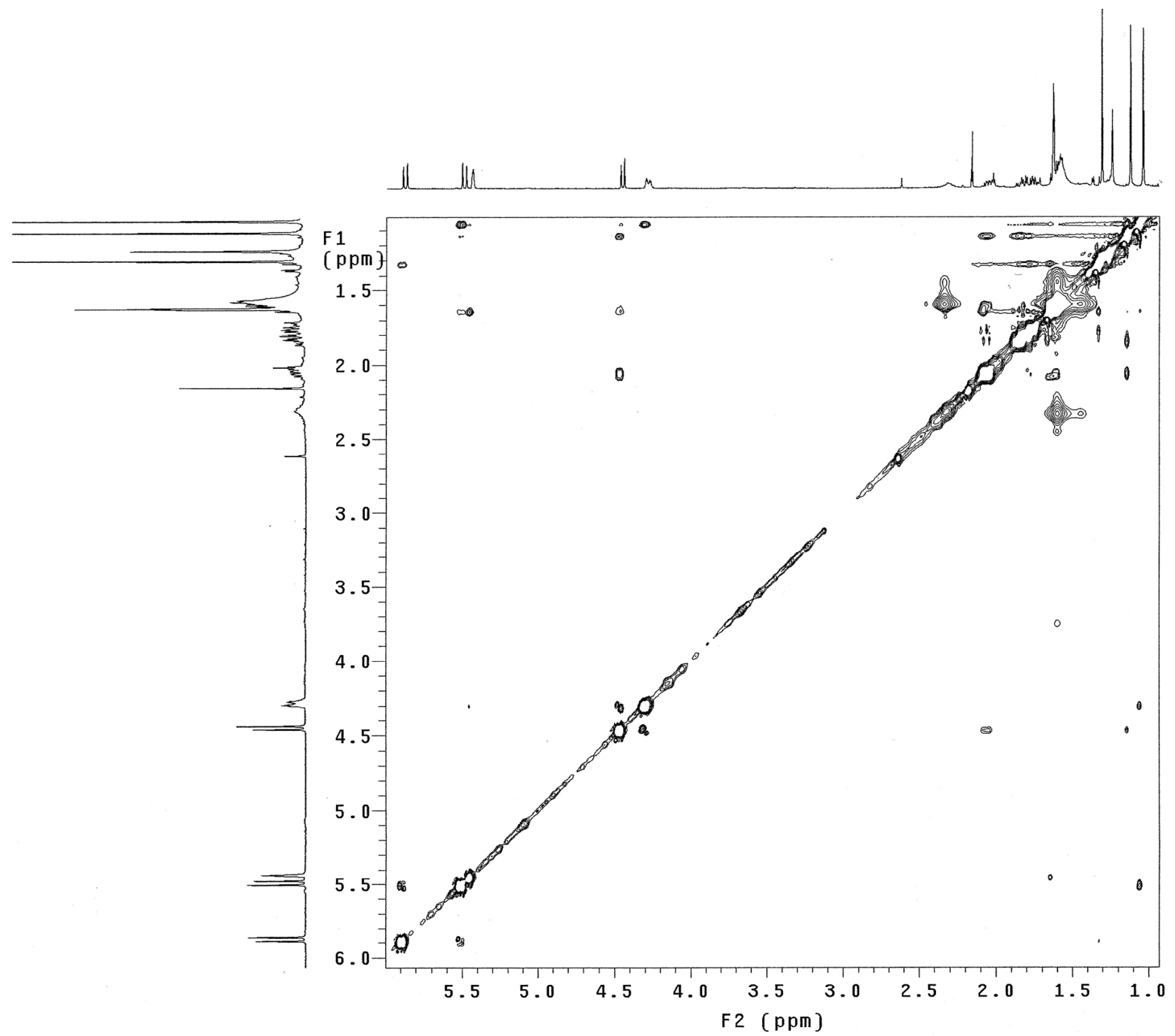

S54. NOESY spectrum of 6 in $\mathrm{CDCl}_{3}$ 


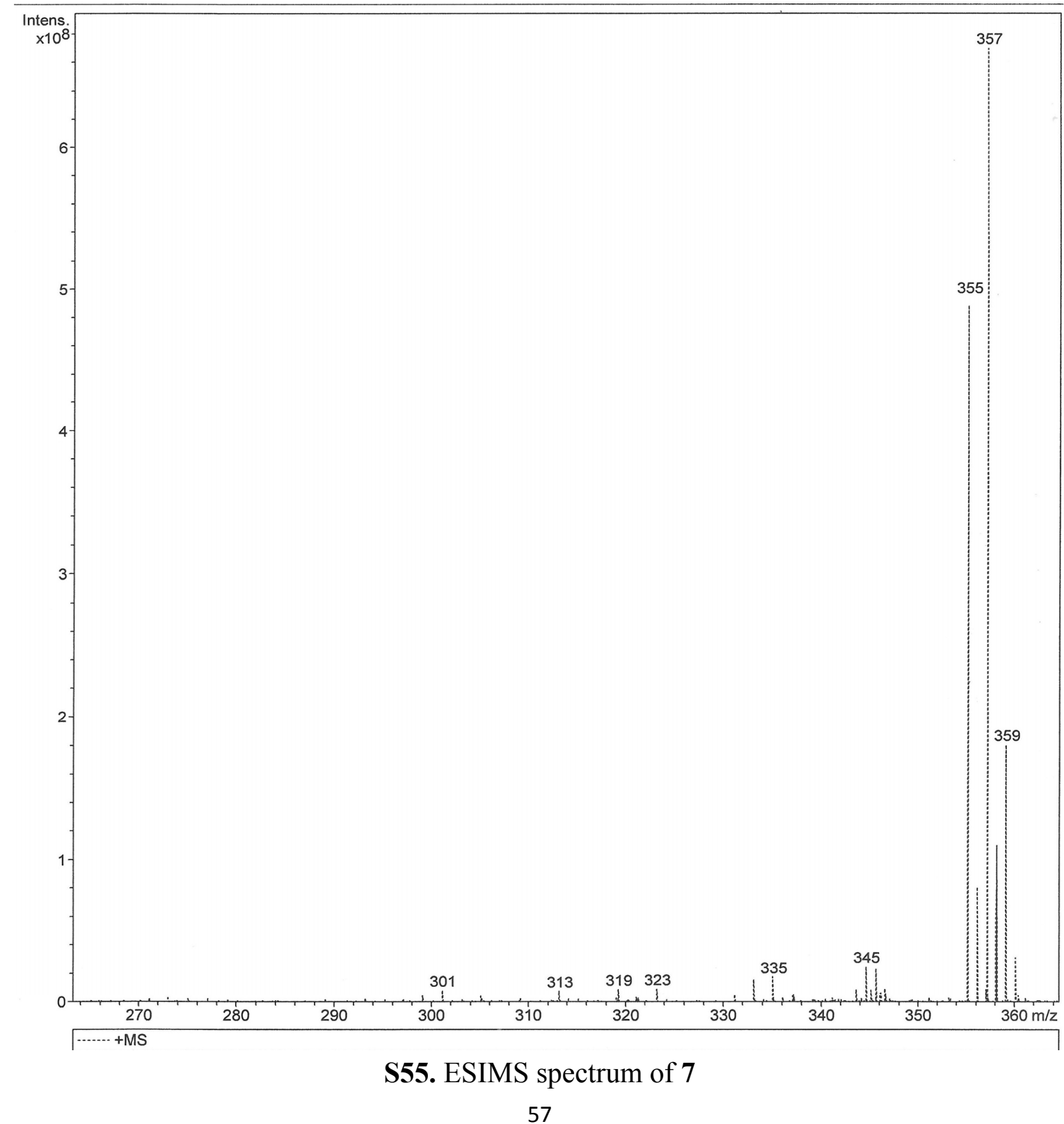

57 


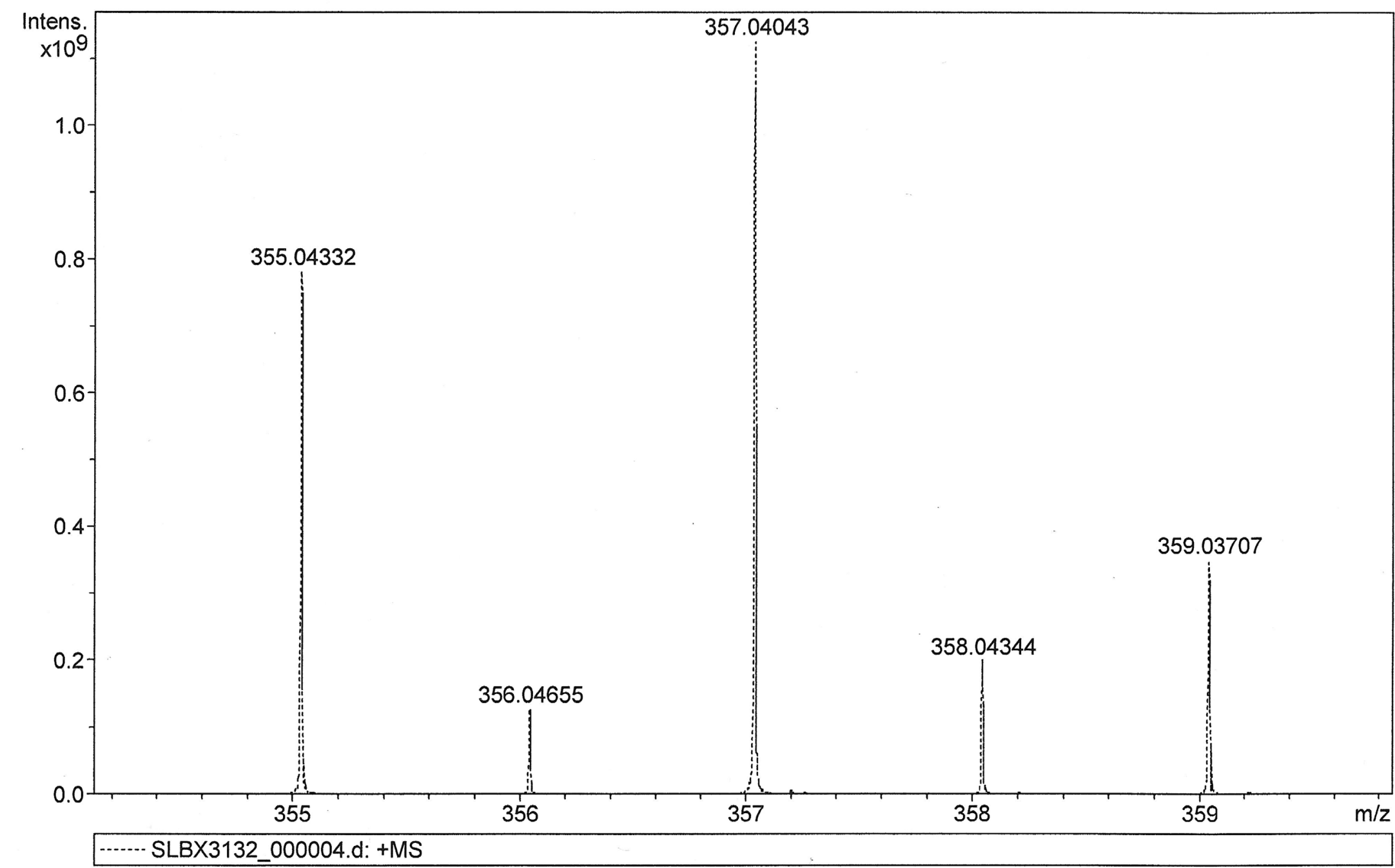

Meas. $\mathrm{m} / \mathrm{z}$ \# Formula

Score $\mathrm{m} / \mathrm{z}$ err [mDa] err [ppm] mSigma $\mathrm{rdb} \mathrm{e}^{-}$Conf N-Rule 355.04332

100.00 355.04348

0.16

0.45

37.23 .5 even

ok

S56. HREIMS spectrum of 7 


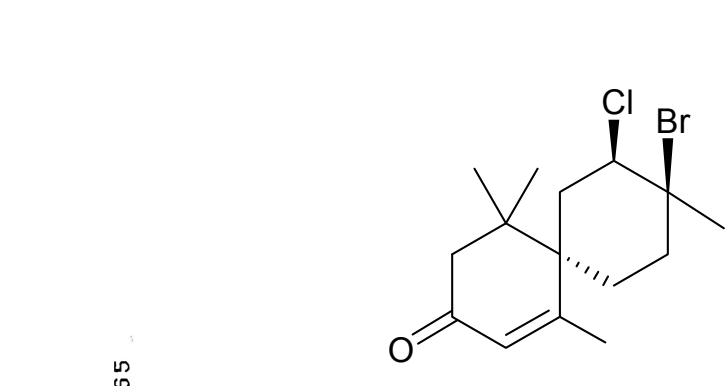

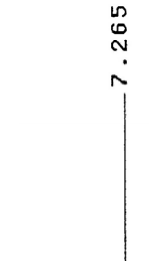
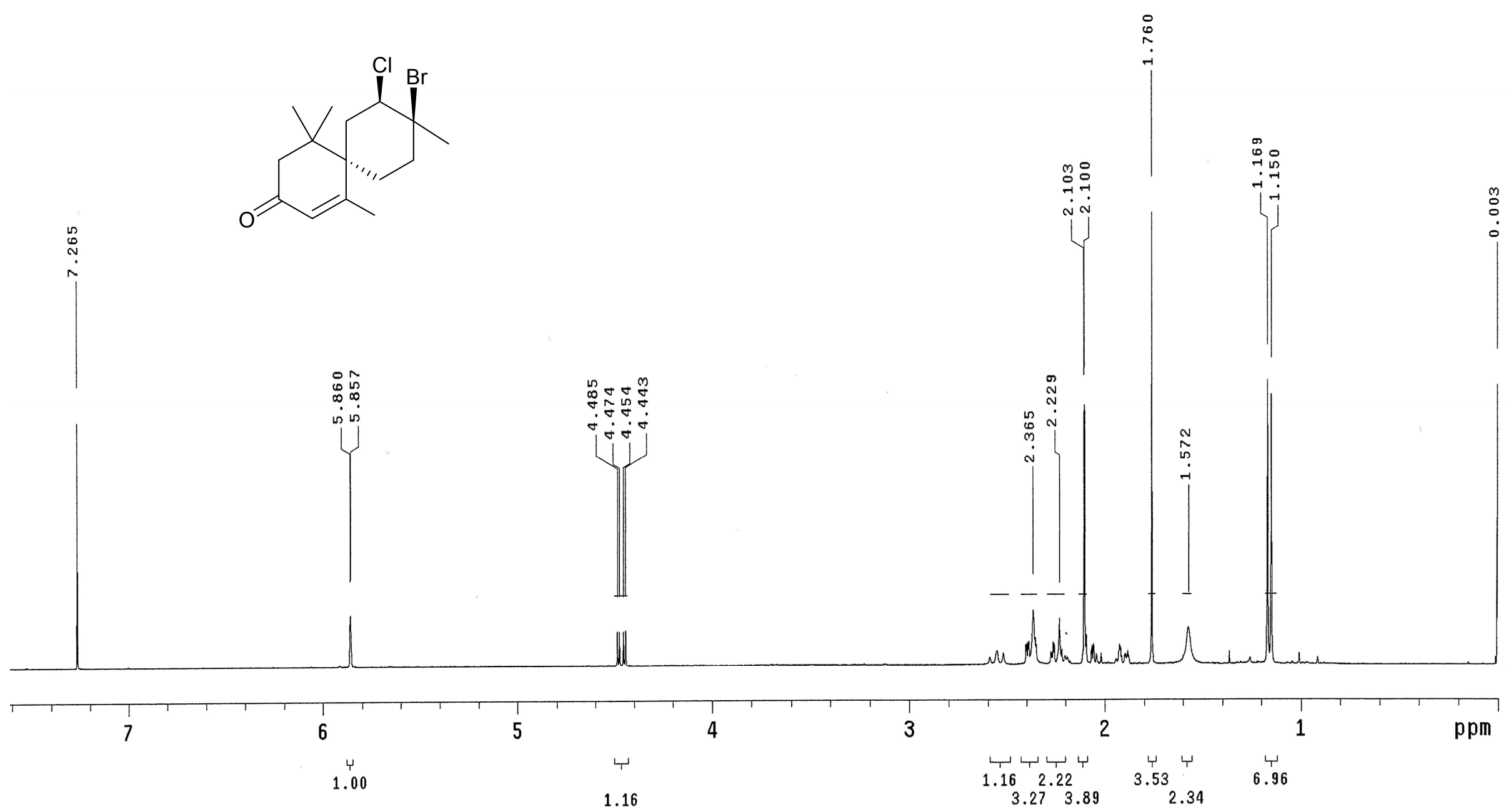

6

1.00

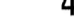

1.16

S57. ${ }^{1} \mathrm{H}$ NMR spectrum of 7 in $\mathrm{CDCl}_{3}$ 


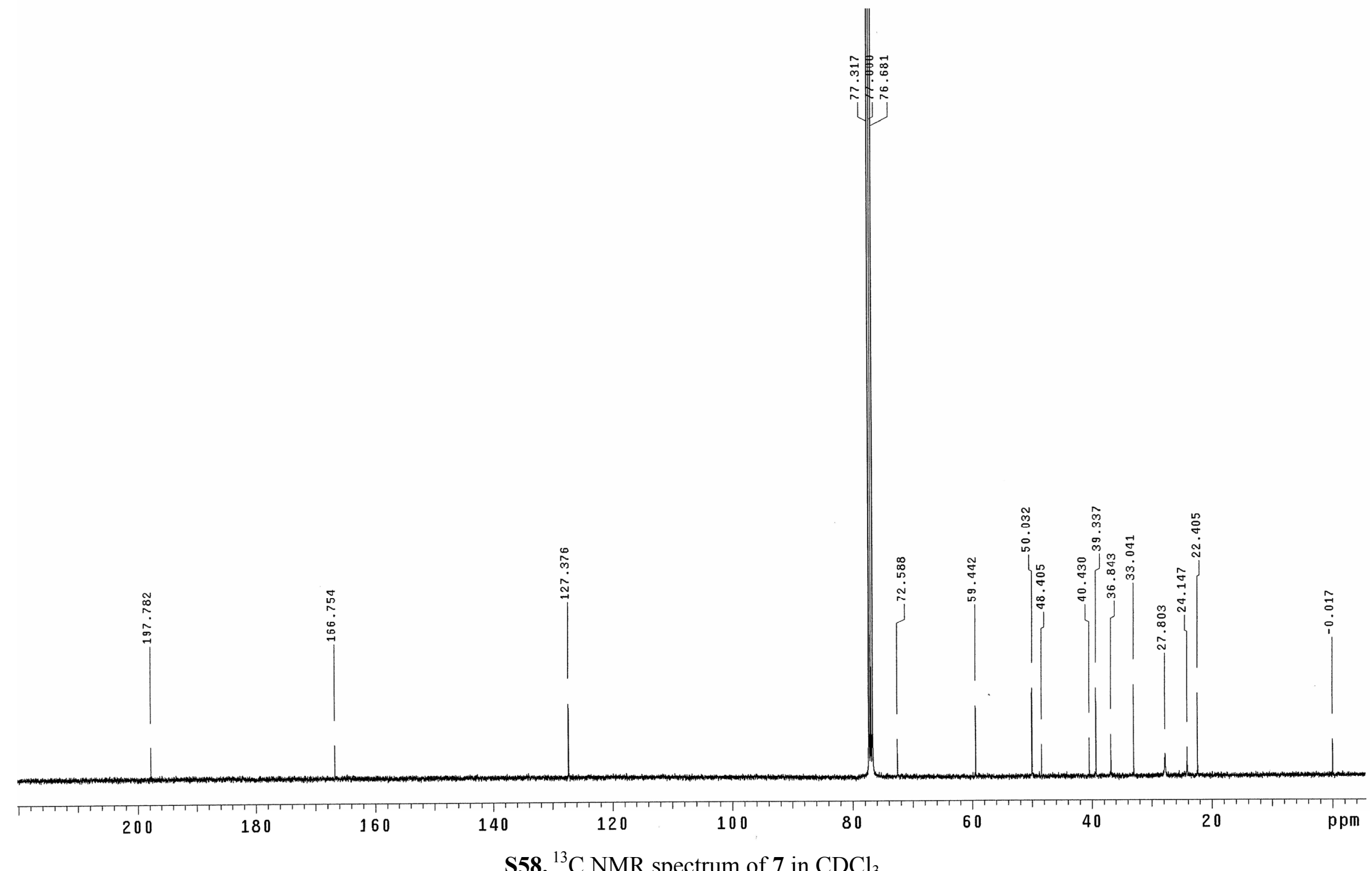



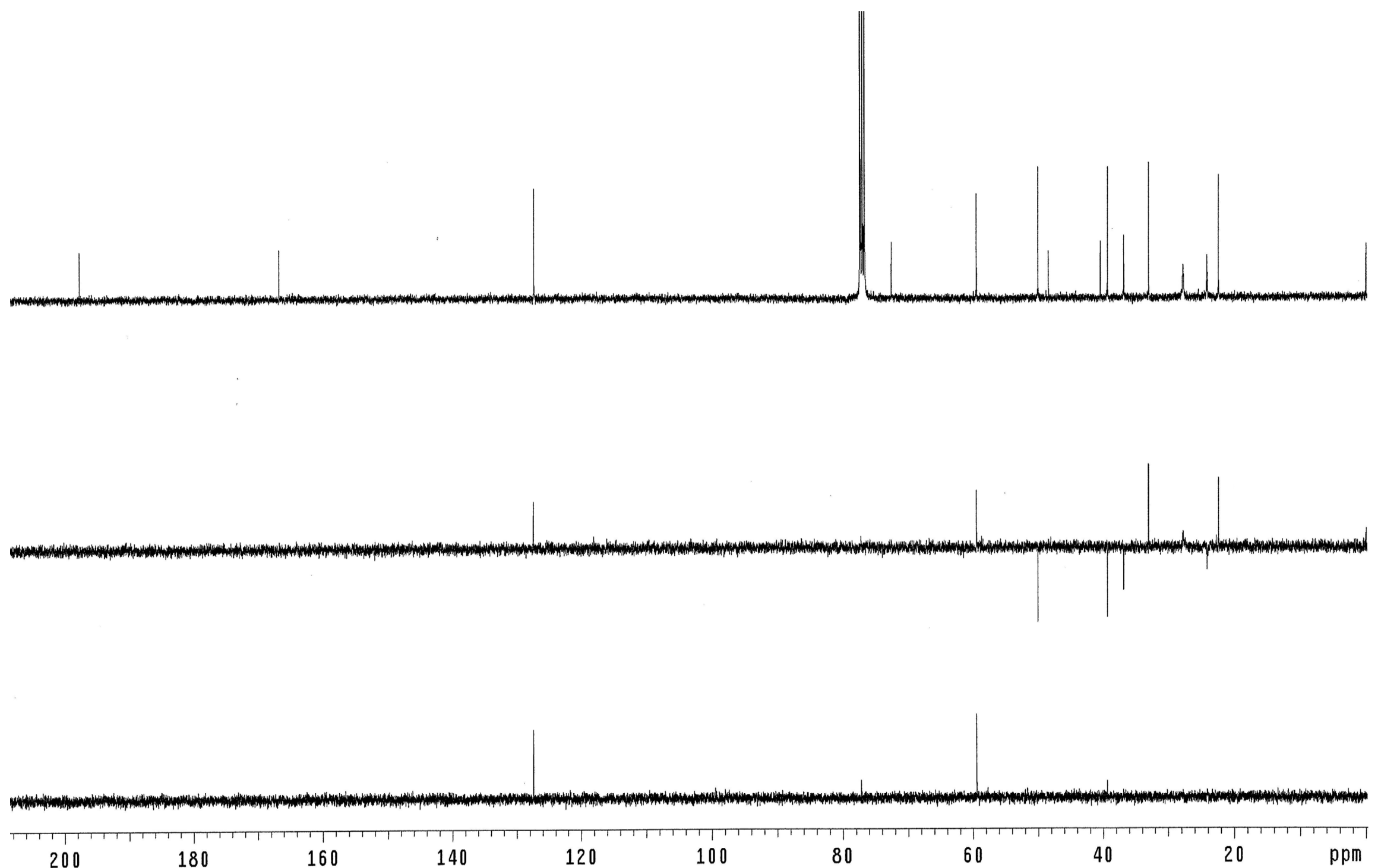

559. DEPT spectra of 7 in $\mathrm{CDCl}_{3}$ 


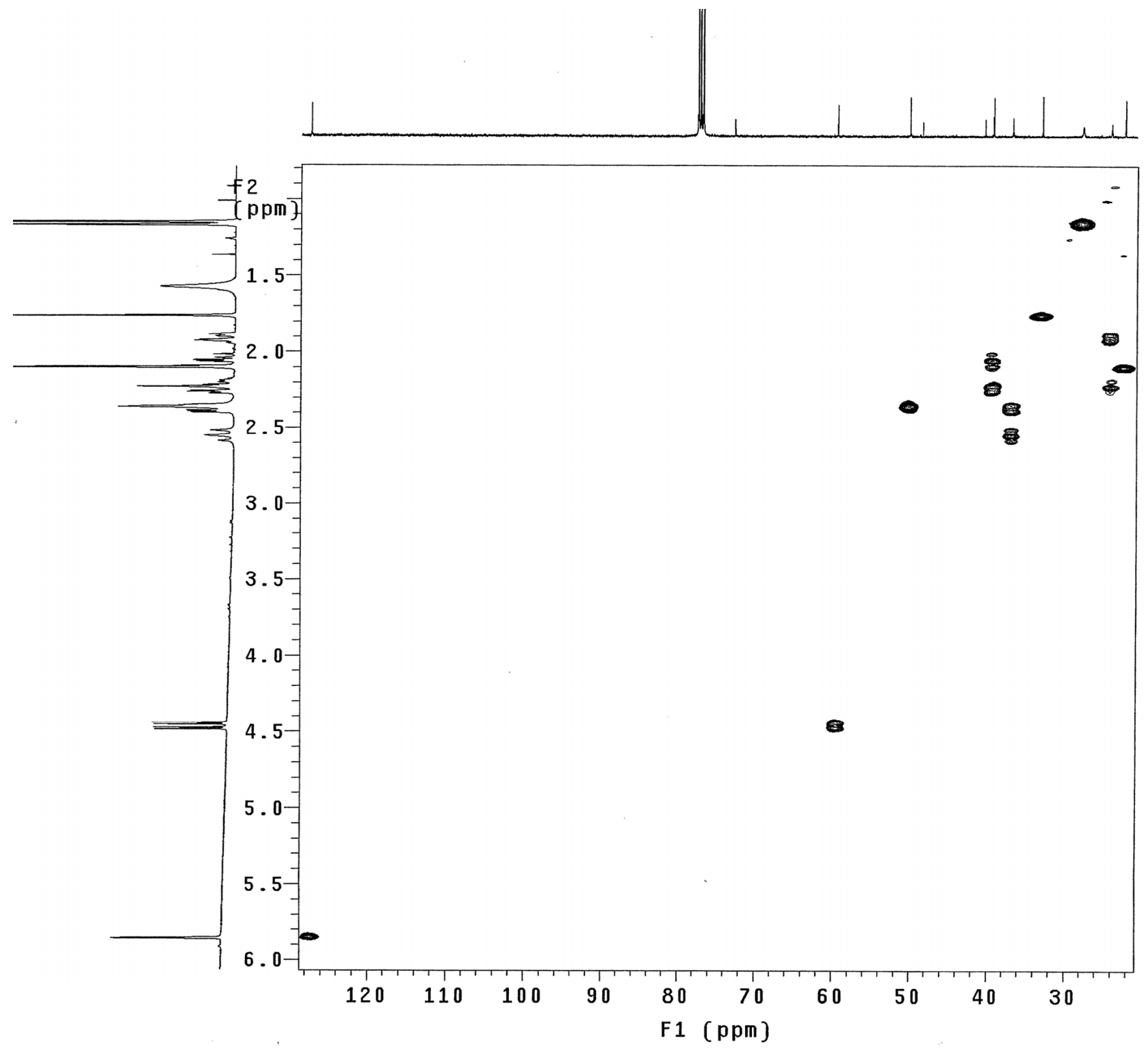

S60. HSQC spectrum of 7 in $\mathrm{CDCl}_{3}$ 


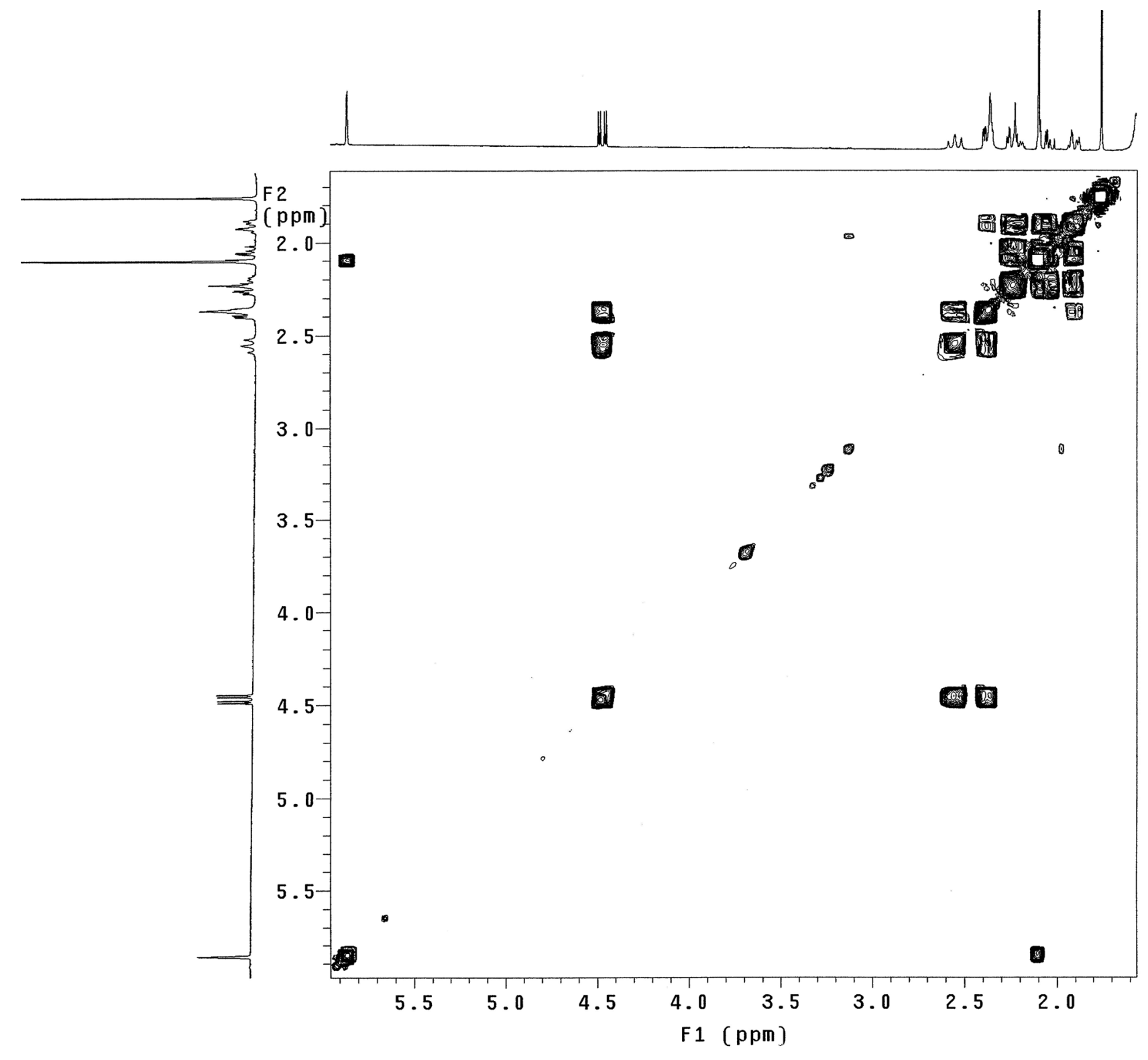

S61. COSY spectrum of 7 in $\mathrm{CDCl}_{3}$ 


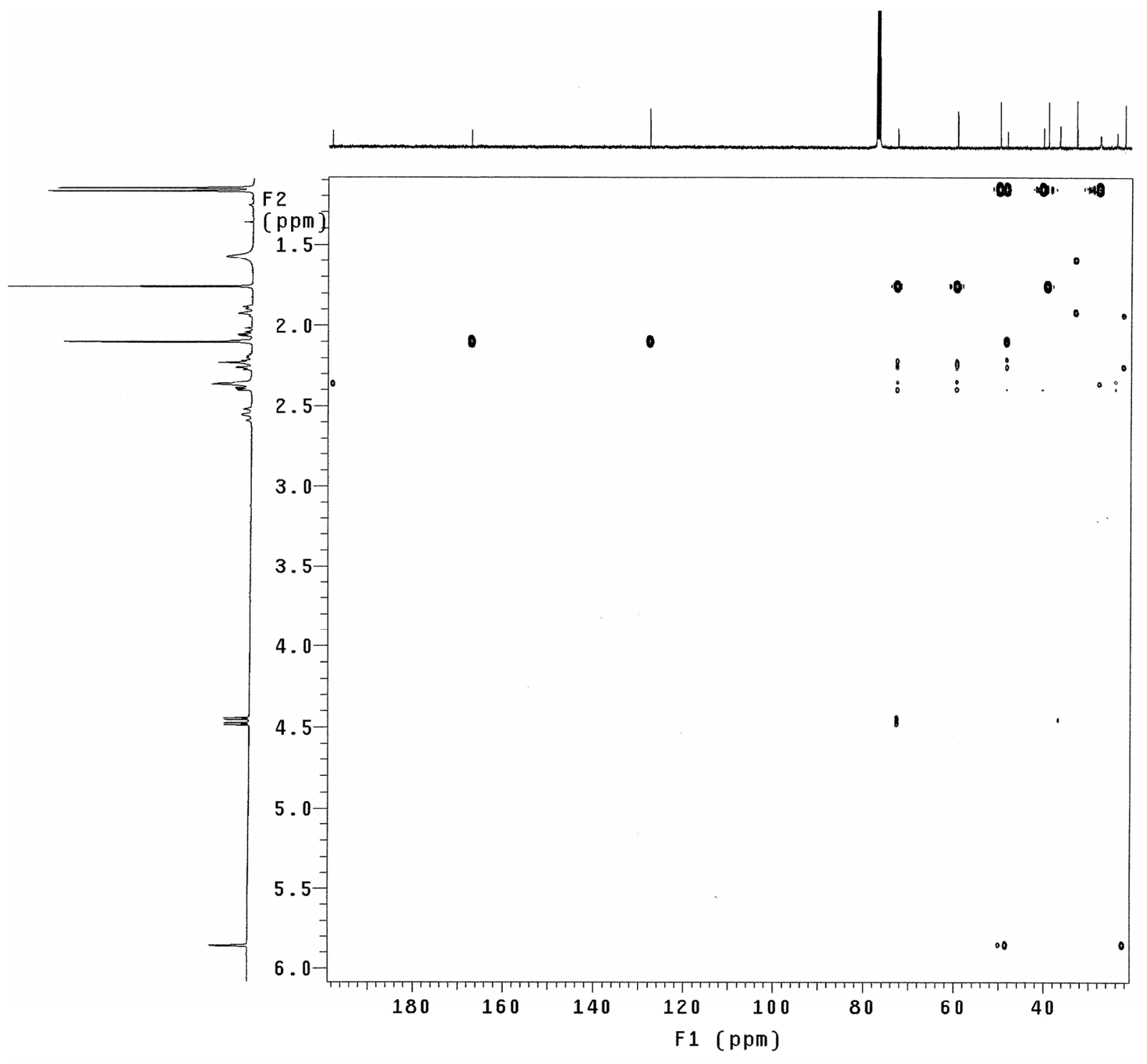

S62. $\mathrm{HMBC}$ spectrum of 7 in $\mathrm{CDCl}_{3}$ 


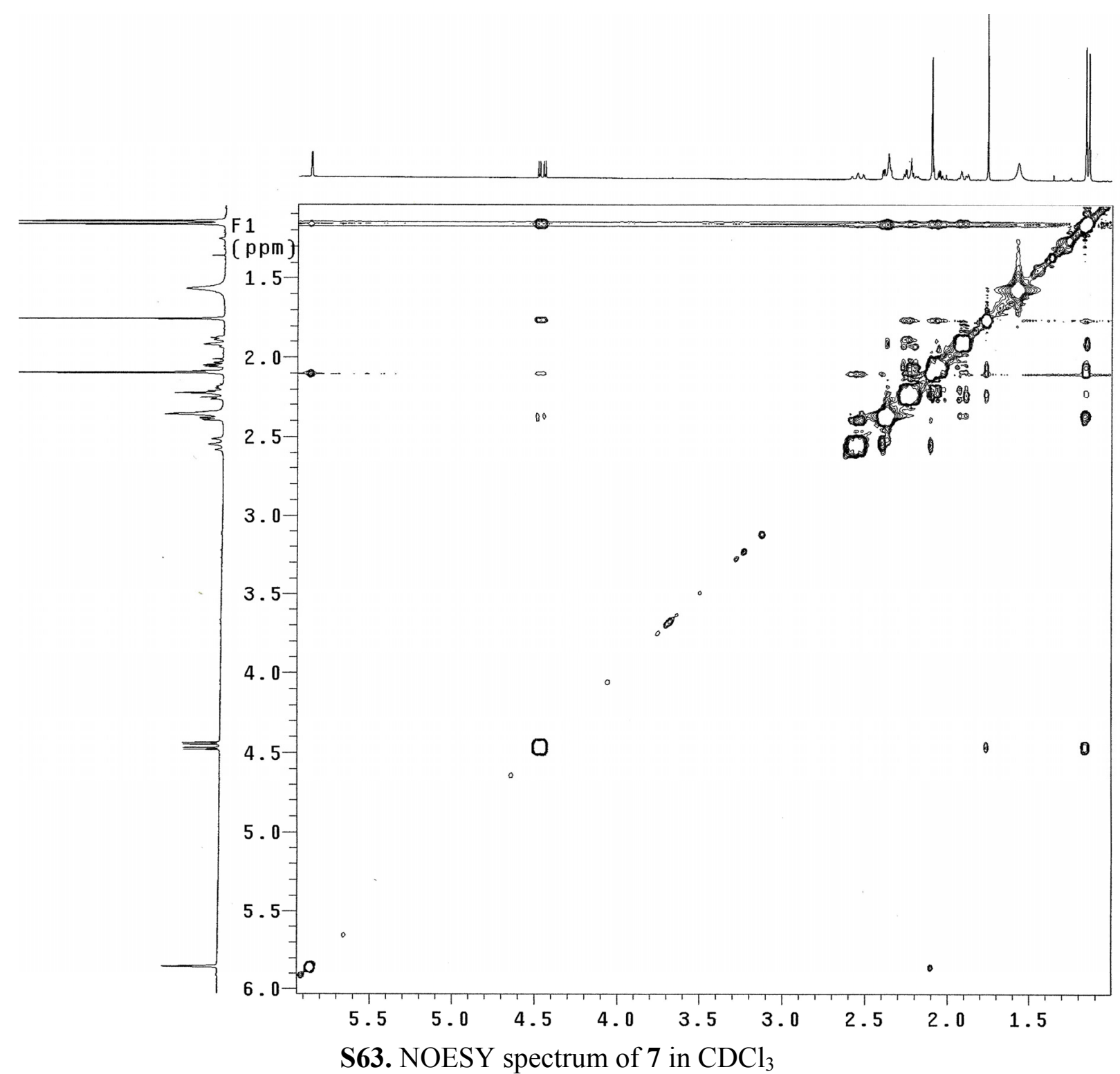




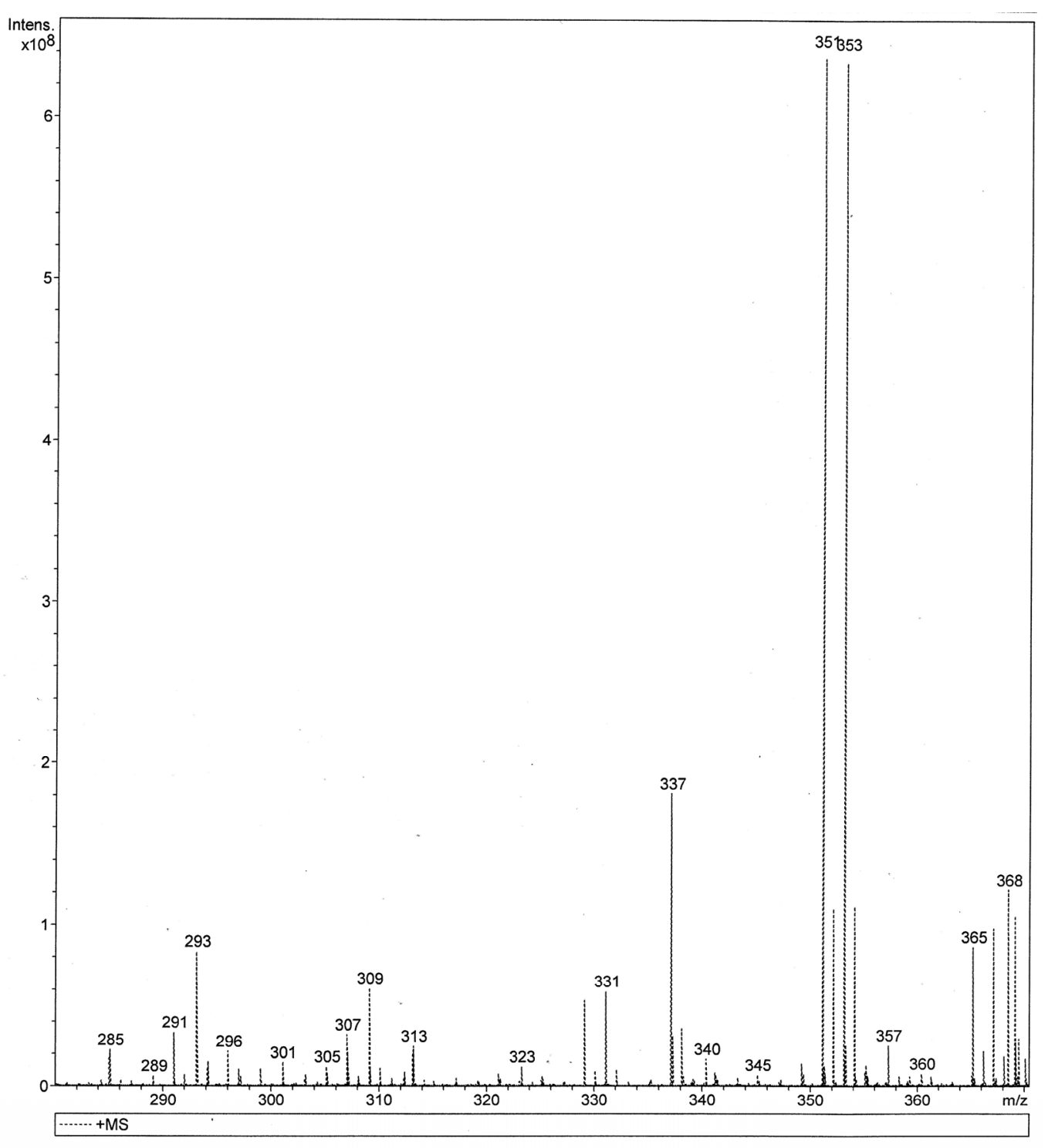

S64. ESIMS spectrum of 8 


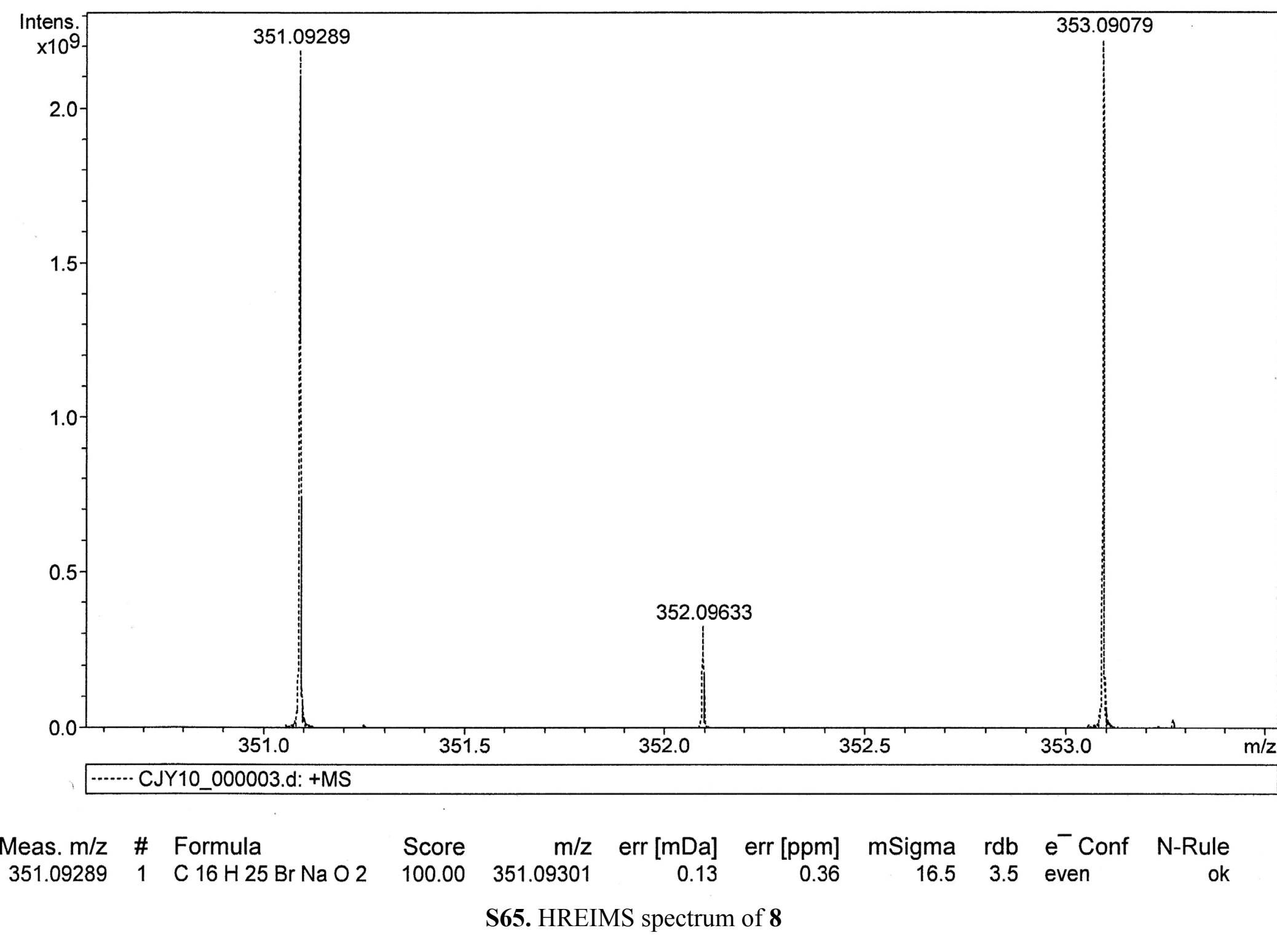




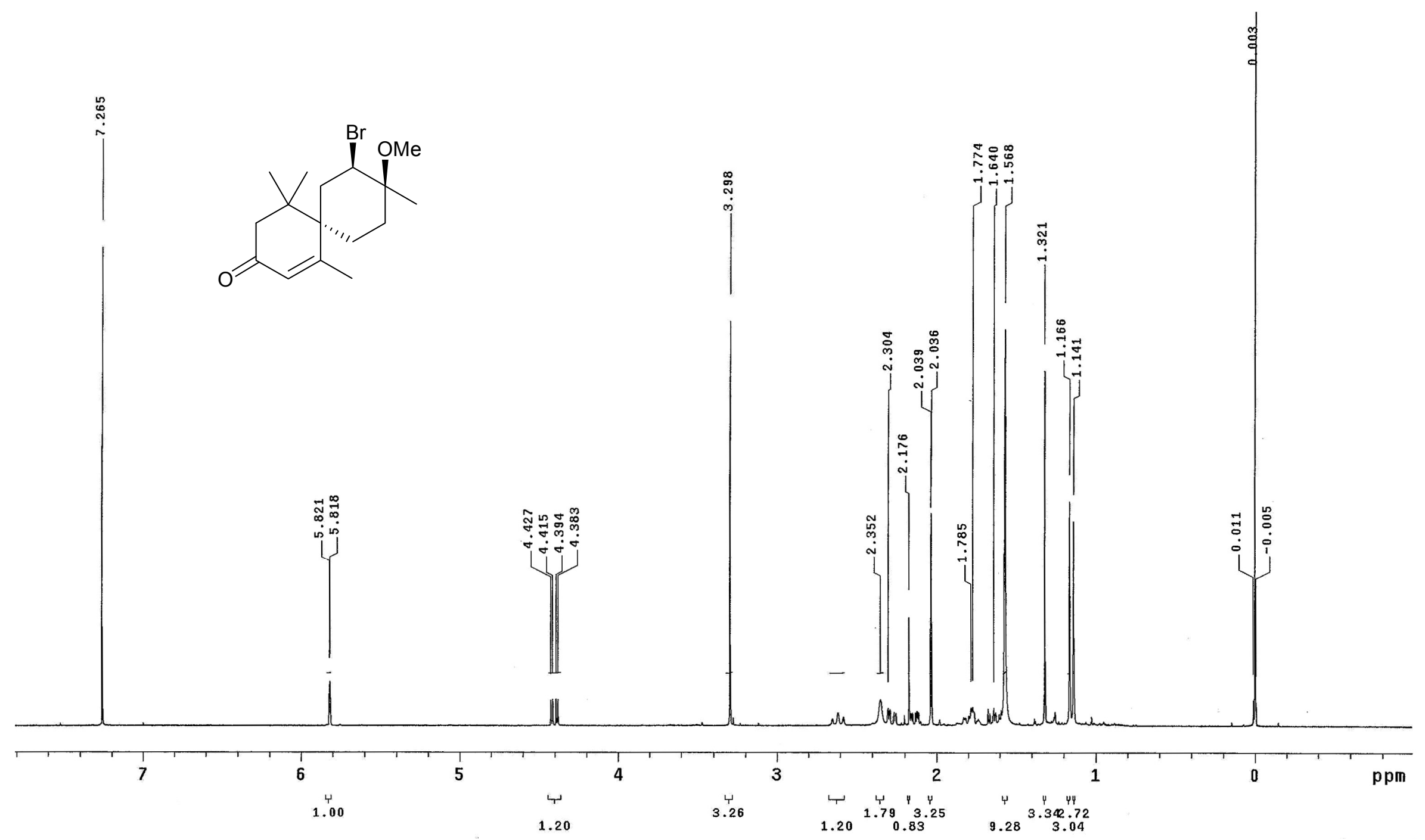

S66. ${ }^{1} \mathrm{H}$ NMR spectrum of 8 in $\mathrm{CDCl}_{3}$ 


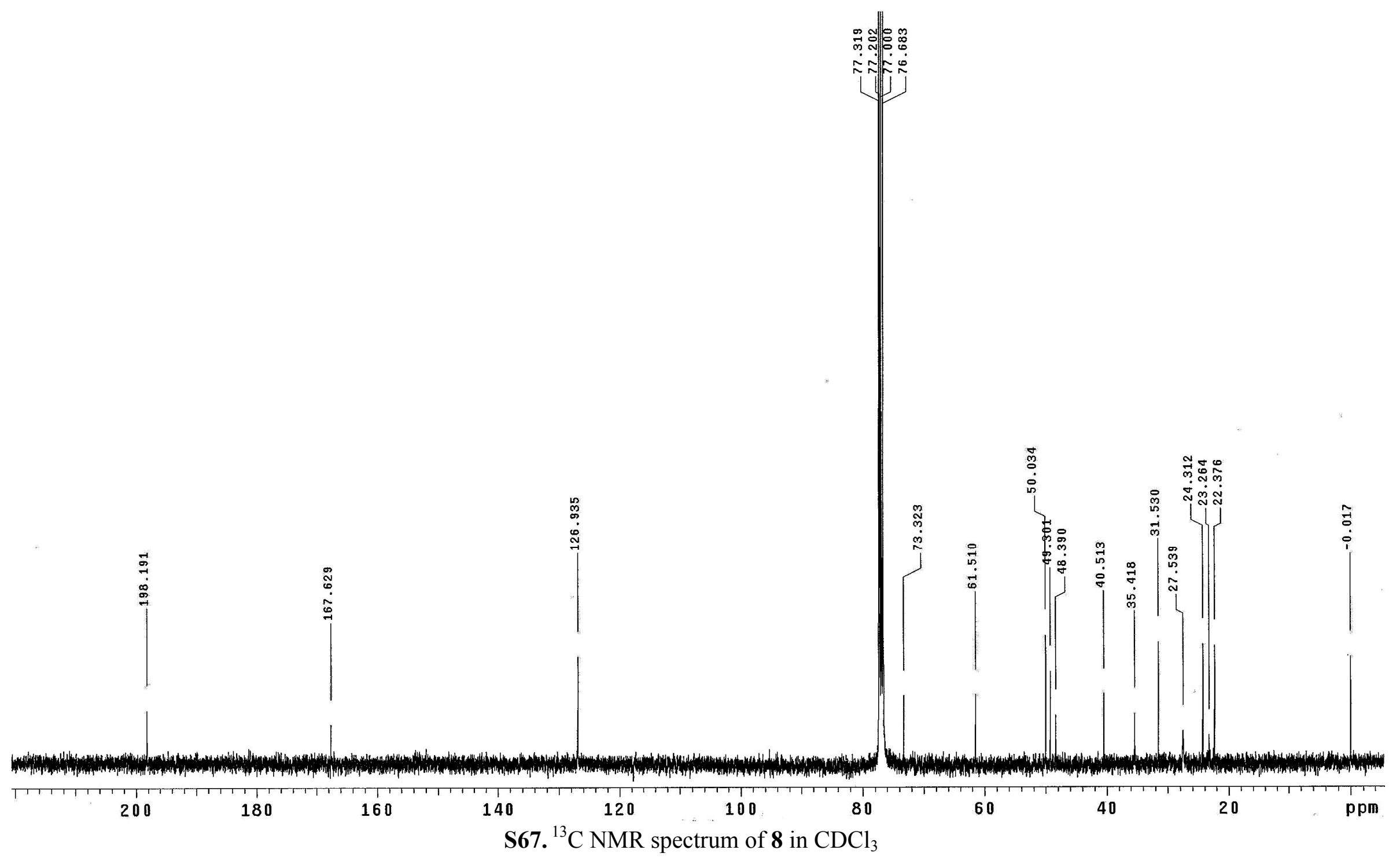




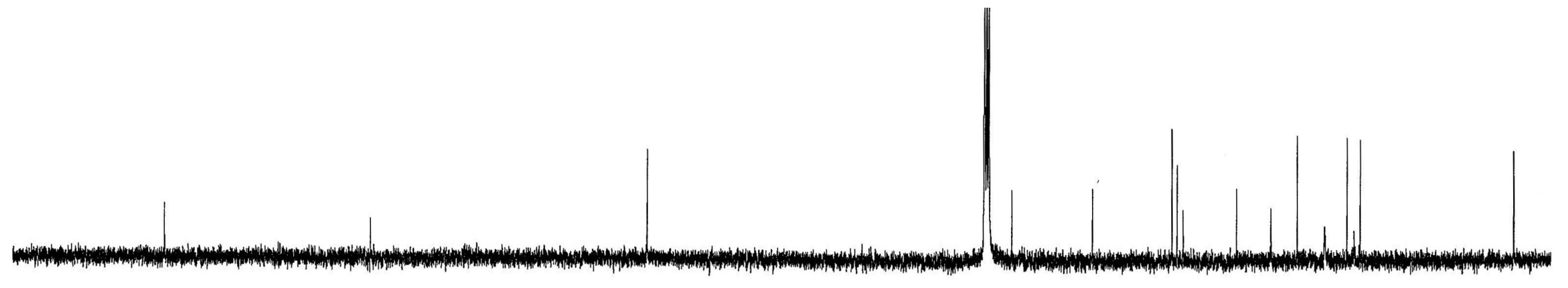

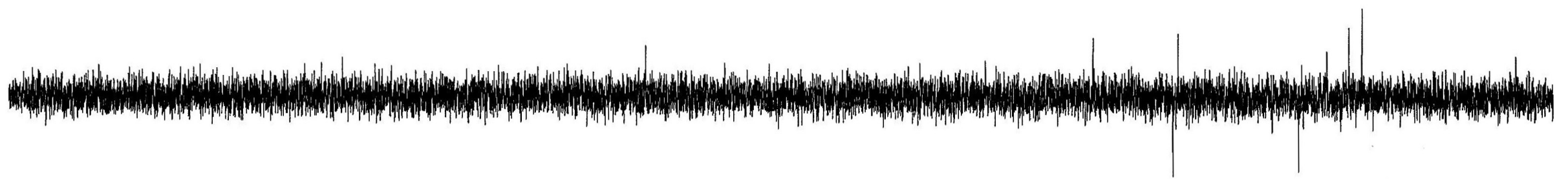

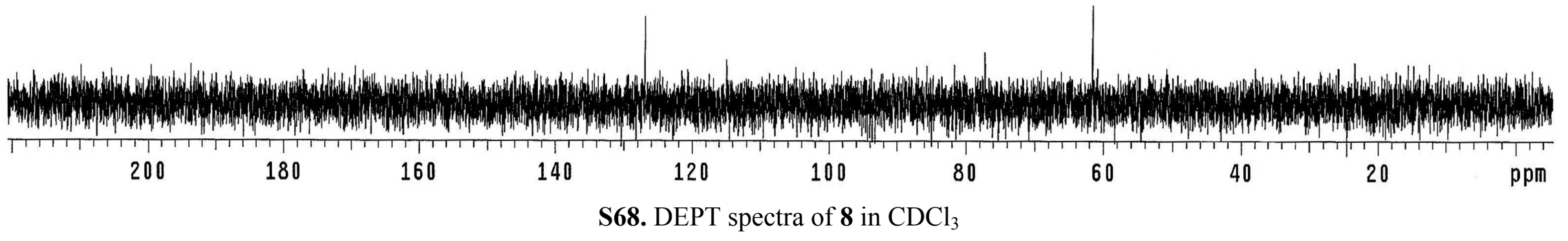




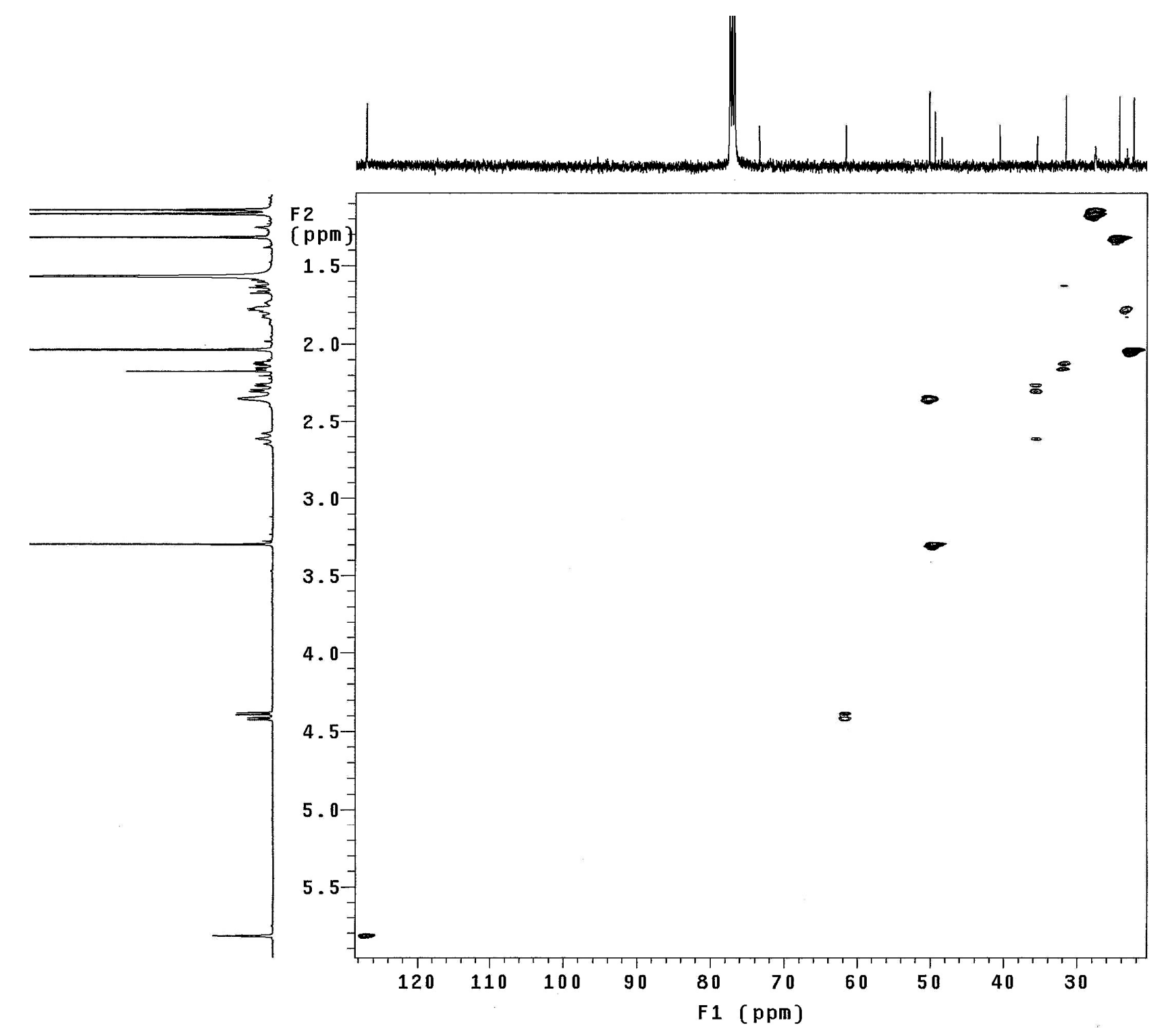

S69. HSQC spectrum of 8 in $\mathrm{CDCl}_{3}$ 


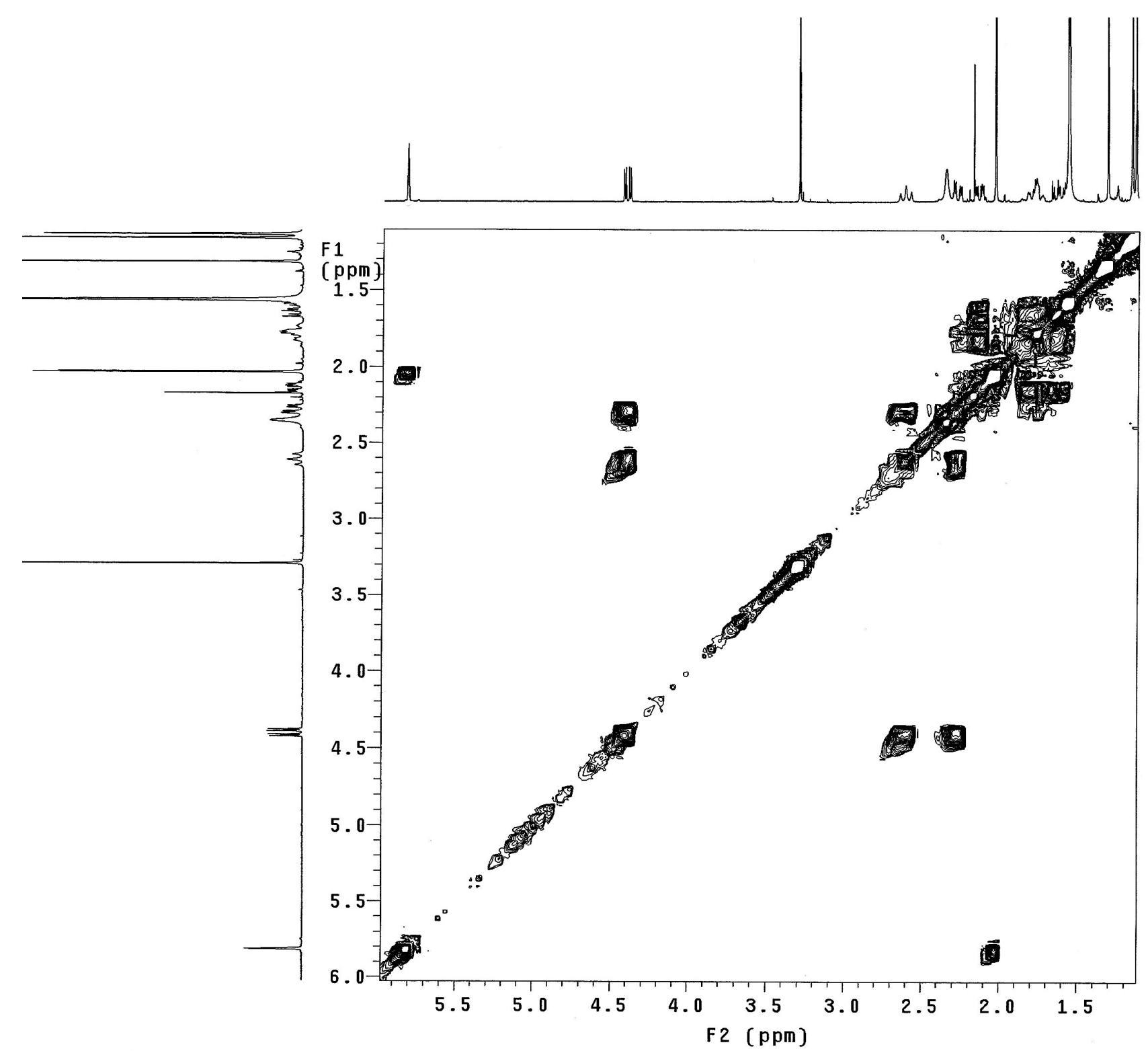

S70. COSY spectrum of $\mathbf{8}$ in $\mathrm{CDCl}_{3}$

72 


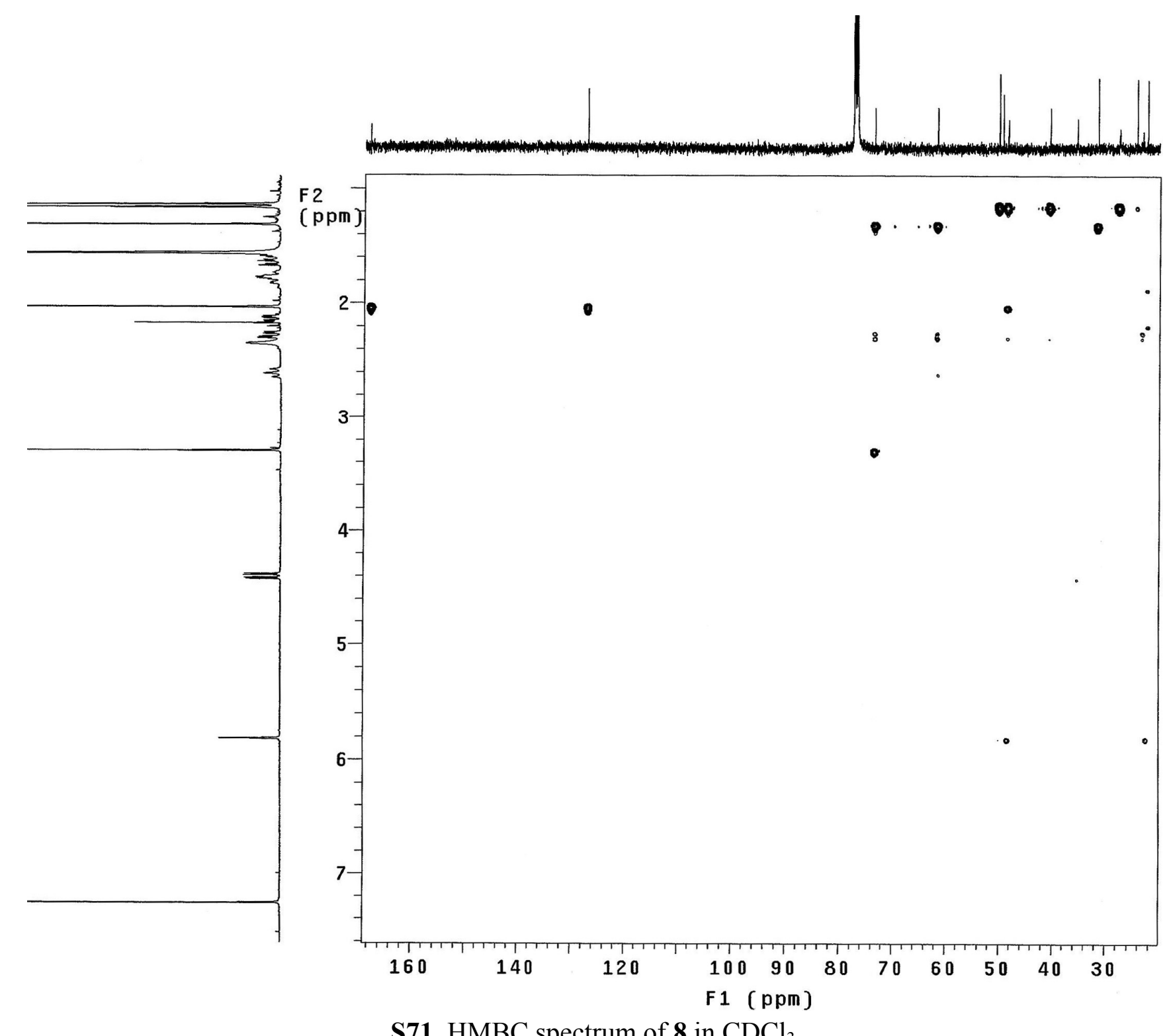

S71. $\mathrm{HMBC}$ spectrum of $\mathbf{8}$ in $\mathrm{CDCl}_{3}$ 


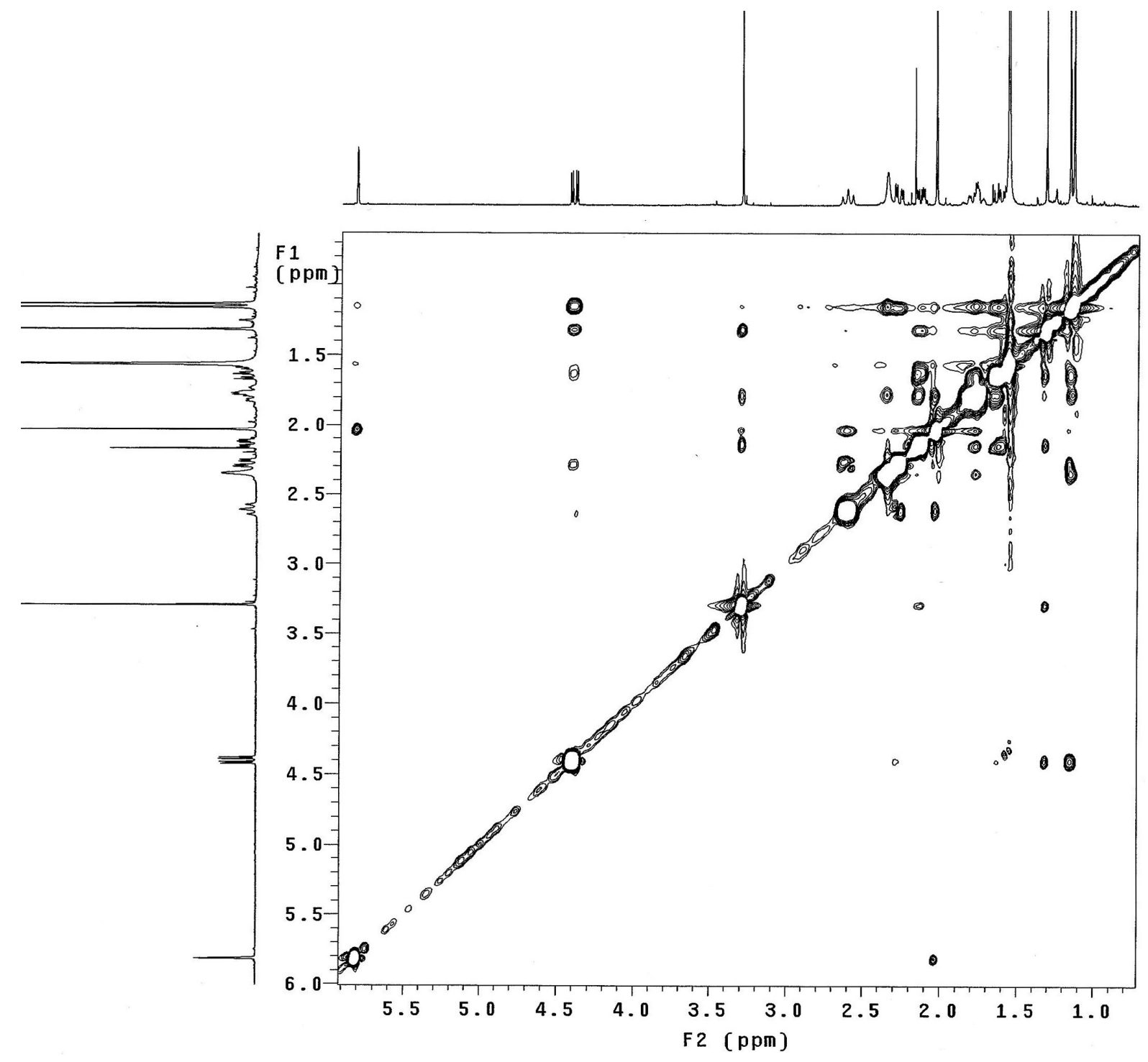

S72. NOESY spectrum of 8 in $\mathrm{CDCl}_{3}$ 


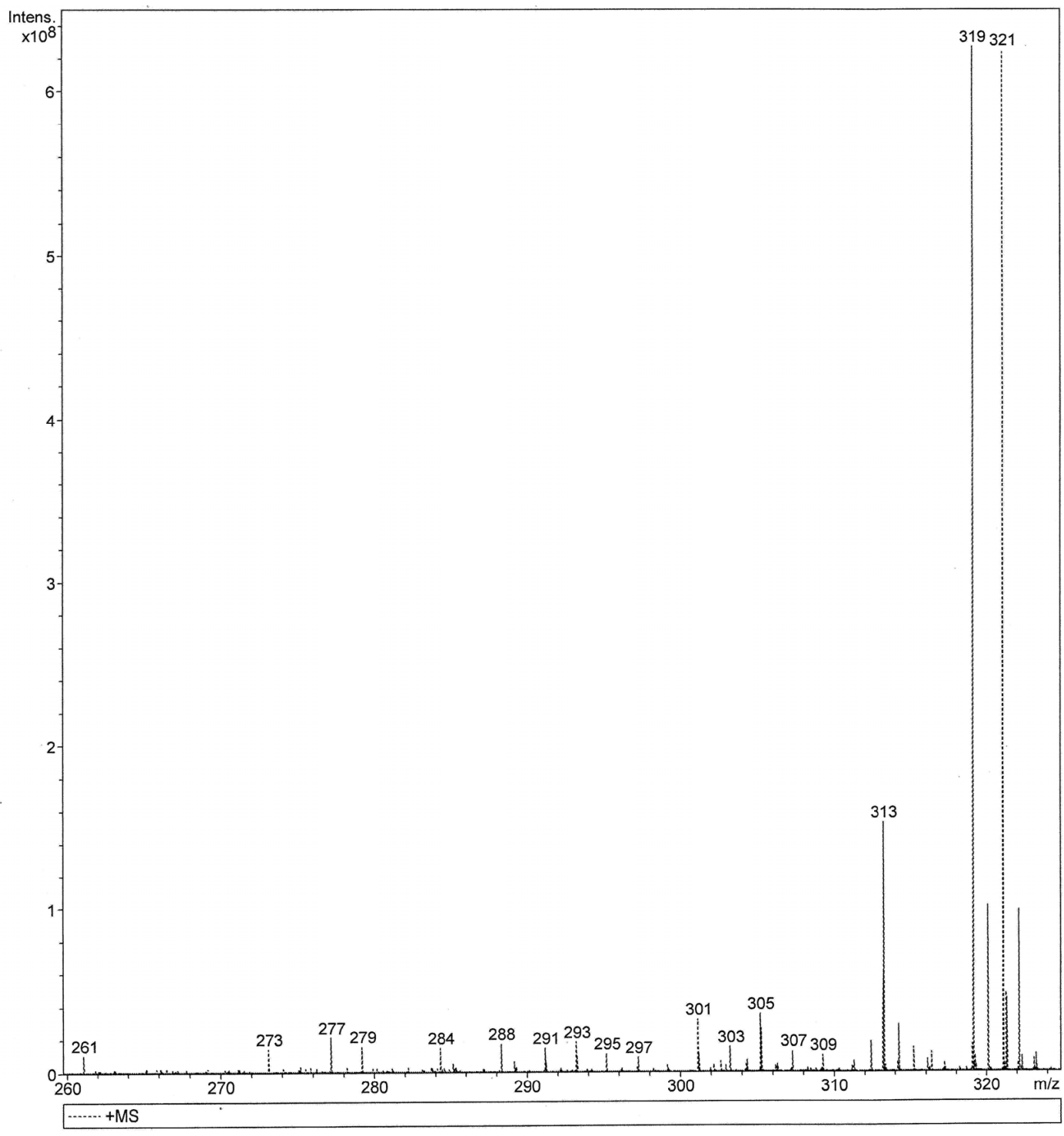

S73. ESIMS spectrum of 9 


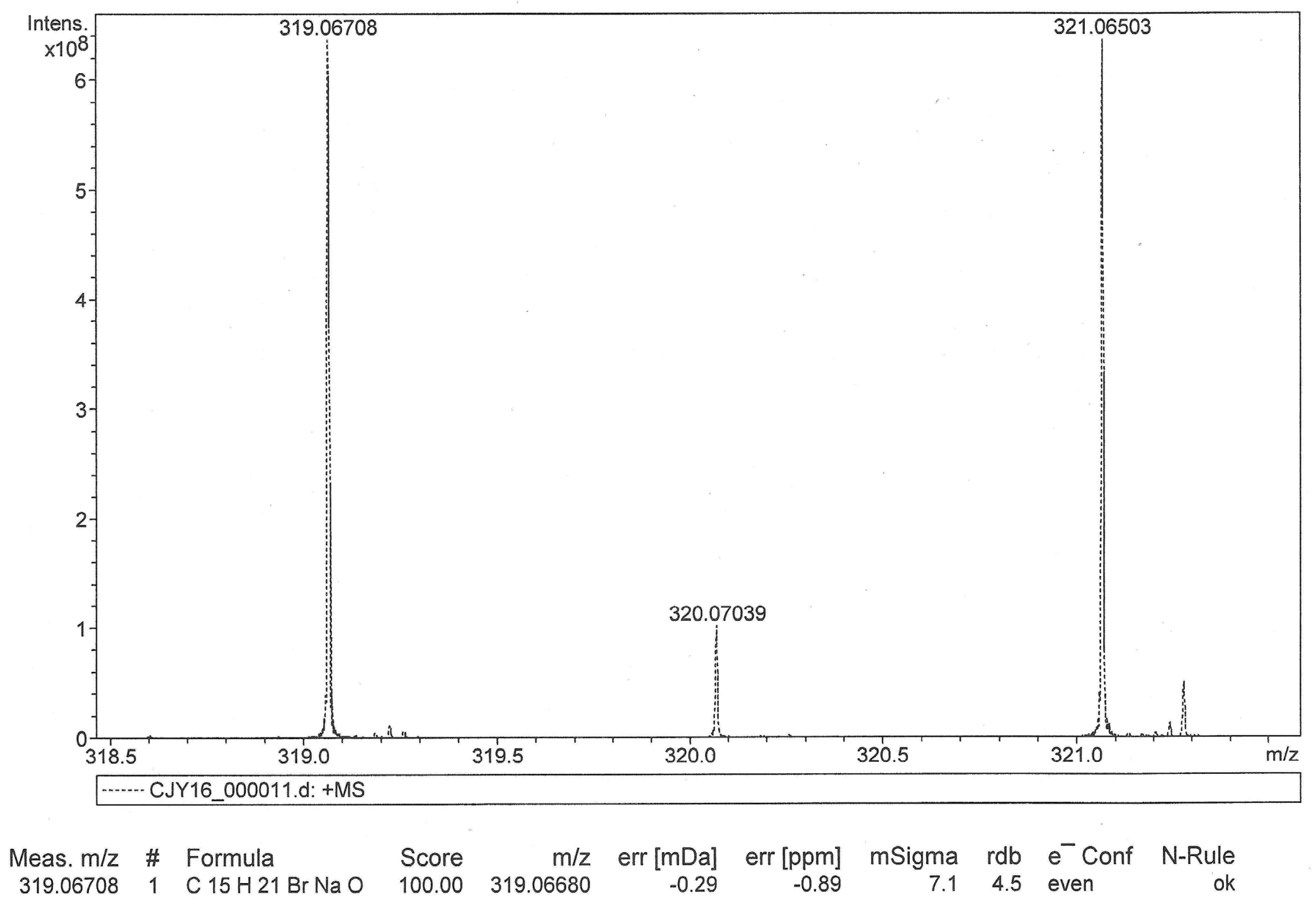

S74. HREIMS spectrum of 9 


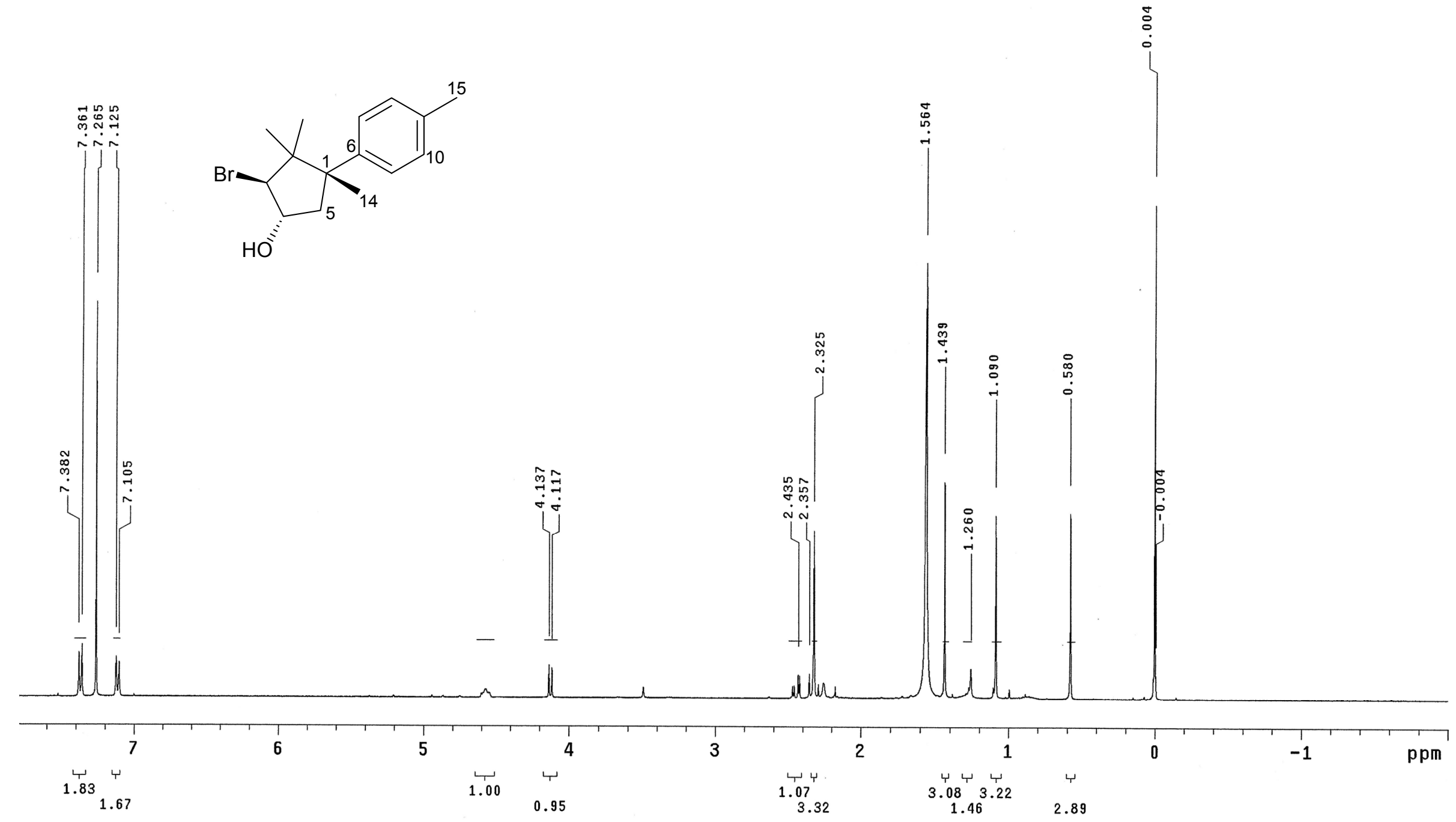

S75. ${ }^{1} \mathrm{H}$ NMR spectrum of 9 in $\mathrm{CDCl}_{3}$ 


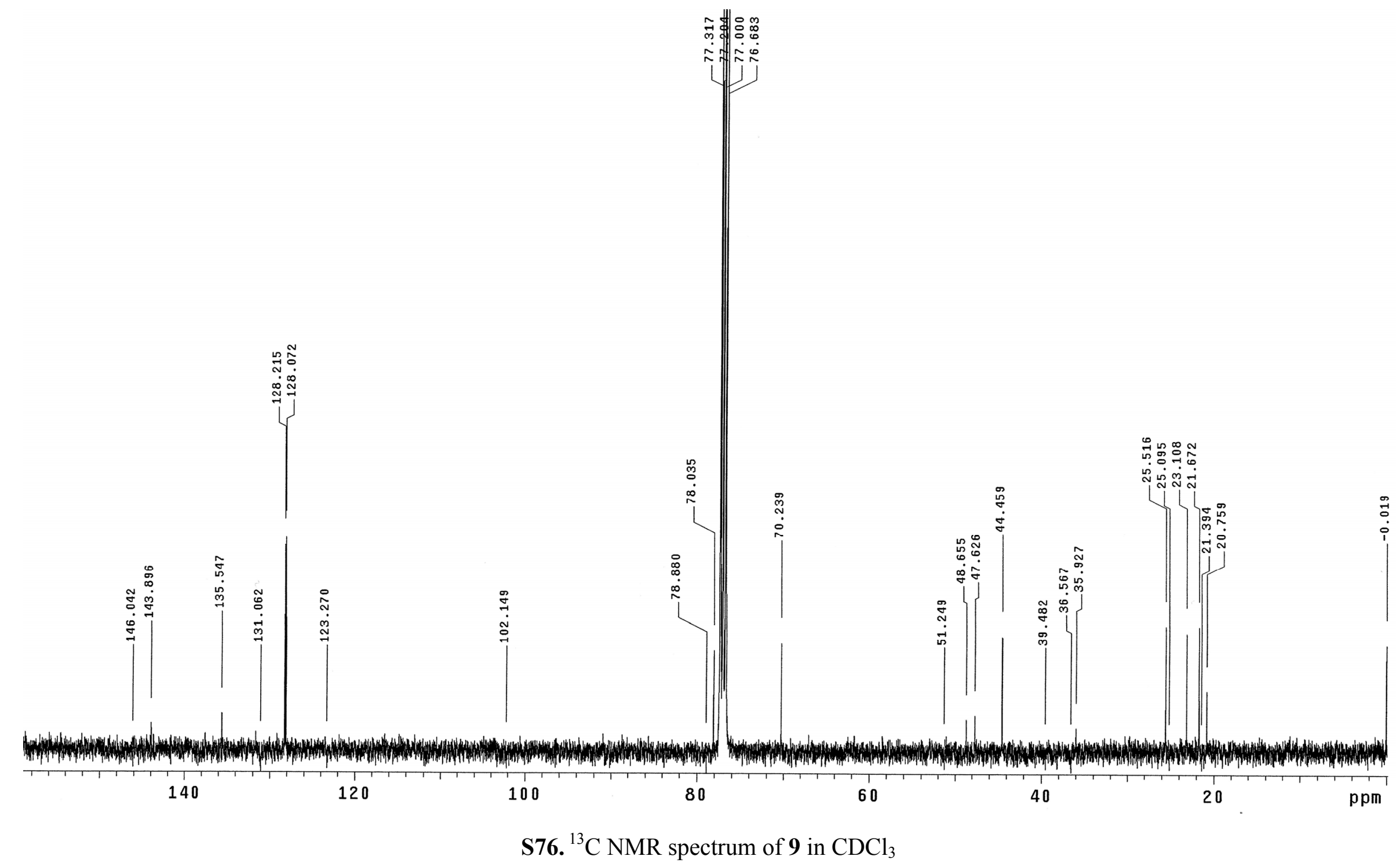




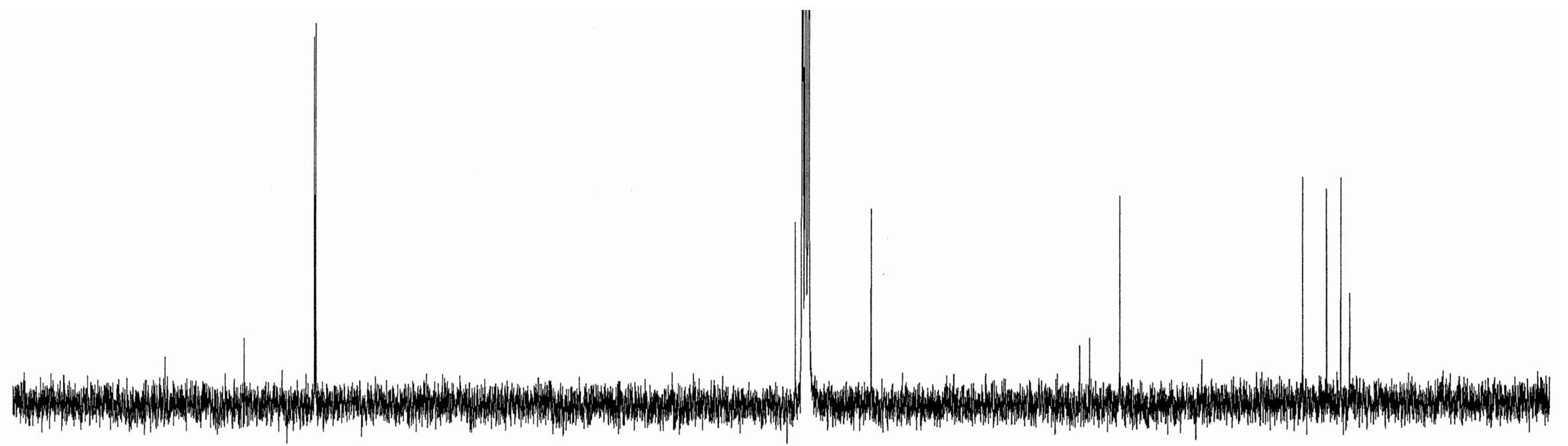

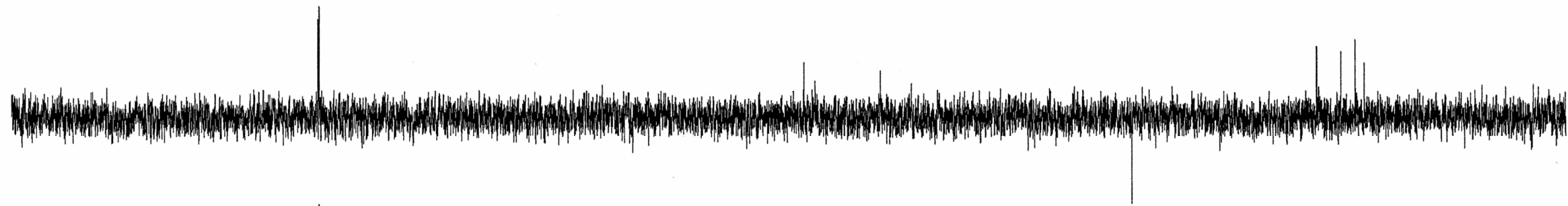

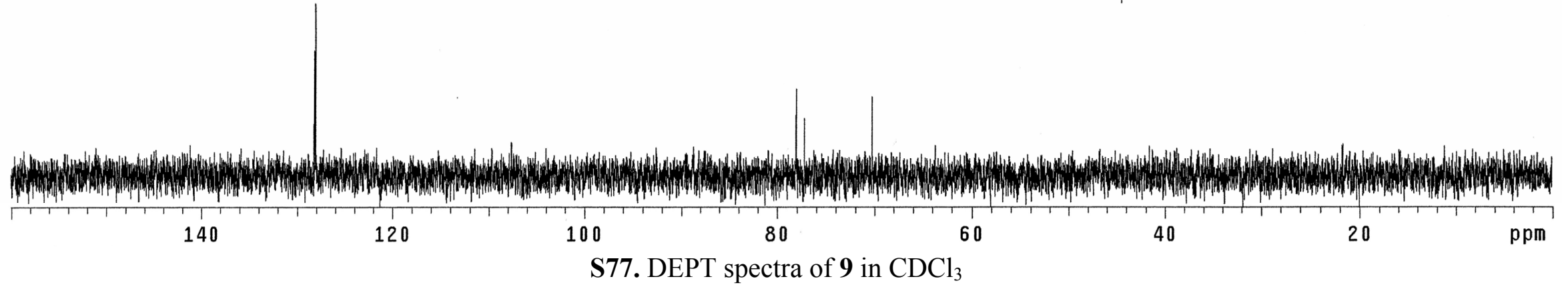




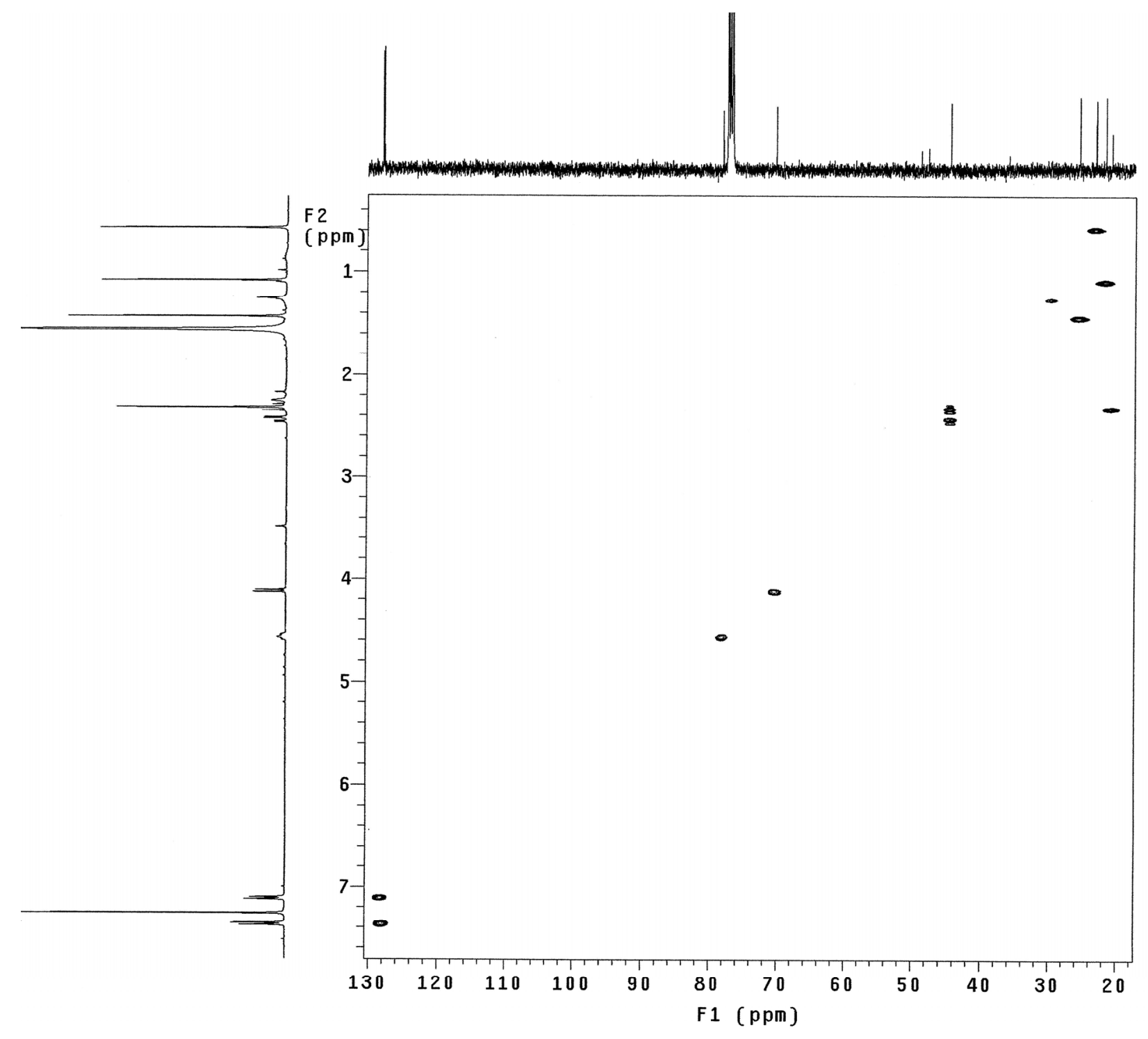

S78. $\mathrm{HSQC}$ spectrum of 9 in $\mathrm{CDCl}_{3}$ 


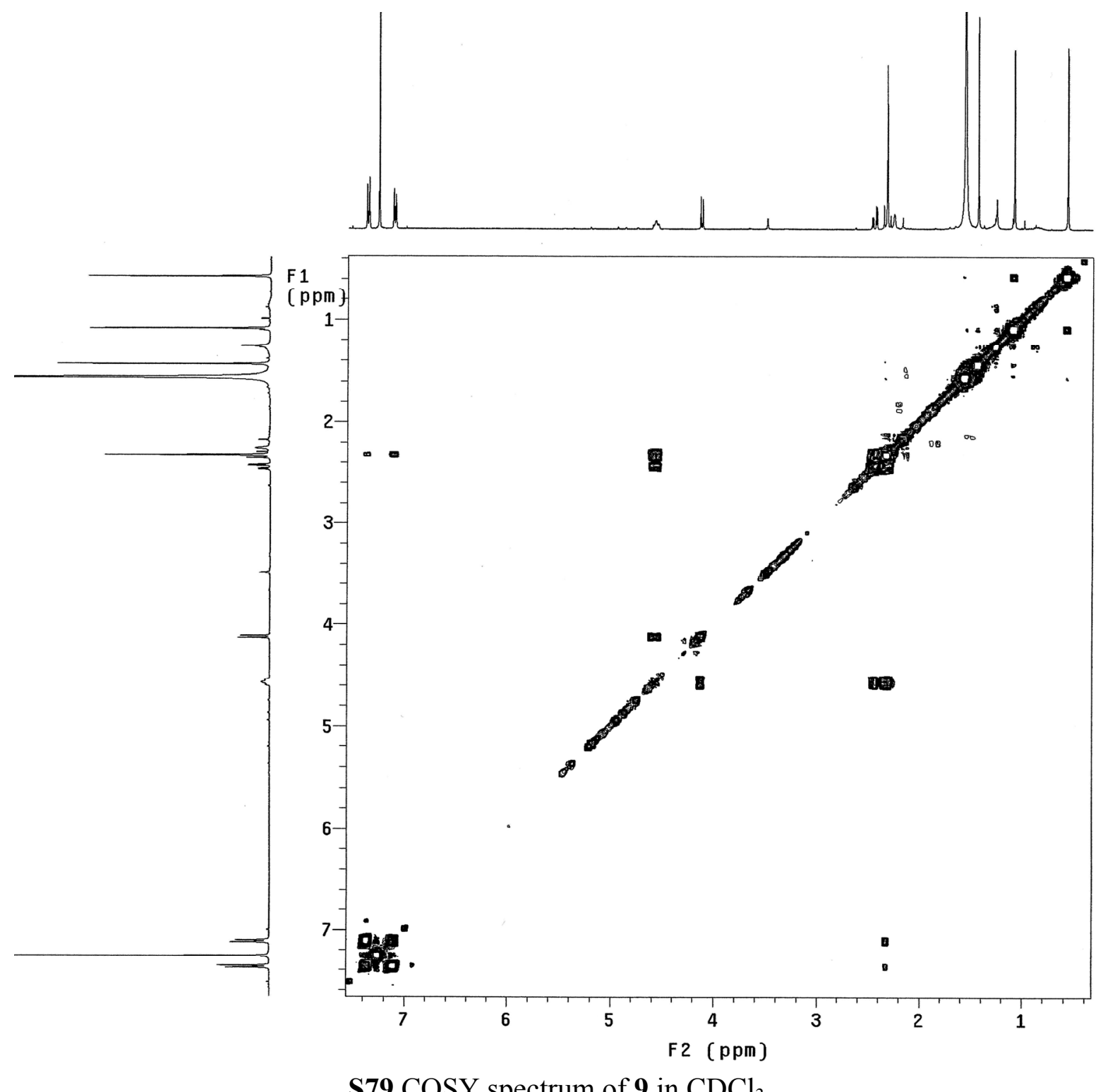

S79.COSY spectrum of 9 in $\mathrm{CDCl}_{3}$ 


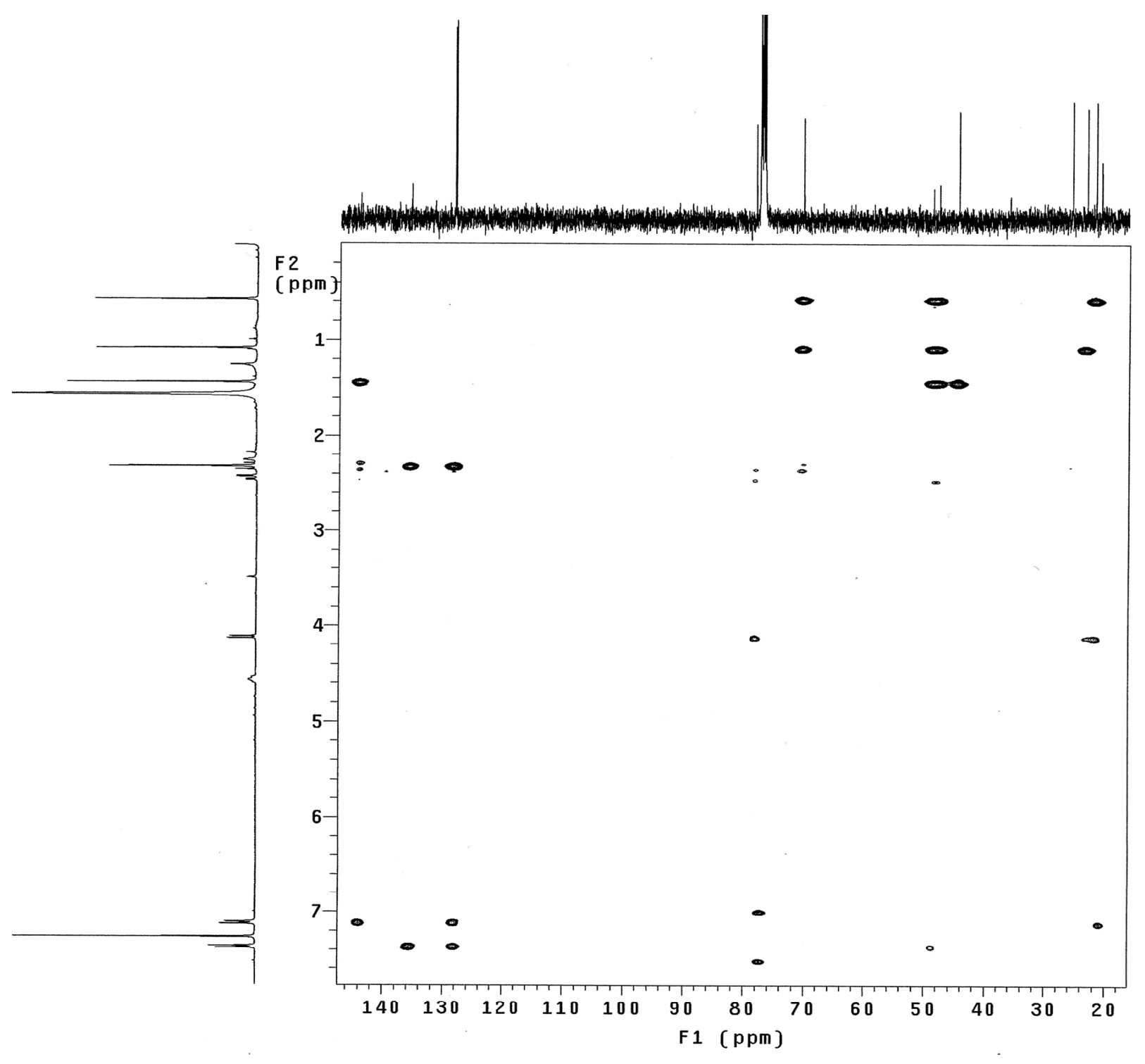

S80. $\mathrm{HMBC}$ spectrum of 9 in $\mathrm{CDCl}_{3}$ 


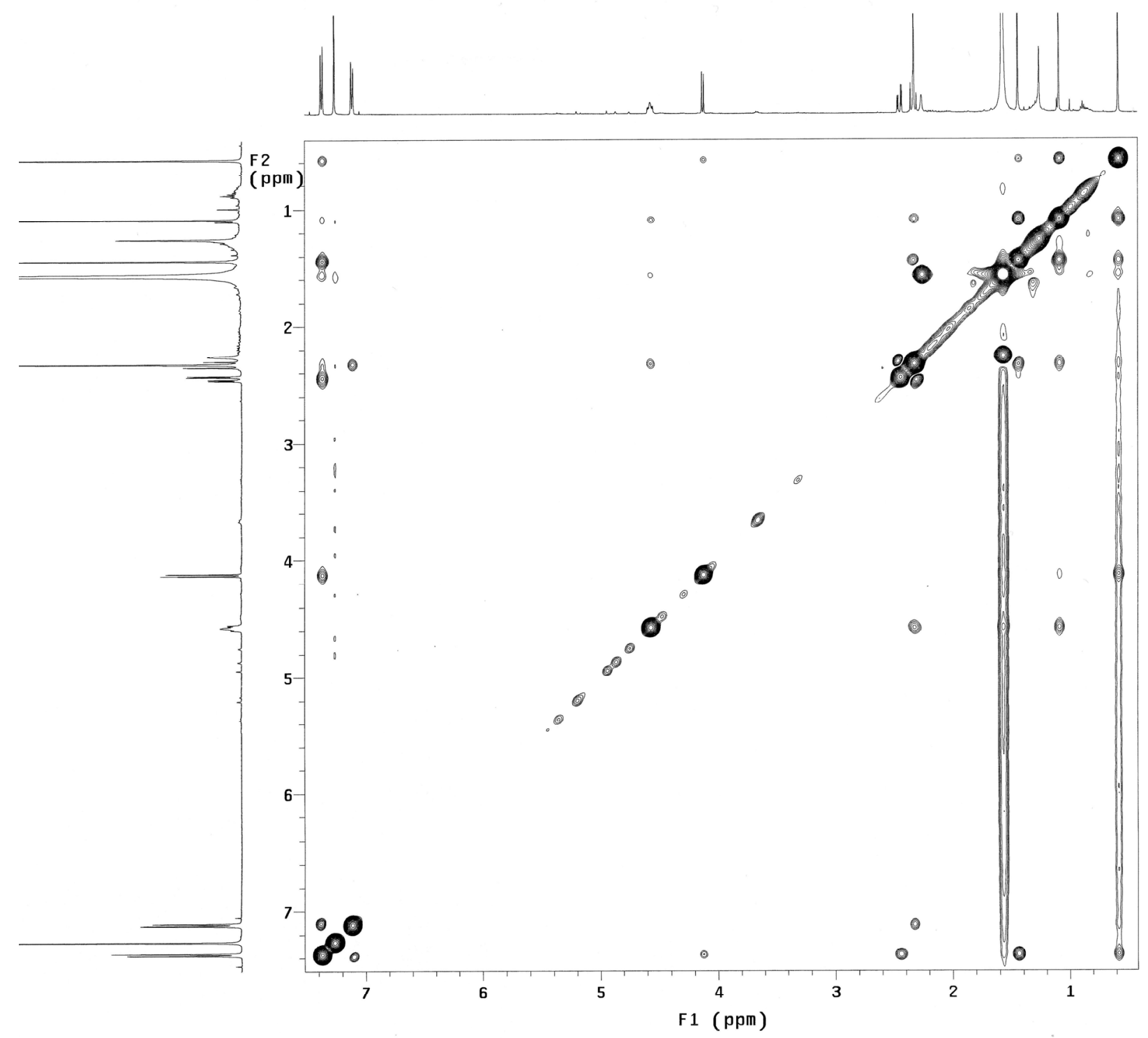

S81. NOESY spectrum of 9 in $\mathrm{CDCl}_{3}$ 


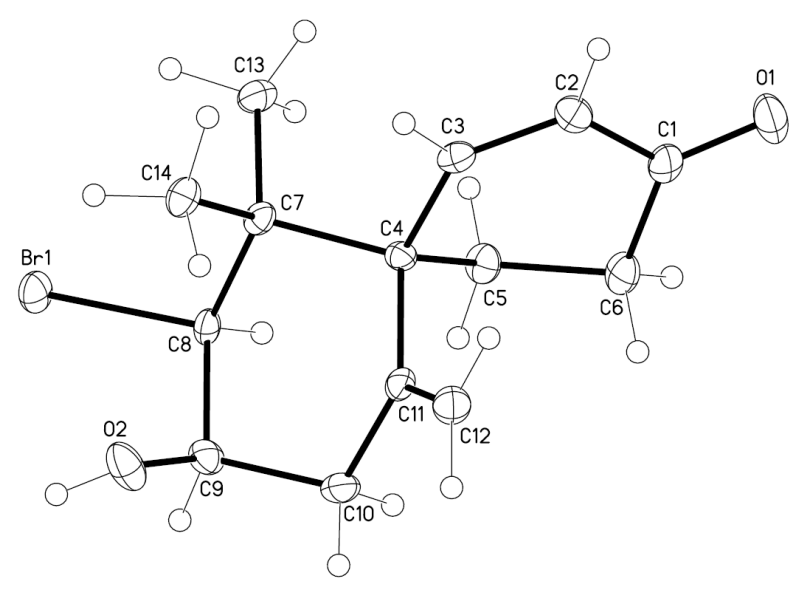

S82. X-ray crystal structure of $\mathbf{1 2 .}$

X-ray Crystallographic Analysis of 12. A suitable colorless crystal $\left(0.28 \times 0.22 \times 0.22 \mathrm{~mm}^{3}\right)$ of $\mathbf{1 2}$ was grown by slow evaporation from an acetone- $n$-hexane $(2: 1)$ solution. Diffraction intensity data were acquired with a CCD area detector with graphite-monochromated $\mathrm{Cu} \mathrm{K} \alpha$ radiation $\left(\lambda=1.54178 \AA\right.$ ). Crystal data for 12: $\mathrm{C}_{14} \mathrm{H}_{19} \mathrm{BrO}_{2}$ (formula weight 299.20), orthorhombic, space group, $P 2_{1} 2_{1} 2_{1}(\# 19)$, T = 100(2) $\mathrm{K}, a$ $=7.3316(5) \AA, b=9.7804(6) \AA, c=17.8769(12) \AA, V=1281.88(15) \AA^{3}, \mathrm{D}_{C}=1.550 \mathrm{Mg} / \mathrm{m}^{3}, Z=4, \mathrm{~F}(000)=616, \mu(\mathrm{Cu} \mathrm{K \alpha})=4.268 \mathrm{~mm}{ }^{-1} . \mathrm{A}$ total of 8296 reflections were collected in the range $5.155^{\circ}<\theta<66.644^{\circ}$, with 2214 independent reflections [R(int) $=0.0228$ ]; completeness to $\theta_{\max }$ was $96.5 \%$; psi-scan absorption correction applied; full-matrix least-squares refinement on $\mathrm{F}^{2}$; the number of data/restraints/parameters were 2214 / 0 / 157; goodness-of-fit on $\mathrm{F}^{2}=1.181$; final $\mathrm{R}$ indices $[\mathrm{I}>2 \sigma(\mathrm{I})], \mathrm{R}_{1}=0.0186, w \mathrm{R}_{2}=0.0488 ; \mathrm{R}$ indices (all data), $\mathrm{R}_{1}=0.0186, w \mathrm{R}_{2}=$ 0.0488 , largest difference peak and hole, 0.262 and $-0.413 \mathrm{e} / \AA^{3}$. Flack parameter $=0.050(6)$. Crystallographic data for ma'ilione have been deposited with the Cambridge Crystallographic Data Centre (deposition number CCDC 1476527). Copies of the data can be obtained, free of charge, on application to the Director, CCDC, 12 Union Road, Cambridge CB2 1EZ, UK (fax: +44-1223-336033 or e-mail: deposit@ccdc.cam.ac.uk). 